University of Tennessee Health Science Center

UTHSC Digital Commons

\title{
NS1 of H5N1 Interacts with SAP-97 in a PDZ-dependent Manner to Disrupt Epithelial Barrier Integrity
}

Veronica Garcia Conoley

University of Tennessee Health Science Center

Follow this and additional works at: https://dc.uthsc.edu/dissertations

Part of the Medical Biochemistry Commons, and the Medical Cell Biology Commons

\section{Recommended Citation}

Conoley, Veronica Garcia , "NS1 of H5N1 Interacts with SAP-97 in a PDZ-dependent Manner to Disrupt Epithelial Barrier Integrity" (2010). Theses and Dissertations (ETD). Paper 337. http://dx.doi.org/ 10.21007/etd.cghs.2010.0057.

This Dissertation is brought to you for free and open access by the College of Graduate Health Sciences at UTHSC Digital Commons. It has been accepted for inclusion in Theses and Dissertations (ETD) by an authorized administrator of UTHSC Digital Commons. For more information, please contact jwelch30@uthsc.edu. 


\title{
NS1 of H5N1 Interacts with SAP-97 in a PDZ-dependent Manner to Disrupt Epithelial Barrier Integrity
}

\author{
Abstract \\ The ability of influenza A virus to cause global pandemics has been a great concern throughout history \\ and poses a serious health risk worldwide. Pandemic outbreaks throughout history, such as the Spanish \\ flu of 1918, have claimed the lives of millions of people worldwide. The current outbreak of avian \\ influenza (H5N1) that began in 1997 is still claiming lives, and therefore efforts to understand the \\ mechanisms of pathogenesis in this highly virulent virus are of the utmost importance. According to the \\ World Health Organization, there have been 447 reported H5N1 human cases, resulting in 263 deaths. The \\ pathology of H5N1 infection includes pulmonary edema and diarrhea. Large scale sequencing of \\ influenza A viruses revealed that nonstructural protein 1 (NS1) contains a class I PDZ motif. The NS1 \\ proteins of avian origin contain the PDZ motif ESEV, which has been found to bind several cellular PDZ \\ domain proteins. The interaction of NS1 and host proteins via the PDZ motif is a determinant in the \\ virulence of influenza viruses of avian origin. Consistent with the clinical symptoms, this study is the first \\ to show that the NS1 protein of A/chicken/Vietnam/C58/04 binds synapse-associated protein-97 \\ (SAP-97), an adherens junction protein, in a PDZ motif-dependent manner. In H5N1 infected tissues, the \\ SAP-97 distribution is reorganized. Functionally, the interaction of NS1 and SAP-97 results in the loss of \\ epithelial barrier function. This mechanism helps to explain why the two disease states, pulmonary \\ edema and diarrhea, in which epithelial barrier is compromised, are both common in human H5N1 \\ infection.

\section{Document Type} \\ Dissertation

\section{Degree Name} \\ Doctor of Philosophy (PhD)

\section{Program} \\ Biomedical Sciences \\ Research Advisor \\ Anjaparavanda P. Naren, Ph.D. \\ Keywords \\ H5N1, host pathogen interaction NS1, protein-protein interaction \\ Subject Categories \\ Medical Biochemistry | Medical Cell Biology | Medical Sciences | Medicine and Health Sciences

\section{Comments} \\ One year embargo expired May 2011
}


NS1 of H5N1 Interacts with SAP-97 in a PDZ-dependent Manner to Disrupt Epithelial Barrier Integrity

\author{
A Dissertation \\ Presented for \\ The Graduate Studies Council \\ The University of Tennessee \\ Health Science Center
}

In Partial Fulfillment

Of the Requirements for the Degree

Doctor of Philosophy

From The University of Tennessee

By

Veronica Garcia Conoley

May 2010 
Copyright (C) 2010 by Veronica Garcia Conoley All rights reserved 


\section{ACKNOWLEDGEMENTS}

I would like to thank the many people that have made it possible for me to obtain this degree including my family, especially my mom, who has always been a strong proponent for education.

I would like to thank my dissertation advisor, Dr. Anjaparavanda Naren, for the guidance and opportunities he has given me throughout my graduate education.

Lastly, I would like to thank my committee members Dr. Donald Thomason, Dr. Richard Webby, Dr. Randal Buddington, and Dr. Kaushik Parthasarathi for their leadership and encouragement.

This work was supported by a pre-doctoral fellowship award from the National Institute of Diabetes and Digestive and Kidney Diseases (F31DK082270). 


\begin{abstract}
The ability of influenza A virus to cause global pandemics has been a great concern throughout history and poses a serious health risk worldwide. Pandemic outbreaks throughout history, such as the Spanish flu of 1918, have claimed the lives of millions of people worldwide. The current outbreak of avian influenza (H5N1) that began in 1997 is still claiming lives, and therefore efforts to understand the mechanisms of pathogenesis in this highly virulent virus are of the utmost importance. According to the World Health Organization, there have been 447 reported H5N1 human cases, resulting in 263 deaths. The pathology of $\mathrm{H} 5 \mathrm{~N} 1$ infection includes pulmonary edema and diarrhea. Large scale sequencing of influenza A viruses revealed that nonstructural protein 1 (NS1) contains a class I PDZ motif. The NS1 proteins of avian origin contain the PDZ motif ESEV, which has been found to bind several cellular PDZ domain proteins. The interaction of NS1 and host proteins via the PDZ motif is a determinant in the virulence of influenza viruses of avian origin. Consistent with the clinical symptoms, this study is the first to show that the NS1 protein of A/chicken/Vietnam/C58/04 binds synapse-associated protein-97 (SAP-97), an adherens junction protein, in a PDZ motif-dependent manner. In H5N1 infected tissues, the SAP-97 distribution is reorganized. Functionally, the interaction of NS1 and SAP-97 results in the loss of epithelial barrier function. This mechanism helps to explain why the two disease states, pulmonary edema and diarrhea, in which epithelial barrier is compromised, are both common in human $\mathrm{H} 5 \mathrm{~N} 1$ infection.
\end{abstract}




\section{TABLE OF CONTENTS}

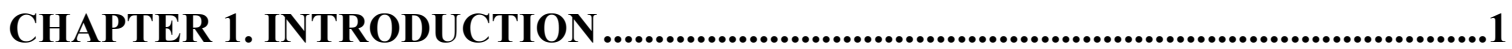

1.1 Influenza A Viruses............................................................................................ 1

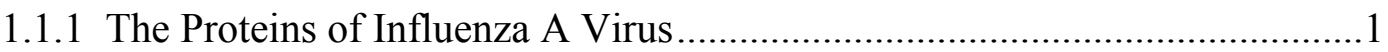

1.1.2 Disease Symptoms of Influenza Virus Infection .............................................

1.1.3 Antigenic Shift and Antigenic Drift ........................................................

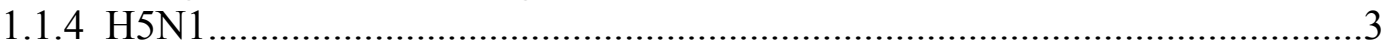

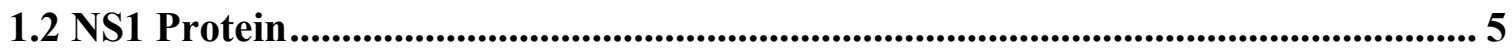

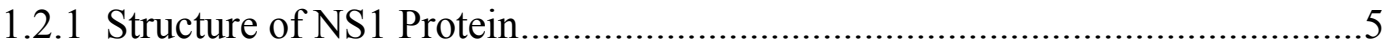

1.2.2 Role of NS1 in mRNA Processing, Translation, and Inhibition of Nuclear

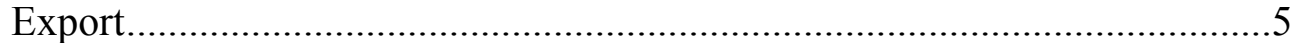

1.2.3 NS1 Acts to Subvert the Cellular Immune Response ...................................

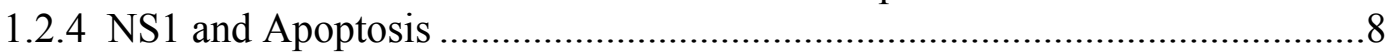

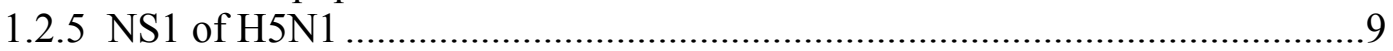

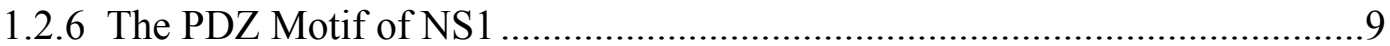

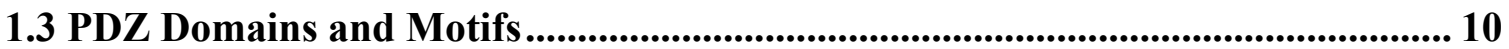

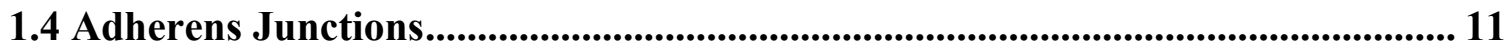

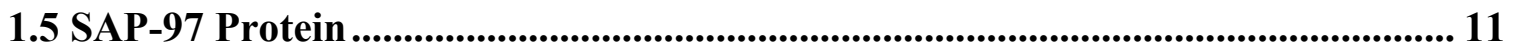

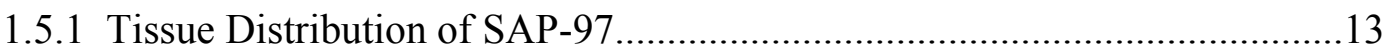

1.5.2 Role of SAP-97 in Adherens Junctions and Cell Polarity ………...................13

1.5.3 SAP-97 Interacts with Other Viral Proteins ...................................................14

1.6 Scope and Objective of Dissertation............................................................................. 15

CHAPTER 2. PDZ-MOTIF MEDIATED PROTEIN INTERACTION OF NS1 AND SAP-97 ….....................................................................................................................16

2.1 Introduction ......................................................................................................................... 16

2.2 Materials and Methods............................................................................................ 16

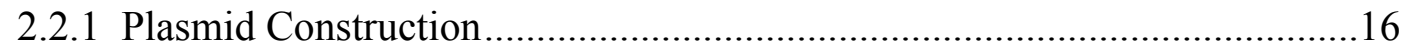

2.2.2 Cell Culture and Transfection.................................................................20

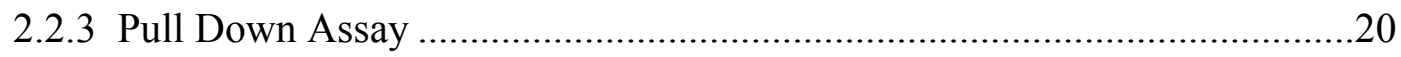

2.2.4 Pairwise Binding Assay ………………………..............................22

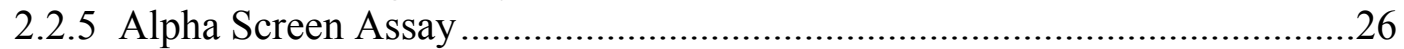

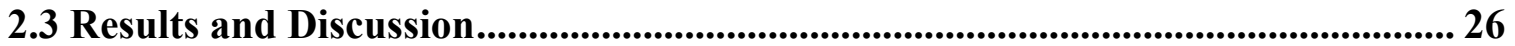




\section{CHAPTER 3. SAP-97 LOCALIZATION IS ALTERED IN NS1}

TRANSFECTED CELLS AND H5N1 INFECTED TISSUES.

3.1 Introduction........................................................................................................................ 29

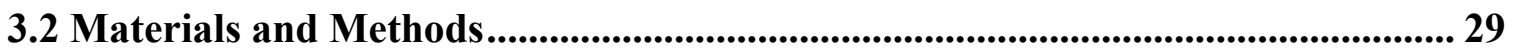

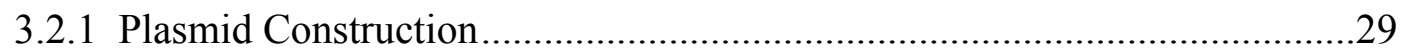

3.2.2 Cell Culture and Transfection..................................................................... 31

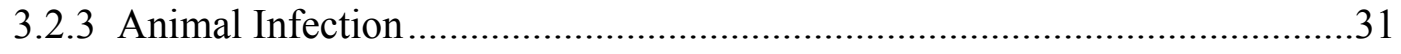

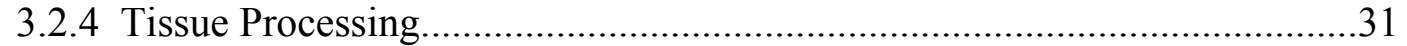

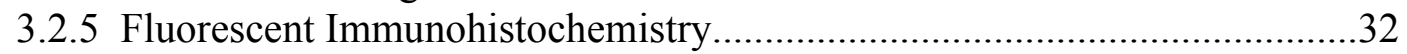

3.2.6 Immunofluorescent Staining of Caco-2 Cells............................................... 32

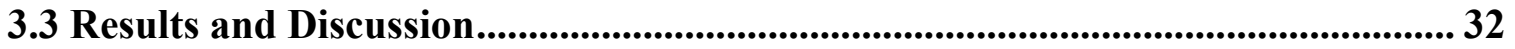

CHAPTER 4. NS1 INTERACTION WITH SAP-97 DISRUPTS EPITHELIAL

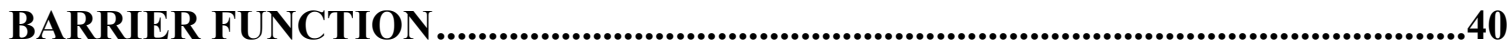

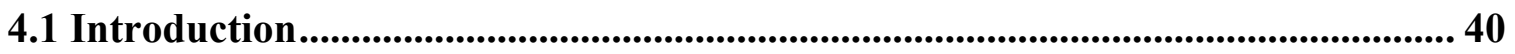

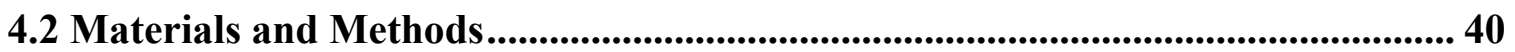

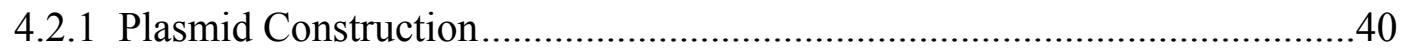

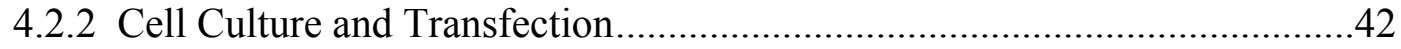

4.2.3 Measurements of TER, Calcium Switch Assays and Inulin Flux Assay......42

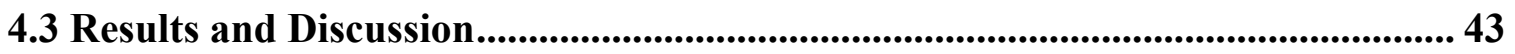

CHAPTER 5. THE PDZ MOTIF OF NS1 ACTS AS A VIRULENCE FACTOR IN H5N1 INFECTED TISSUES ...........................................................................................50

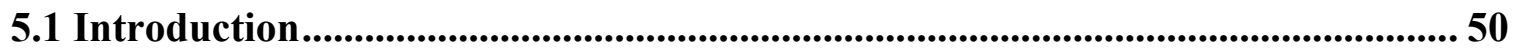

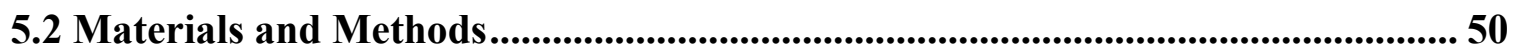

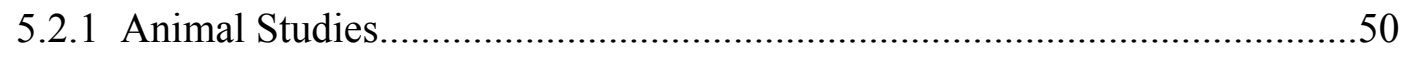

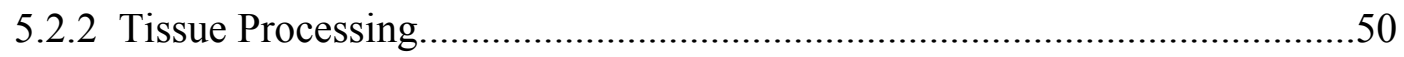

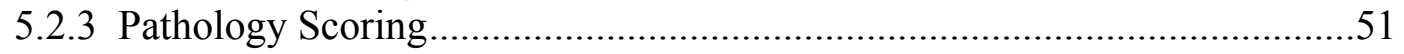

5.2.4 Immunohistochemical Staining of H5N1 Antigen .................................51

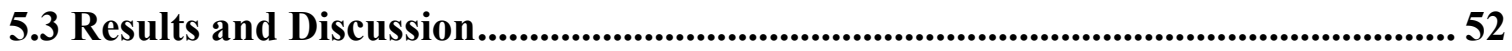

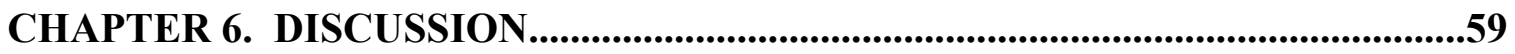

LIST OF REFERENCES .................................................................................62

VITA 


\section{LIST OF FIGURES}

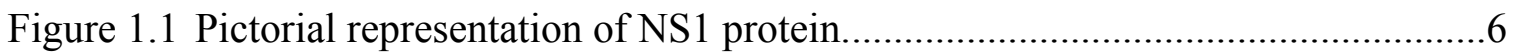

Figure 1.2 Pictorial representation of SAP-97 protein..............................................12

Figure 2.1 PCR products for cloning pTriEX-NS1 constructs...........................................17

Figure 2.2 PCR products for cloning pGEX4T1-SAP-97 PDZ constructs.......................19

Figure 2.3 Pulldown of SAP-97 in HEK-293 cells transiently transfected with NS1

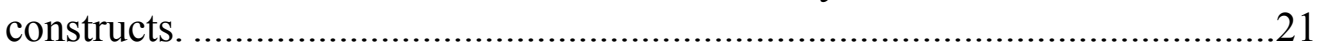

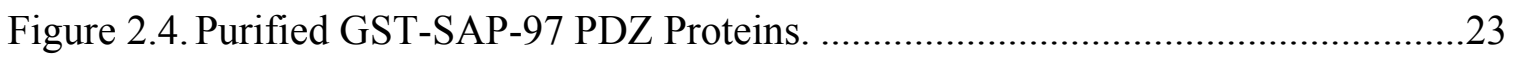

Figure 2.5. Purified His-S-NS1 Proteins.......................................................................24

Figure 2.6. Pairwise binding of NS1 and individual PDZ domains of SAP-97.................25

Figure 2.7. Interaction of biotinylated NS1-WT peptide and individual PDZ domains

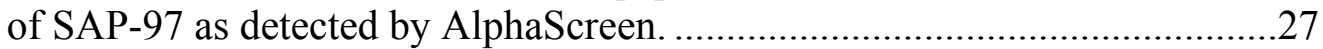

Figure 2.8. AlphaScreen competition assay between NS1 peptide binding to SAP-97

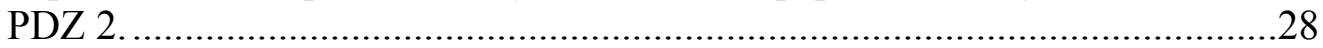

Figure 3.1 Screened colonies of cloning pCDNA3-CFP-NS1-WT and pCDNA3-

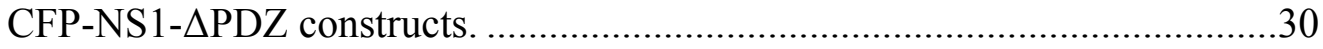

Figure 3.2. SAP-97 staining in normal and $\mathrm{H} 5 \mathrm{~N} 1$ infected mouse lungs. ...........................33

Figure 3.3. SAP-97 staining in proximal small intestine of normal and $\mathrm{H} 5 \mathrm{~N} 1$

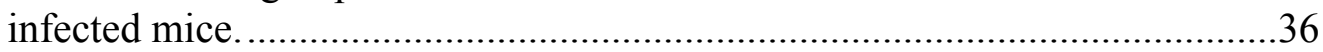

Figure 3.4. SAP-97 staining in NS1 transfected Caco-2 cells.............................................38

Figure 4.1 PCR products for cloning pTriEX-NS1-VTN constructs................................41

Figure 4.2 NS1 interacts with SAP-97 to disrupt junctional integrity in transfected Caco-2 cells

Figure 4.3 NS1 disrupts junctional integrity in transfected Caco-2 cells...........................46

Figure 4.4 NS1 disrupts junctional integrity in transfected Calu-3 cells. .........................47

Figure 4.5 Inulin Flux in NS1 transfected Caco-2 cells..................................................48

Figure 4.6 Calcium switch assay in NS1-VTN and NS1-VTN-ESEV transfected Caco-2 cells. 49

Figure 5.1 Pathology of H5N1 infection in mouse lungs...............................................53

Figure 5.2 Lung pathology scoring of H5N1 infection in mouse lungs...........................54

Figure 5.3 Influenza A antigen staining in H5N1 infected mouse lungs. .........................55

Figure 5.4 Pathology of H5N1 infection in mouse intestines. .........................................56

Figure 5.5 Pathology scoring of edematous tissue in intestines of mice infected with H5N1. 


\section{LIST OF ABBREVIATIONS}

\begin{tabular}{|c|c|}
\hline$\beta$-ME & Beta Mercaptoethanol \\
\hline AJM-1 & Apical Junction Molecule \\
\hline ARDS & Acute Respiratory Distress Syndrome \\
\hline BSA & Bovine Serum Albumin \\
\hline CPSF & Cleavage and Polyadenylation Specificity Factor \\
\hline CFP & Cyan Fluorescent Protein \\
\hline DHR & Discs Large Homology Repeat \\
\hline Dlg & Discs large \\
\hline DMEM & Dulbecco's Modified Eagle Medium \\
\hline DNA & Deoxyribose Nucleic Acid \\
\hline dsRNA & Double Stranded RNA \\
\hline EDTA & Ethylenediaminetetraacetic Acid \\
\hline E1B-AP5 & E1B-55 kDa-Associated Protein 5 \\
\hline eIF2 & Eukaryotic Initiation Factor 2 \\
\hline GST & Glutathione S-Transferase \\
\hline HA (H) & Hemagglutinin \\
\hline $\mathrm{hDlg}$ & Human Discs Large \\
\hline HEK-293 & Human Embryonic Kidney 293 \\
\hline HPV & Human Papillomavirus \\
\hline HRP & Horse Radish Peroxidase \\
\hline HTLV-1 & Human T cell Leukemia Virus Type 1 \\
\hline IFN & Interferon \\
\hline IPTG & Isopropyl $\beta$-D Thiogalactopyranoside \\
\hline IRF & Interferon Regulatory Factors \\
\hline LIC & Ligation Independent Cloning \\
\hline LIMK2 & Lim-motif Containing Protein Kinase 2 \\
\hline M1 & Matrix 1 \\
\hline M2 & Matrix 2 \\
\hline MAGUK & Membrane Associated Guanylate Kinase \\
\hline MODS & Multi-organ Dysfunction Syndrome \\
\hline mRNA & messenger RNA \\
\hline NA $(N)$ & Neuramidase \\
\hline NEP & Nuclear Export Protein \\
\hline NMDA & $N$-methyl $D$-aspartate \\
\hline NP & Nucleoprotein \\
\hline NP40 & Nonyl Phenoxylpolyethoxyl Ethanol \\
\hline NS1 & Nonstructural Protein 1 \\
\hline NS2 & Nonstructural Protein 2 \\
\hline Nup 98 & Nuclear Pore Complex Protein 98 \\
\hline NXF1 & Nuclear RNA export factor 1 \\
\hline OAS & 2'-5'-Oligoadenylate Synthetase \\
\hline PA & Polymerase Acidic Protein \\
\hline PABII & poly (A) Binding Protein II \\
\hline
\end{tabular}




$\begin{array}{ll}\text { Par3 } & \text { Partitioning Defective Protein 3 } \\ \text { PB1 } & \text { Polymerase Basic Protein 1 } \\ \text { PB1-F2 } & \text { Polymerase Basic Protein 1-F2 } \\ \text { PB2 } & \text { Polymerase Basic Protein 2 } \\ \text { PBS } & \text { Phosphate Buffered Saline } \\ \text { PCR } & \text { Polymerase Chain Reaction } \\ \text { PIP3 } & \text { Phosphatidylinositol-3,4,5-triphosphate } \\ \text { PI3K } & \text { Phosphatidylinositol 3-kinase } \\ \text { PKR } & \text { Protein Kinase R } \\ \text { PMSF } & \text { Phenylmethanesulfonyl Fluoride } \\ \text { PVDF } & \text { Polyvinylidene Fluoride } \\ \text { Rae1 } & \text { RNA export 1 homolog } \\ \text { RIG-I } & \text { Retinoic Acid-induced Gene I Product } \\ \text { RNA } & \text { Ribonucleic Acid } \\ \text { RNAi } & \text { RNA Interference } \\ \text { SAP-97 } & \text { Synapse Associated Protein-97 } \\ \text { SH3 } & \text { Src Homology 3 } \\ \text { TBS-T } & \text { Tris-buffered Saline Tween 20 } \\ \text { TNF- } \alpha & \text { Tumor Necrosis Factor- } \alpha\end{array}$




\section{CHAPTER 1. INTRODUCTION}

\subsection{Influenza A Viruses}

Influenza A viruses belong to the family Orthomyxoviridae. The viruses in this family are defined by their RNA genome, which is negative-sense (complementary to the mRNA sense), single stranded, and segmented [1]. There are three genera, or types, of influenza viruses: A, B, and C. Influenza A and B viruses have 8 gene segments, while influenza $\mathrm{C}$ has 7 gene segments. The 8 viral gene segments of influenza A encode 11 gene products. These include the PB1, PB1-F2, PB2, PA, HA, NP, NA, M1, M2, NS1, and NS2 proteins.

\subsubsection{The Proteins of Influenza A Virus}

PB1, PB2, and PA are the influenza polymerase proteins. PB2 polymerase is encoded by the largest RNA segment (segment 1), while PA is encoded by segment 3 . PB1 and PB1-F2 are encoded by segment 2. Together, the polymerase proteins form a complex necessary for viral RNA-dependent RNA polymerase activity [1,2]. PB1-F2 protein is only about 90 amino acids long and is encoded by the +1 reading frame of the PB1 gene segment $[3,4]$. PB1-F2 has been implicated in contributing to viral pathogenesis in certain influenza strains.

The nucleoprotein (NP) is encoded by viral RNA segment 5 . NP plays a major role in binding and encapsidating the viral RNA to form ribonucleoprotein (RNP). NP is one of the most abundant proteins in the virion and in infected cells [1].

The matrix protein (M1) and the ion channel M2 are both encoded from RNA segment 7. Matrix is the most abundant protein in the influenza virion and is also the most highly conserved protein of all the influenza A proteins [2,5]. M1 binds RNP to shut off transcription. M2 protein is an ion channel that is inserted into the virus membrane. The main function of $\mathrm{M} 2$ is to transport protons into the virion during uncoating. M2 forms a tetramer, and on the surface of the infected cell it is found in large amounts, but is found in smaller amounts on the virion [2].

The nonstructural proteins, NS1 and NS2, are encoded by the smallest RNA segment, segment 8 . NS1 protein is produced from the unspliced RNA, while NS2 is produced from spliced RNA. Due to an overlapping reading frame, these 2 proteins have the same 9 amino acids at their amino termini. These proteins were originally named nonstructural because they were both thought to be abundantly synthesized in the infected cell but not incorporated into virions. However, it has been found that NS2 binds to M1 and is incorporated into virions [5]. NS2 contains a nuclear export signal and plays a role in nucleo-cytoplasmic export of RNP. Therefore, it is also known as the nuclear export protein (NEP) [6]. NS1 has been detected in cells only after active infection. The multifunctional protein NS1 will be discussed in greater detail below. 
Hemagglutinin (HA) is encoded by RNA segment 4. The hemagglutinin protein is a membrane protein that is necessary for binding the virion to the receptor on the host cell. The HA protein undergoes posttranslational modification, such as glycosylation, acylation, and proteolytic cleavage. HA is cleaved into 2 subunits by host-produced proteases. This cleavage by host proteases is essential for infectivity. HA also forms the major surface antigen and is the main target of the host immune response $[1,5]$.

The neuraminidase (NA) protein is encoded by RNA segment 6. Like HA, it is an integral membrane glycoprotein and is also a major surface antigen. The main function of NA is to cleave terminal sialic acid residues from glycoproteins. This enables nascent virions to free themselves from the host cell receptors of the infected cells from which they arose [2].

Influenza viruses have a standardized naming system and are named according to genus, animal species the virus was isolated from, geographical location, isolate number, and year. Influenza A viruses are further classified by hemagglutinin $(\mathrm{H})$ and neuraminidase $(\mathrm{N})$ antigenic subtypes. Of these subtypes, there are 16 distinct hemagglutinin antigens (H1-H16) and 9 distinct neuramidase antigens (N1-N9) [7]. According to the conventional naming scheme, the virus, A/chicken/Vietnam/C58/04 (H5N1), is of influenza type A and was isolated from a chicken in Vietnam in 2004.

\subsubsection{Disease Symptoms of Influenza Virus Infection}

Influenza A virus infection in humans is highly contagious and causes a respiratory disease commonly referred to as the flu. Symptoms include high fever, inflammation of the trachea and upper respiratory tree, coryza, headache, and malaise. Symptoms often linger for 7 to 10 days [8]. Influenza $B$ and influenza $C$ viruses also cause respiratory disease in humans. Influenza B viruses have caused local epidemics, but the number of hospital admissions is far less than seen with influenza $A$ viruses [1,9]. Influenza $C$ virus causes less severe disease than the other influenza types because most individuals have developed antibodies against influenza $\mathrm{C}$ by early adulthood $[1,10]$.

Although influenza B and $\mathrm{C}$ cause disease in humans, unlike influenza A virus, they do not have the ability to cause global pandemics. There are two main reasons influenza $A$ viruses are able to cause global pandemics while influenza $B$ and $C$ are not. The first main reason for this is the ability of influenza A virus to escape neutralizing antibodies through antigenic drift and shift. The second main factor is that influenza A virus has a wide species tropism [10]. Influenza $B$ and $C$ viruses mainly infect humans, although influenza $B$ virus has been recovered from seals, and influenza $C$ virus has been recovered from pigs [11,12]. Influenza $A$ viruses on the other hand, infect a wide variety of animal species, including humans, swine, horses, dogs, cats, sea mammals, and, most importantly, birds [1,2]. Aquatic birds are thought to be the primary reservoir for all influenza A viruses which can be thought of as an avian virus that infects many other species [2]. Influenza $\mathrm{B}$ and $\mathrm{C}$ viruses, on the other hand, have not been recovered from 
avian hosts [2]. Of the 16 hemagglutinin and 9 neuraminidase subtypes, only a few combinations of these have been recovered from humans, while all combinations of the subtypes are found in birds [2].

\subsubsection{Antigenic Shift and Antigenic Drift}

One remarkable feature of influenza viruses are their ability to generate new antigenic variants that evade host immunity causing annual epidemics and worldwide pandemics. The processes that make this happen are antigenic drift and antigenic shift. Antigenic drift results from the accumulation of point mutations during viral replication. Point mutations accumulate because the influenza RNA polymerase complex does not have any proofreading activity. The mutation rates are extremely high, and have been observed to be greater than $10^{-3}$ substitutions per site per year [13]. There is little difference between the mutation rates of avian influenza viruses and mammalian influenza viruses [13]. A host can develop immunity to influenza virus by developing antibodies to the HA and NA proteins. Antigenic drift gives the virus an advantage by changing the surface epitopes, allowing the virus to evade the preexisting protective immune response of the host. Further, certain regions of the surface proteins, such as antibody binding sites, are more susceptible to accumulating mutations than other sites of the same protein [14].

The process of antigenic shift is only seen in influenza A viruses. Antigenic shift is the process by which the virus obtains new gene segments by reassortment of two or more different subtypes of influenza viruses [15]. This occurs when more than one influenza virus isolates infect the same host cell. Antigenic shift results in a virus with a completely different antigenic structure that has not been seen to circulate in the population before and may play a major role in causing world wide pandemics and epidemics [14].

\subsubsection{H5N1}

In 1997, a highly pathogenic influenza virus causing severe respiratory disease resulted in the death of a small child in Hong Kong. Earlier that year, three Hong Kong chicken farms reported a highly lethal epidemic of avian influenza. It was subsequently found that a subtype of influenza A virus, H5N1, was responsible for both the human and chicken deaths [16]. Efforts to control this outbreak were quickly undertaken, but despite increased supervision of poultry farms more human cases of H5N1 began to appear. Therefore, in December 1997 the Hong Kong government decided to cull all the chickens in Hong Kong [16]. With the culling of the chickens, the H5N1 outbreak was brought under control. In total, the 1997 H5N1 outbreak in Hong Kong infected 18 people and resulted in 6 deaths. This outbreak of $\mathrm{H} 5 \mathrm{~N} 1$ was distinctive in that the virus was transmitted directly from chickens to humans without first infecting an intermediate mammalian host $[17,18]$. Most of the H5N1 patients had close contact with dead or sick birds prior the onset of illness [19]. 
In 2003, a resurgence of H5N1 virus caused an epidemic in domestic poultry that has spread from Asia to Europe. Human cases of H5N1 also re-emerged in 2003, and new cases of human $\mathrm{H} 5 \mathrm{~N} 1$ infection are being reported to the World Health Organization (WHO) to date. Of the confirmed human cases reported to WHO, H5N1 claimed the lives of about $60 \%$ of those infected [20].

In humans, the incubation period of H5N1 is typically between 2 and 5 days, and the duration from the onset of symptoms to death is about 9 days [19]. Clinical features of the H5N1 virus in human infection vary from individual to individual. They include respiratory symptoms, high fever, malaise, cough, sore throat, and diarrhea as well as acute respiratory distress syndrome (ARDS) and multi-organ dysfunction syndrome (MODS) $[19,21,22]$. H5N1 infection differs from seasonal influenza in that gastrointestinal symptoms are a common early clinical feature, including abdominal pain, vomiting, and watery diarrhea [19]. A large number of $\mathrm{H} 5 \mathrm{~N} 1$ patients present with diarrhea. In fact, one retrospective report documenting the clinical features of H5N1 in Vietnam found that diarrhea was more common in fatal than nonfatal H5N1 cases [23].

Autopsies of H5N1 victims have revealed diffuse alveolar damage, edema, fibrous exudates, hyaline membranes, and hyperplasia of type II pneumocytes in the lungs $[22,24,25]$. Histopathological features in the lungs have included cystically dilated airspaces, apoptosis of alveolar epithelial cells, pleuritis, and desquamation of epithelial cells into the alveolar spaces [26]. Pathology has also been noted in other organs such as the spleen, bone marrow, liver, and lymph nodes [22,24,26]. Our study focuses on the clinical features of pulmonary edema and diarrhea and therefore the lung and intestines.

In $\mathrm{H} 5 \mathrm{~N} 1$ patient tissues, viral antigens and genomic RNA have been found in various tissues. Viral antigens and viral RNA have been detected in the respiratory tract. Among cell types found to be positive for viral antigen and sequence are epithelial cells of the trachea and type II pneumocytes [26]. Viral RNA has been detected in the brain, and viral antigens have been found in neurons [24,25,27]. Further, virus has been isolated from cerebrospinal fluid [28]. Viral RNA specific for the HA protein was found in the spleen [25]. Viral antigens and viral sequences have been found in both the large and small intestine [25,27]. Viral RNA has also been detected in rectal swabs of patients $[28,29]$. One report confirms that $\mathrm{H} 5 \mathrm{~N} 1$ can replicate in the gastrointestinal tract even in patients that don't experience diarrhea [25].

Attempts to elucidate the molecular mechanisms for viral pathogenesis of $\mathrm{H} 5 \mathrm{~N} 1$ have been pursued since the beginning of the outbreak in 1996. Among the findings are the single amino acid change in the RNA polymerase PB2 at position 627 and an amino acid change at position 66 of the PB1-F2 protein both of which modulate virulence [3032]. The hemagglutinin protein has also been shown to be an important mediator of virulence in $\mathrm{H} 5 \mathrm{~N} 1$ viruses. Increased cleavability of the receptor by ubiquitous proteases has been shown to correlate with increased virulence [30,32]. NS1 has also been reported to play a role in the virulence of H5N1. Single amino acid changes in NS1 at residues 42, 92, and 149 have been found to increase the virulence of H5N1 [33-35]. Details of the H5N1 NS1 studies will be discussed in more detail in the following section. 


\subsection{NS1 Protein}

Nonstructural protein 1 (NS1) is encoded by the smallest gene segment (vRNA segment 8) of influenza A virus, which encodes both the NS1 and NS2/NEP proteins. NS1 is made only during viral infection and has not been found in mature virions. NS1 is synthesized during early viral infection, with protein synthesis reaching a peak at 2.5 hours post infection and remaining high for at least 3 hours after it peaks [36]. NS1 protein has been shown to have many functions and has been reported to interact with various cellular proteins.

\subsubsection{Structure of NS1 Protein}

NS1 has two major domains, the RNA binding domain and the effector domain (Figure 1.1). The RNA binding domain of NS1 encompasses the N-terminal 73 amino acids. The RNA binding domain of NS1 binds double stranded RNA (dsRNA) with very low affinity compared to other cellular proteins that are able to bind dsRNA [37,38]. Structural studies of the RNA binding domain have found that it forms a homodimer in solution and is composed of 3 alpha helices [39]. Dimerization of the RNA binding domain is critical to its function in binding dsRNA, and each homodimer of NS1 binds dsRNA in a $1: 1$ ratio $[38,40]$.

NS1 proteins from different viruses vary in length of the C-terminus; however, amino acid 74 to the $\mathrm{C}$-terminal amino acid makes up the effector domain. Studies on the structure of the effector domain of NS1 have found that, like the RNA binding domain, it also forms a homodimer [41,42]. This has been found to be the case for NS1 of both human and avian influenza viruses [41,42]. None of the structural studies of the effector domain were able to crystallize the last 25 amino acids of the protein. It is thought that the C-terminus of NS1 is highly disordered and only adopts an ordered structure upon binding to other proteins [43].

\subsubsection{Role of NS1 in mRNA Processing, Translation, and Inhibition of Nuclear Export}

NS1 and NS2/NEP are both encoded by vRNA segment 8 . NS1 is encoded by the unspliced mRNA, while NS2/NEP is encoded by the spliced transcript. NS1 has a much higher expression level than does NS2/NEP because only about $10 \%$ of the viral mRNA is spliced [44]. In fact, NS1 inhibits splicing of its own viral pre-mRNA in vitro and in vivo $[43,45,46]$.

NS1 regulates posttranslational processing of RNA polymerase II-driven mRNA transcripts. NS1 inhibits the splicing of mRNA, and it blocks the export of mRNAs that contain 3' poly(A) tails [45]. It was found that both of these functions of NS1 were attributable to the effector domain of the protein [47]. Further studies revealed that NS1 binds the cleavage and polyadenylation specificity factor (CPSF). CPSF is important in pre-mRNA processing and is necessary for cleavage and addition of the poly(A) tail. By 


\begin{tabular}{|l|l|l|}
\hline \multicolumn{2}{|c|}{73} & 225 \\
\hline $\begin{array}{l}\text { RNA binding } \\
\text { domain }\end{array}$ & Effector domain & $\begin{array}{l}\text { PDZ } \\
\text { motif }\end{array}$ \\
\hline
\end{tabular}

Figure 1.1 Pictorial representation of NS1 protein.

Pictorial representation of NS1 protein of influenza A/chicken/Vietnam/ C58/04 used in these studies. NS1 protein of this virus contains the PDZ motif ESEV commonly found in highly pathogenic H5N1 viruses. 
binding to CPSF, NS1 prevents the addition of the poly(A) tail and, as a result, mRNAs are not exported from the nucleus [48]. Despite this inhibition by NS1, some host premRNAs in the nucleus are still cleaved and short poly(A) tails are added to them. NS1 is able to block further elongation of these poly(A) tails by targeting the poly(A)-binding protein II (PABII) [49]. The binding sites for these protein-protein interactions were mapped. NS1 amino acid residues 180-215 are necessary for binding CPSF. The $23 \mathrm{C}-$ terminal amino acids of NS1 are important for binding PABII [50]. During influenza virus infection, cellular mRNA and pre-mRNAs trapped in the nucleus are degraded, while viral RNA which is selectively exported becomes the predominant mRNA to reach the translation machinery [44].

In addition to targeting proteins involved in processing cellular pre-mRNAs, NS1 is able to bind and inhibit proteins that play crucial roles in the mRNA nuclear export. NS1 is able to bind p15, NXF1, Rae1, E1B-AP5, and Nup98 - all of which form a complex and are import protein constituents of the nuclear export machinery [51]. The p15 protein was found to interact with residues in the effector domain of NS1. Both RNA binding domain and effector domain of NS1 were needed to bind the other proteins in the complex [51].

During influenza virus infection there is a global decrease in cellular protein expression. This effect has been attributed to the NS1 protein due to its ability to block mRNA processing and nuclear export. However, NS1's role in translation has also been studied and it has been found that NS1 enhances translation initiation of viral mRNAs [52]. It is thought that NS1 is able to enhance translation of viral mRNAs by interacting with 5' extracistronic sequences in the viral mRNA [52]. Another report has shown that NS1 can also augment translation of cellular proteins and that this effect was not promoter specific [53]. NS1's ability to enhance translation may be attributed to NS1's ability to block protein kinase R (PKR) activity, as PKR acts to block translation in virus infected cells [53]. Further, it was shown that the global shut-off of protein expression was not attributable to NS1 as cells infected with an NS1 deficient virus still have a global reduction in host protein expression [53].

\subsubsection{NS1 Acts to Subvert the Cellular Immune Response}

NS1 is a multifunctional protein, and among its many functions, NS1 plays a major role in subverting the immune system. There are many defenses that the infected host cell activates upon virus infection. One early cellular response to viral infection is the cellular transcription, activation, and translocation of interferon regulatory factors (IRFs) from the cytoplasm to the nucleus [54]. In influenza A virus infection, NS1 counteracts this innate immune response by blocking the maturation of mRNAs that encode the IRFs [55]. NS1 accomplishes this by inhibiting the 3' end processing of cellular pre-mRNAs by binding to the cleavage and polyadenylation specificity factor (CPSF) and the poly(A)-binding protein II (PABII) [37]. 
Another method that host cells use to detect viral replication is through cellular proteins that detect dsRNA made during virus infection. One such pathogen detector, the retinoic acid-induced gene I product (RIG-I), is targeted by NS1 [56]. It has been proposed that NS1 blocks interferon- $\beta$ (IFN- $\beta$ ) production through forming a complex with RIG-I, although this interaction is not direct [56].

NS1 is also able to inhibit the activation of protein kinase $\mathrm{R}$ (PKR). PKR is activated in infected cells in response to dsRNA. PKR plays a role in inhibiting viral replication by phosphorylating the $\alpha$-subunit of eIF2, a protein important in translation initiation [37]. NS1 interacts directly with PKR, through residues in its effector domain. The RNA binding domain of NS1 may also play a role in inhibiting PKR activation; in vitro studies have shown the RNA binding domain to be sufficient for inhibition of PKR [37].

The NS1 RNA binding domain also functions to subvert the innate immune response through another pathway. 2'-5'-oligoadenylate synthetase (OAS) is activated by dsRNA made during viral replication. OAS in turn activates RNase L which degrades RNA, both cellular and viral, and therefore inhibits viral replication [57]. NS1 acts to inhibit the OAS/RNase L pathway by out competing OAS for binding of dsRNA [58]. Inhibition of the OAS/RNase L pathway is thought to be the principal function of NS1's RNA binding domain [58].

\subsubsection{NS1 and Apoptosis}

Differing reports have been published on the role of NS1 in apoptosis. While some studies have reported that NS1 has pro-apoptotic functions, others have reported that NS1 has anti-apoptotic functions. One theory that integrates the varying data is that NS1 may suppress apoptosis during early viral infection while promoting it during later time points of infection. Others maintain that the conflicting data are a result of the different experimental procedures, cell types, virus strains, and NS1 constructs used [43].

Two studies have reported that NS1 induces apoptosis in cultured epithelial cells. The first study found that RNA binding domain is necessary for the NS1 protein to induce apoptosis [59]. The second study reported that NS1 induces apoptosis through the death receptor caspase pathway [60]. A number of studies also report that NS1 is antiapoptotic [61-64]. These studies also have used various viral constructs and cell types.

One report concluded that the anti-apoptotic function of NS1 is dependent on its ability to block IFN [61]. In human macrophages, it seems that the NS1 protein is working to block apoptosis through the inhibition of caspase-1 [62].

Another mechanism by which NS1 may be inhibiting apoptosis is through the $\mathrm{PI} 3 \mathrm{~K} /$ Akt signaling pathway. The major role of PI3K is to phosphorylate membrane phosopholipids, resulting in the generation of phosphatidylinositol-3,4,5-triphosphate (PIP3), an important signaling mediator. PI3K is activated upon binding of its regulatory subunit, p85. Several studies have revealed that NS1 is able to bind and activate 
phosphatidylinositol-3-kinase (PI3K) by binding the p85 $\beta$ subunit of PI3K [64-67]. NS1 activation of PI3K is important both for virus replication and inhibition of apoptosis through inhibiting the caspase-9 apoptotic pathway $[64,65]$.

\subsubsection{NS1 of H5N1}

Since the beginning of the H5N1 outbreak, efforts have been underway to elucidate the molecular mechanisms that contribute to the pathogenicity of this lethal virus. Several reports have shown that NS1 plays a role in the virulence of H5N1. Early studies showed that recombinant viruses containing the NS1 of $\mathrm{H} 5 \mathrm{~N} 1$ had increased pathogenesis in pigs. A single amino acid change at position 92 from aspartic acid to glutamic acid was found in the NS1 proteins of these virusesm, and this single amino acid change made these viruses more resistant to interferon (IFN) and tumor necrosis factor- $\alpha$ $($ TNF- $\alpha$ ) [35]. Further characterization of these viruses in a mouse model found that viruses that contained the NS gene of $\mathrm{H} 5 \mathrm{~N} 1$ induced the production of inflammatory cytokines while decreasing the production of anti-inflammatory cytokines [68].

Other studies have uncovered other amino acid residues of NS1 that play a role in increasing the pathogenesis of $\mathrm{H} 5 \mathrm{~N} 1$. Using recombinant viruses in a mouse model, it was found that a single amino acid change at residue 42 also increased virulence of H5N1 viruses. A substitution of serine for proline at this position increases virulence by antagonizing the induction of IFN though the IRF-3 pathway [34].

By utilizing a chicken model, it was found that amino acid 149 of NS1 also plays a role in the virulence of $\mathrm{H} 5 \mathrm{~N} 1$ viruses. In this study, only recombinant viruses that contain the amino acid alanine at position 149 of NS1 were able to cause disease and death in chickens [33]. It was also shown that alanine at position 149 correlates with the ability of these viruses to inhibit the IFN response in chicken embryo fibroblasts [33].

\subsubsection{The PDZ Motif of NS1}

In 2006, a group at St. Jude Children's Research Hospital (Memphis, TN) undertook the task of sequencing 336 avian influenza viruses. The viruses sequenced in this project were collected between 1976 and 2004. Among the viruses sequenced, all 16 HA and 9 NA subtypes were represented. This large-scale sequencing revealed that avian viruses have greater sequence variability in their HA, NA, PB1-F2, and NS1 proteins than influenza viruses of non-avian origin [69]. This study also identified that the NS1 protein of avian influenza A viruses contain a class I PDZ motif. By assessing the sequences of NS1 protein from avian, swine, and human viruses, this study found that a majority of NS1 proteins from avian influenza viruses contain the PDZ motif ESEV while the NS1 proteins of human influenza viruses contain the PDZ motif RSKV. Further, it was found that the highly virulent viruses isolated from the 2003-2004 H5N1 outbreak in Hong Kong and Vietnam had the PDZ motif ESEV [69]. Binding studies revealed that NS1 protein containing the PDZ motif ESEV was able to bind 24 human PDZ proteins while 
the NS1 protein containing the PDZ motif RSKV was not able to bind these proteins with great affinity [69]. The PDZ proteins NS1 was found to bind in this study include Partitioning-defective protein 3 (Par3) which plays a role in cell polarity and Lim motifcontaining protein kinase 2 (LIMK2), a protein that plays a role in microtubule disassembly [70]. Based on these findings, it was hypothesized that influenza viruses in which NS1 contains a PDZ motif of avian origin may interact with host PDZ proteins, thus disrupting normal cellular pathways and leading to greater mortality rates [69].

Further investigation into the role of NS1's PDZ motif showed that the PDZ motif of NS1 plays a role in increasing virulence of influenza viruses. Using a reverse genetics system, several known PDZ motifs of NS1 were incorporated into the NS1 protein of the human influenza virus A/WSN/33 [71]. This study showed that influenza viruses, in which NS1 contains the PDZ motifs EPEV or ESEV, have increased virulence and pathogenicity in infected mouse lungs. These are the same PDZ motifs found in the H5N1 outbreaks in 1997 and 2003, respectively. The NS1 PDZ motif, KSEV, from the 1918 H1N1 Spanish flu was also found to increase pathogenicity of the virus in infected mouse lungs [71]. Influenza virus in which the NS1 PDZ motif was truncated showed less pathogenicity in the infected mice. This study also investigated whether the differences in pathology seen in mouse lungs infected with the recombinant viruses were due to an altered ability to circumvent the IFN response; however, it was shown that this increased pathogenicity is not caused by changes in the interferon response [71]. Therefore, it is likely that interactions of NS1 with other host proteins may be responsible for the increased virulence seen with influenza viruses that contain a PDZ motif of avian origin in the NS1 protein.

\subsection{PDZ Domains and Motifs}

PDZ domains are modular protein-protein interaction domains that were first recognized as regions of sequence homology in the 3 proteins postsynaptic density-95 (PSD-95), discs large (미) - the Drosophilia septate junction protein, and zona occludens-1 (ZO-1) - the epithelial tight junction protein. Therefore the acronym PDZ was created. In the literature, PDZ domains are also referred to as discs large homology repeat, or DHR domains, and GLGF repeats for the highly conserved amino acid sequence within the domain [72]. PDZ domains are typically about 90 amino acids long and show substantial sequence variation. The significant sequence variation of PDZ domains may be what gives these diverse proteins very specific binding capabilities [73]. The structures of at least $8 \mathrm{PDZ}$ domains have been resolved. Through these studies, we have learned that these domains are compact. The $\mathrm{N}$ - and C-termini of these protein domains are brought together in the folded state [72]. PDZ domains fold into six antiparallel $\beta$-strands that are framed by two $\alpha$-helices $[72,73]$. So far, the human genome has been found to encode more than $250 \mathrm{PDZ}$ domains in over 100 proteins [74]. PDZ proteins assemble together to form supramolecular complexes that function in localized signaling and are found in high abundance at points of cell-cell contact $[73,75]$. PDZ proteins are also involved in key processes, such as maintenance of cell polarity and the regulation and trafficking of membrane associated proteins $[73,75]$. 
While PDZ domains have been found to interact with phospholipids and internal $\beta$ hairpin structures, a majority of PDZ domains mediate interactions with proteins containing a sequence-specific carboxy-terminal binding motif (or PDZ motif)[73,76,77]. There are three classes of PDZ motifs based on the specificity of the ligand. For class I PDZ motifs, this sequence is $\mathrm{X}-\mathrm{S} / \mathrm{T}-\mathrm{X}-\mathrm{V} / \mathrm{L}$, where $\mathrm{X}$ is any amino acid [73]. Class II PDZ motifs have the carboxy-terminal consensus sequence $X-\varphi-X-\varphi$, while class III PDZ motifs have the consensus sequence $\mathrm{X}-\mathrm{D}-\mathrm{X}-\mathrm{V}$ [73]. X represents any amino acid, while $\varphi$ represents a hydrophobic amino acid residue. PDZ domains preferentially bind Cterminal peptides through interactions with the highly conserved GLGF motif found in PDZ domains. Protons found in the GLGF motif form hydrogen bonds with the terminal carboxylate group of the PDZ motif - thus giving rise to the specificity for C-terminal peptides [73]. Different PDZ domains have different stringency requirements for peptide binding, giving rise in part to a wide range of binding affinities between PDZ domains and their ligands. Binding affinities measured for PDZ domains and motifs have ranged from a $\mathrm{K}_{\mathrm{d}}$ of $10^{-8} \mathrm{M}$ to $10^{-6} \mathrm{M}$ [73]. Binding affinities in this range are considered modest and make PDZ domain/motif interactions ideal for processes that must be regulated and reversible [72]. Although much has been uncovered about PDZ domain interactions, relatively few proteins have been studied. Therefore, future studies are likely to reveal much more about these physiologically important interactions.

\subsection{Adherens Junctions}

The adherens junction is made up a large protein complex and has many functions, including initiating and maintaining cell-cell adhesion, regulating the actin cytoskeleton, and intracellular signaling. Cell-cell adhesion is indispensable to epithelial cell function and morphology and is essential in the process of epithelial cell polarization. Adherens junction formation is also crucial for the formation of tight junctions in polarized epithelial cells. The adherens junction initiates cell-cell contact though the binding of Ecadherin proteins on neighboring cells $[78,79]$.

\subsection{SAP-97 Protein}

Synapse associated protein-97 (SAP-97) belongs to the family of proteins designated membrane-associated guanylate kinase (MAGUK). Each protein in the MAGUK family has multiple protein-protein interaction domains, including three PDZ domains, a src homology 3 (SH3) domain, and a guanylate kinase (GUK)-like domain (Figure 1.2) $[80,81]$. The guanylate kinase-like domain of SAP-97 is referred to as such because it was found that this domain does not actually encode an active guanylate kinase despite high sequence similarity to such domains [82]. Each protein in the SAP family is located at synapses. SAP-97 is the only protein in the SAP family that is also found in epithelial cells, where it localizes to cell-cell junctions [80]. Proteins homologous to SAP-97 have been studied in other animal systems. In Drosophila, this protein is known as the discs large (Dlg) tumor suppressor. In Caenorhabditis elegans, this protein has been designated DLG-1, whereas in mammalian cells it is referred to as SAP-97. SAP-97 is 


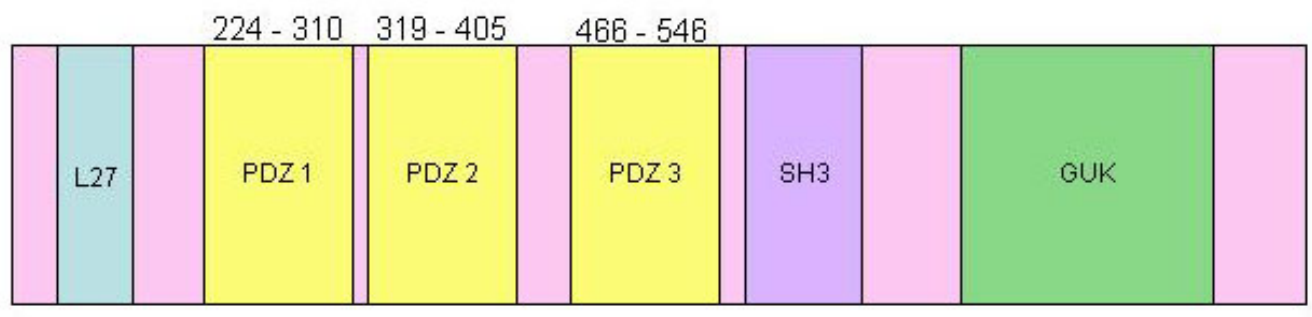

Figure 1.2 Pictorial representation of SAP-97 protein.

SAP-97 belongs to the MAGUK family of proteins and has three PDZ domains (yellow), an SH3 domain (purple), and a GUK-like domain (green). The above numbers correspond to the amino acid residues of the individual PDZ domains. 
also referred to as human discs large $(\mathrm{hDlg})$ in human systems; however, all these proteins are homologous and serve similar functions. SAP-97 was first cloned and characterized in 1994, and it was immediately recognized to bind protein 4.1, a cytoskeletal protein that also localizes to adherens junctions [81]. SAP-97 is a multifunctional protein. In neurons, SAP-97 interacts with the NMDA receptor and inward rectifying potassium channels [80]. SAP-97 also acts as a tumor suppressor in some cell types [83].

\subsubsection{Tissue Distribution of SAP-97}

Mammalian characterization of SAP-97 reveal that SAP-97 mRNA is expressed in heart, testis, muscle, liver, and lung tissues of rats [84]. In humans, SAP-97 mRNA or protein is detected in heart, muscle, liver, lung, spleen, kidney, brain, and cervical epithelia, as well as in T-cells and B-cells [81]. Immunohistological staining of intestinal tissues show bright SAP-97 staining in the intestinal villi of rats [84]. In colons of mice and human intestine, SAP-97 can be seen at the apical, lateral, and basolateral membranes of epithelial cells $[85,86]$.

SAP-97 staining can be seen at points of cell-cell contact in MCF-7 cells, a human breast carcinoma cell line [81]. In T84 cells, a human intestinal epithelial cell line, SAP97 only localizes to sites of cell-cell contact, and staining is not seen at cell membranes that are not in contact with other cells or in isolated cells [84]. In Caco-2 cells, SAP-97 is found to localize at the lateral membrane where it co-localizes with E-cadherin [87].

\subsubsection{Role of SAP-97 in Adherens Junctions and Cell Polarity}

SAP-97 was first studied in Drosophila, where the protein is designated discs large (Dlg). Early work revealed that mutations in Dlg lead to a loss in epithelial cell polarity and intercellular adhesion [88]. This loss of cell polarity and cell-cell adhesion leads to an overgrowth of the cells of the imaginal discs. The imaginal discs of the Drosophila larvae are the epithelia that give rise to the adult appendages, including the legs, antennae, and wings. A complete loss of Dlg in Drosophila leads to loss of the septate junctions in the epithelia of larvae [89].

Work in Caenorhabditis elegans, has shown that DLG-1 is required for the formation of adherens junctions [90,91]. DLG-1 is also required for the recruitment of other adherens junction proteins, such as AJM-1 and cypin. In these studies it was noted that other apical and basolateral proteins are properly localized even after complete knockdown of DLG-1; therefore, it was concluded that DLG-1 plays a major role in the establishment and maintenance of adherens junctions but does not play a role in cell polarity [90].

The adherens junction plays a critical role in preserving adhesion between neighboring epithelial cells. SAP-97 has been shown to play critical roles in adherens 
junction integrity, cell polarity, and epithelial cell differentiation and growth $[85,87-$ 89,92-95]. SAP-97 is recruited to cell-cell adhesion sites in the intestinal epithelial cell line Caco-2 [87]. In Caco-2 cells treated with EGTA to remove extracellular calcium, SAP-97 distribution moves more intracellularly but remains associated with the actin cytoskeleton [87]. In Caco-2 cells grown in low calcium media, SAP-97 staining is seen in the cell cytoplasm [87]. It was also noted that E-cadherin mediates the recruitment of SAP-97 to sites of cell-cell contact, although it does not bind SAP-97 directly [87]. The amino terminal region (first 65 amino acids) of SAP-97 is important in localizing SAP-97 to the lateral membranes of epithelial cells [96].

Using human derived intestinal epithelial cell lines, it was shown that decreased expression of SAP-97 through using RNAi leads to decreased E-cadherin, F-actin and phosphatidylinositol 3-kinase (PI3K) at cell-cell contacts [85]. SAP-97 directly interacts with the $\mathrm{p} 85$ regulatory subunit of PI3K [85]. This finding is of particular significance because PI3K recruitment to the primordial adherens junction promotes junctional assembly with components of the cytoskeleton, which stabilizes the adherens junction and allows for differentiation of enterocytes [97]. Therefore, while in Drosophila, Dlg plays a role in both cell polarity and adherens junctions; in mammalian cells and in $C$. elegans, it is thought that this protein plays a major role in adherens junctions and a lesser role in cell polarity.

\subsubsection{SAP-97 Interacts with Other Viral Proteins}

Interestingly, SAP-97 has been found to be a target of several viral proteins. These viral proteins bind to SAP-97 through PDZ-motif dependent interactions. The first virus studied was the subgroup D adenovirus type 9. This virus is able to induce estrogendependent mammary tumors in rats. The adenovirus type 9 viral protein, designated Ad 9 E4 region ORF 1 protein (9ORF1), is the first viral protein identified to interact with SAP-97 [98]. The protein 9ORF1 was found to bind strongly to the second PDZ domain of SAP-97, but a weak interaction is also seen with PDZ1 and PDZ3 [98]. This interaction was found to be dependent on the PDZ motif of 9ORF1, because proteins that contained mutations in this region are not able to bind SAP-97 [98]. Remarkably, viruses with mutations in the PDZ motif of 9ORF1 are not able to elicit tumors in rats [98].

Other oncogenic viruses also have proteins that posses a PDZ motif. Human T cell leukemia virus type 1 (HTLV-1) is a retrovirus that causes aggressive and sometimes fatal T cell leukemia in adults. The Tax oncoprotein of HTLV-1 contains the PDZ motif ETEV, and has also been found to bind SAP-97 protein in a PDZ-dependent manner $[98,99]$.

The human papillomaviruses type 18 and 16 (HPV-18) are associated with genital lesions and pose a high risk for cervical cancer. The E6 oncoprotein of HPV-18, which contains the PDZ motif ETQV, binds SAP-97 through PDZ-mediated interactions $[98,100]$. The PDZ motif of HPV-18 is able to bind all three PDZ domains of SAP-97 [100]. Similarly, the E6 protein of HPV-16 (PDZ motif ETQL) also binds SAP-97 PDZ 
2 in a PDZ-dependent manner [101]. For HPV-16, ability of the E6 oncoprotein to bind SAP-97 correlates with the ability to transform rodent cells [101]. Not only does E6 of HPV bind SAP-97, it targets SAP-97 for ubiquitin-mediated degradation [100,102].

While both E6 of HPV-16 and HPV-18 are able to target SAP-97 for degradation, the increased binding affinity of HPV-18 E6 correlates with an increased level of degradation of SAP-97 both in vitro and in vivo [102]. In immortalized human epidermal keritinocytes, cells expressing E6 have a lower tendency to associate with neighboring cells and had a loss of integrity of their adherens junctions [103].

\subsection{Scope and Objective of Dissertation}

The objective of this dissertation project was to investigate the PDZ motif-mediated interactions of NS1 with host cell proteins and to determine if these interactions act to modulate the pathogenicity of H5N1 influenza viruses. In this study, I demonstrate that NS1 interacts with a host protein, SAP-97, through the PDZ motif. The data shed light into the differences in pathology caused by H5N1 in the presence and absence of the NS1 PDZ motif. This study is the first to show that NS1 can interact with SAP-97, an important adherens junction protein, and that the NS1 and SAP-97 interaction has a functional consequence in disrupting epithelial barrier integrity. 


\section{CHAPTER 2. PDZ-MOTIF MEDIATED PROTEIN INTERACTION OF NS1 AND SAP-97}

\subsection{Introduction}

Human $\mathrm{H} 5 \mathrm{~N} 1$ infection is characterized by severe respiratory symptoms, including pulmonary edema as well as severe diarrhea [21,23]. Both of these disease states result from a breakdown in epithelial barrier function and are not common in seasonal influenza outbreaks. Therefore, it was of interest to investigate whether the PDZ motif of NS1 (found in influenza viruses of avian origin) has a role in disrupting the structural integrity of the epithelial barrier. We sought to identify PDZ proteins important in junctional formation that may be interacting with NS1. For this study, NS1 protein of A/Chicken/Vietnam/C58/04 containing the PDZ motif ESEV (NS1-WT) was used. Constructs containing mutations in the PDZ motif were also generated. The construct NS1-HuPDZ contains the PDZ binding motif RSKV found in the NS1 protein of influenza A viruses of human origin [69], and NS1- $\triangle \mathrm{PDZ}$ (stop codon at amino acid 223) contains no PDZ binding motif. Several key tight junction and adherens junction proteins were tested for their ability to bind NS1. Proteins examined all contained multiple PDZ domains. We found that the tight junction protein ZO-1 was not able to bind NS1, however we identified that NS1 of H5N1 binds SAP-97, and important adherens junction protein.

\subsection{Materials and Methods}

\subsubsection{Plasmid Construction}

We obtained from the lab of Dr. Richard Webby, the p5H58-NS construct that encodes NS1 of influenza A/chicken/Vietnam/C58/04. The p5H58-NS plasmid was used as a template to create the pTriEx-4-NS1-WT, pTriEX-4-NS1-HuPDZ, and pTriEx-NS1$\triangle \mathrm{PDZ}$ constructs by ligation independent cloning (LIC). The 5' primer used for all three reactions was 5' GACGACGACAAGATGGATTCCAACACT 3'. The 3' primer used for creating NS1-WT was 5' GAGGAGAAGCCCGGTTCAAACTTCTGACTCAAT 3'. For NS1-HuPDZ the 3' primer used was: 5'

GAGGAGAAGCCCGGTTCAAACCTTTGATCTAAT 3'. The reverse primer used to create NS1- $\triangle$ PDZ was 5' GAGGAGAAGCCCGGT TCACTCAATTGTTCTCGC 3'. NS1 was amplified using the polymerase chain reaction (PCR). The PCR conditions used were as follows: 2 minute denaturation at $95^{\circ} \mathrm{C}, 30$ amplification cycles with an annealing temperature of $62^{\circ} \mathrm{C}$, and final extension of $72^{\circ} \mathrm{C}$ for 7 minutes. PCR products were run on a $1 \%$ agarose gel to check for proper size (Figure 2.1). PCR products of the correct size were excised from the gel and extracted using the Qiagen gel extraction kit. Purified PCR products were treated with T4 DNA polymerase at room temperature for 30 minutes to create overhangs that are compatible with the vector. T4 DNA polymerase 


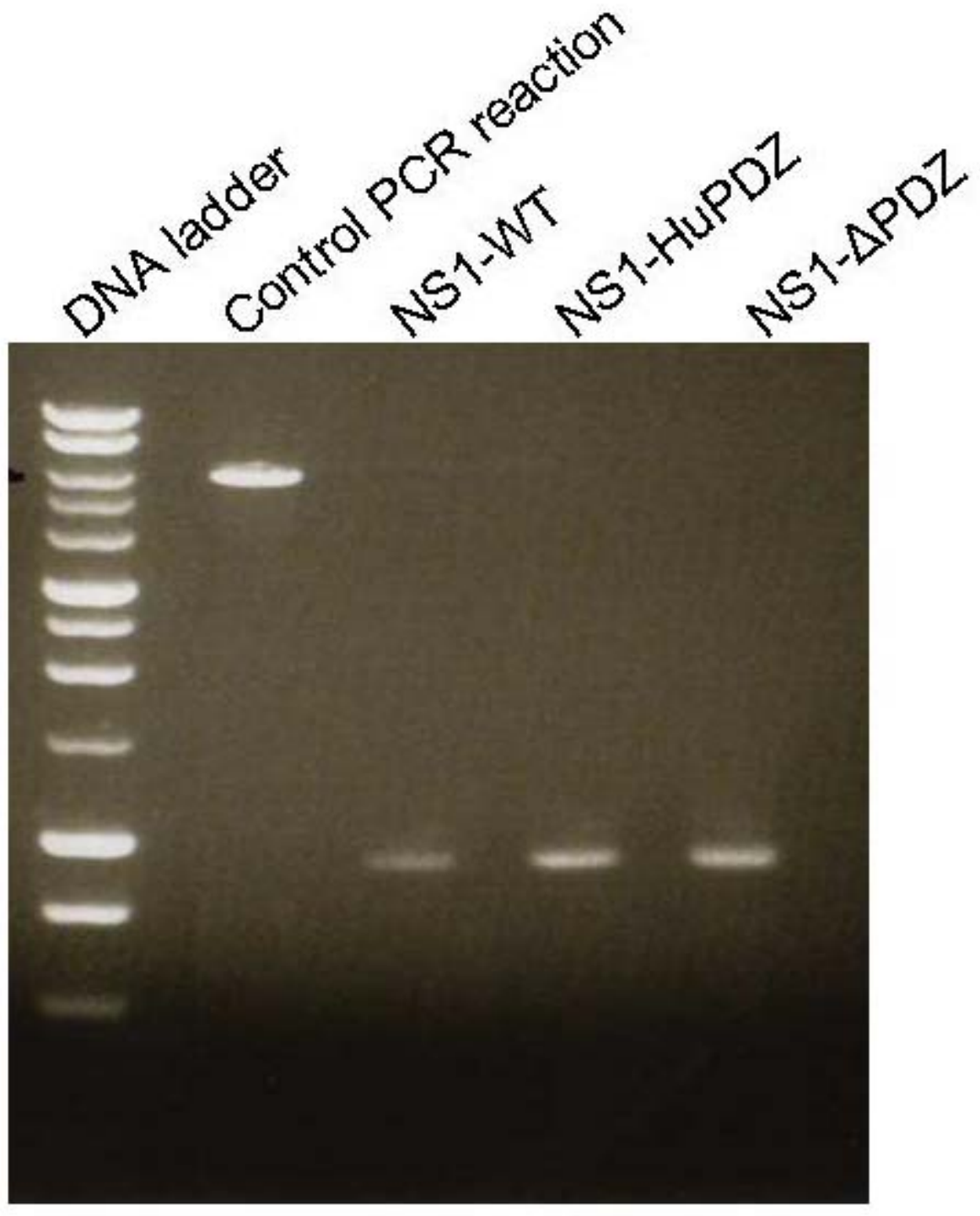

Figure 2.1 PCR products for cloning pTriEX-NS1 constructs.

Agarose gel to confirm proper size of PCR products for the cloning of pTriEX NS1WT, pTriEX-NS1-HuPDZ, and pTriEX NS1- $\triangle$ PDZ. 
was then heat inactivated by incubation for 20 minutes at $75^{\circ} \mathrm{C}$. Each insert was then incubated with pTriEX-4 LIC vector for annealing. Resulting plasmids were transformed using NovaBlue competent $E$. coli. for DNA expression and Oragami competent $E$. coli for protein expression. DNA was extracted from select colonies using a Qiagen miniprep kit. Clones were screened for proper sequence at the University of Tennessee's Molecular Resource Center using the T7 promoter primer and the TriEXDOWN primer. The pTriEx vector has N-terminal his6 and S tags. Using the same primers and template, NS1-WT, NS1-HuPDZ, and NS1- $\triangle \mathrm{PDZ}$ were also cloned into the LIC vector pET41. The pET41 vector contains N-terminal Glutathione S-transferase (GST), his6, and S tags.

The UniProtKB/Swiss-Prot entry for SAP-97 (Q12959) was used to determine the amino acids that encompass the individual PDZ domains. Of the full length SAP-97 protein, the sequence for amino acids 224 to 310 was used to create PDZ 1. Amino acid residues of the full length SAP-97 protein used to make PDZ 2 were 319 to 405, and amino acids 466 to 546 were used to create SAP-97 PDZ 3. The individual PDZ domains of SAP-97 were cloned into the LIC vector pTriEX-4, which contains an N-terminal his6 and S tags. The plasmid pCDNA3 myc-SAP-97 was used as a template for this cloning. This plasmid contains the full length human SAP-97 coding sequence with an N-terminal myc tag. The primers used for SAP-97 PDZ 1 were 5'

GACGACGACAAGATGGAAATCACACACTTGAAAGGGGA 3' for the forward sequence and 5' GAGGAGAAGCCCGGTTCACCTTCTTTTTACATACAAGCGTAC 3' for the reverse sequence. The SAP-97 PDZ 2 primers forward and reverse were as follows: 5' GACGACGACAAGATGGAAATAAGCTCATTAAAGGTCCT 3' and GAGGAGAAGCCCGGTTCAGGGTTTTGCCACTTTCAATAAAC 3'. The forward and reverse primers used for SAP-97 PDZ 3 were 5' GACGACGACAAGATGAAAGTTGTTCTTCATCGTGGCTCA 3’ and 5'GAGGAGAAGCCCGGTTCATCGATATTGTGCAACAATTGTGAC 3'. The same protocol for LIC cloning was used as stated above for pTriEX-NS1 constructs.

SAP-97 PDZ 1, PDZ 2, and PDZ 3 were subsequently cloned into the pGEX-4T-1 expression vector, which contains a GST tag in frame and upstream of the multiple cloning site. The templates used for cloning were pTriEX-SAP-97 PDZ 1, pTriEX-SAP97 PDZ 2, and pTriEX-SAP-97 PDZ 3. Primers created for cloning the SAP-97 PDZs into pGEX-4T-1 contained 5' EcoRI and 3' XhoI restriction site. The sequences for the primers used were 5' GGAATTCGAAATCACACTTGAA 3' and 5'

CGGCTCGAGTCACCTTCTTTTTACATA 3' for SAP-97 PDZ 1 forward and reverse, respectively. The SAP-97 PDZ 2 primers used were 5'GGAATTCGAAATAAAGCTCATT 3' for the forward sequence and 5' CGGCTCGAGTCAGGGTTTTGCCACTTT 3' for the reverse sequence. The SAP-97 PDZ 3 primers were as follows: 5' GCAATTCAAAGTTGTTCTTCAT 3' for the forward sequence and 5' CGGCTCGAGTCATCGATATTGTGCAAC 3' for the reverse sequence. PCR products were generated using the following conditions: 2 minute denaturation at $95^{\circ} \mathrm{C}, 30$ amplification cycles with an annealing temperature of $55^{\circ} \mathrm{C}$, and final extension of $72^{\circ} \mathrm{C}$ for 7 minutes. A $10 \mu \mathrm{L}$ sample of the complete PCR reaction was run on a $1 \%$ agarose gel to verify that the PCR inserts were of the proper size (Figure 2.2). The PCR products were then purified using a Qiagen PCR purification kit and 


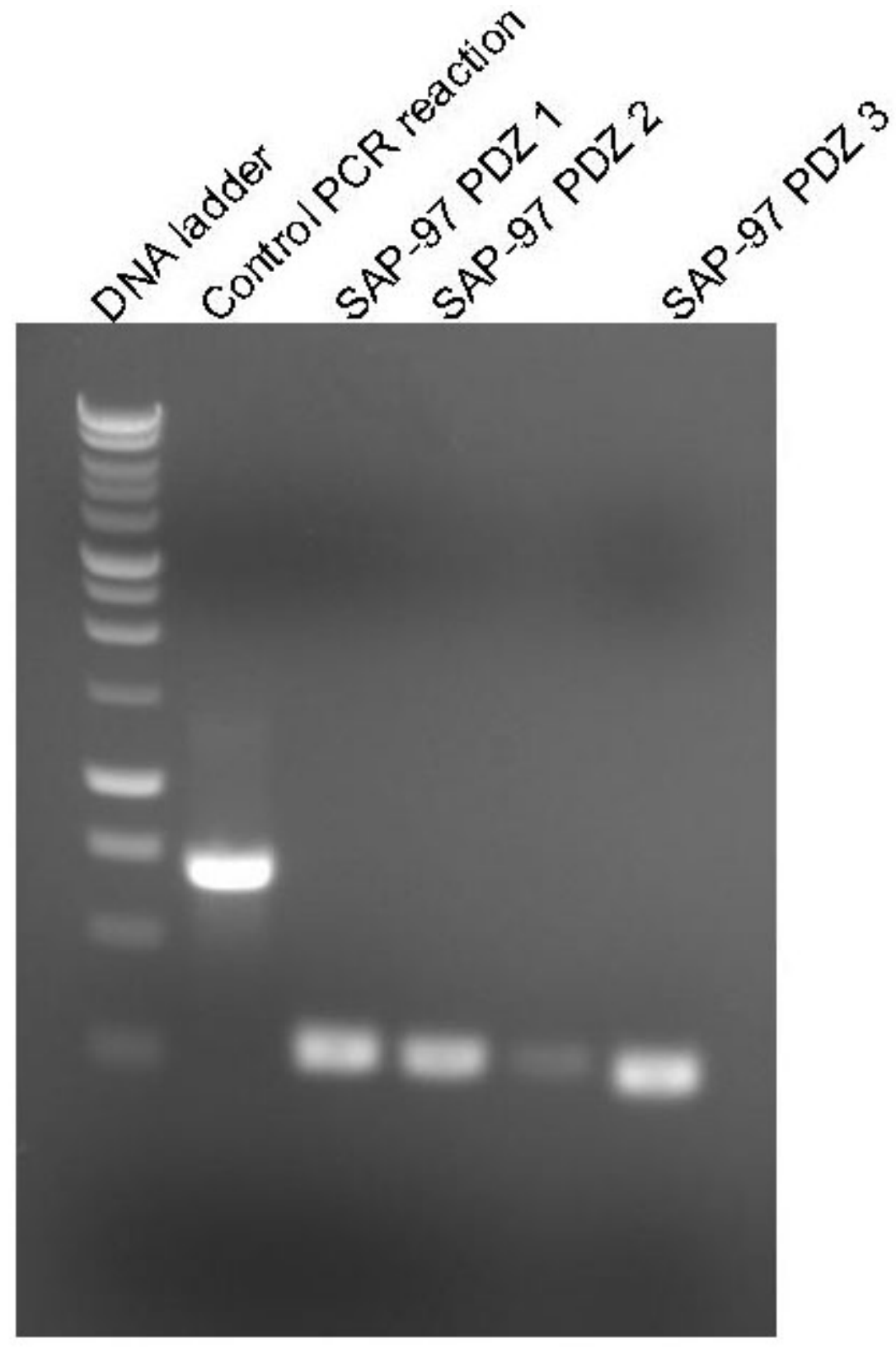

Figure 2.2 PCR products for cloning pGEX4T1-SAP-97 PDZ constructs.

The agarose gel confirms proper size of PCR products for the cloning of pGEX4T1SAP-97 PDZ 1, pGEX4T1-SAP-97 PDZ 2, and pGEX4T1-SAP-97 PDZ 3. 
digested with EcoRI and XhoI at $37^{\circ} \mathrm{C}$. The pGEX-4T1 vector was digested with the same enzymes. The digested inserts were purified on a $1 \%$ agarose gel and extracted using the Qiagen gel extraction kit. The purified vector and insert were ligated using the Takara DNA ligation kit version 1. Plasmids were transformed using DH5 $\alpha$ competent E. coli. Colonies were screened for proper insert by sequencing with the pGEX 5' and pGEX3' primers.

\subsubsection{Cell Culture and Transfection}

HEK-293 cells were cultured in DMEM-F12 (Gibco) supplemented with 10\% serum and $1 \%$ penicillin-streptomycin. HEK-293 cells were cultured in a 5\% $\mathrm{CO}_{2}$ incubator at $37^{\circ} \mathrm{C}$. HEK-293 cells were transfected using the following protocol: Cells were seeded on $35 \mathrm{~mm}$ tissue culture dishes at $70-80 \%$ confluency. The next day the cells were washed with culture media containing no antibiotics, then incubated with $1.5 \mathrm{~mL}$ of the antibiotic free media. The transfection mix was set up in two tubes. The first tube contained $200 \mu \mathrm{L}$ of OptiMEM media and $1 \mu \mathrm{g}$ DNA. The second tube contained $200 \mu \mathrm{L}$ of OptiMEM media and $2.5 \mu \mathrm{L}$ of Lipofectamine ${ }^{\mathrm{TM}} 2000$ transfection reagent (Invitrogen). These tubes were mixed gently, then allowed to incubate at room temperature for 20 minutes. Following incubation, the contents of the tube containing the transfection reagent was added to the tube containing the DNA mixture. The tube was mixed gently and allowed to incubate at room temperature for 30 minutes. The transfection mixture was then added to the cell culture dishes in a drop wise fashion and incubated at $37^{\circ} \mathrm{C}$ for 24 hours.

\subsubsection{Pull Down Assay}

HEK-293 cells were transfected with pTriEx NS1 constructs using Lipofectamine 2000 (Invitrogen). Twenty-four hours post transfection the cells were washed in PBS and lysed in lysis buffer (PBS containing $0.2 \%$ Triton-X-100 and protease inhibitors (aprotinin $[1 \mu \mathrm{g} / \mathrm{mL}]$, leupeptin $[1 \mu \mathrm{g} / \mathrm{mL}]$, pepstatin $[1 \mu \mathrm{g} / \mathrm{mL}]$, and phenylmethanesulfonyl fluoride (PMSF) $[500 \mu \mathrm{M}])$ ). Cell lysate was mixed at $4{ }^{\circ} \mathrm{C}$ for 15 minutes then centrifuged $(13,000 \mathrm{rpm})$ for 10 minutes. S-Protein Agarose beads (Novagen, Darmstadt, Germany) were added to the cleared cell lysate and mixed at room temperature for 1 hour. S-Protein agarose beads were centrifuged at $3000 \mathrm{rpm}$ and washed 3 times with lysis buffer. Proteins were eluted from S-Protein agarose beads with Laemmli sample buffer. Eluates were separated on a $4-15 \%$ gel, transferred to a PVDF membrane by Western, and immunoblotted with anti-SAP-97 antibody (Stressgen, Ann Arbor, MI). The image of this Western blot can be seen in Figure 2.3. 


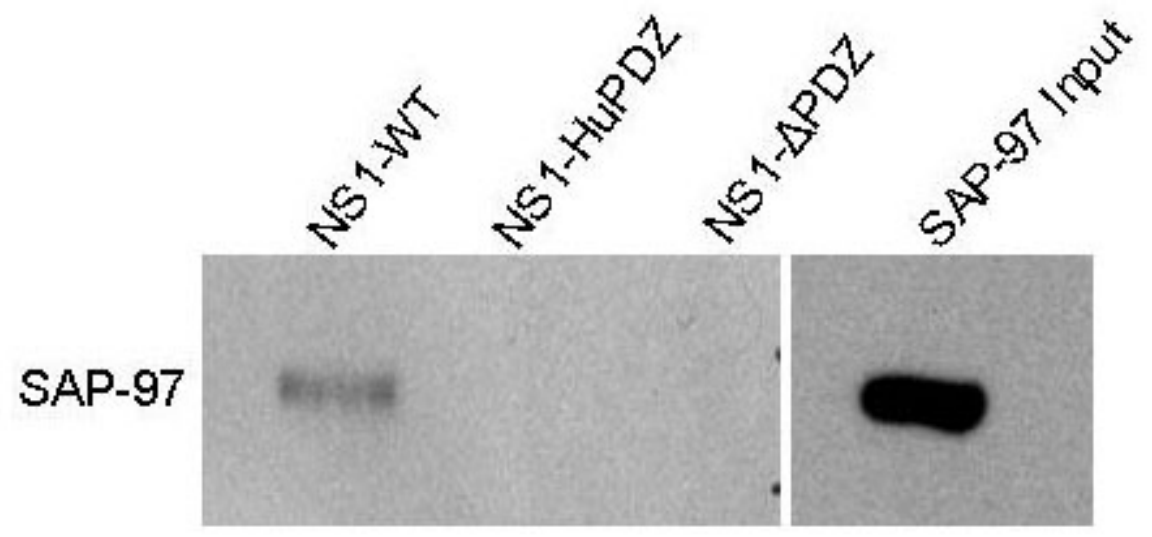

Figure 2.3 Pulldown of SAP-97 in HEK-293 cells transiently transfected with NS1 constructs.

HEK-293 cells were transiently transfected with pTriEX-NS1 constructs. NS1 was pulled down using S-Protein agarose beads. Eluted protein was transferred by Western Blot and probed with anti-SAP-97 antibody. 


\subsubsection{Pairwise Binding Assay}

GST-SAP-97 PDZ proteins were purified from transformed DH5 $\alpha$ E. coli bacteria. Protein expression was induced using isopropyl $\beta$-D thiogalactopyranoside (IPTG) (200 $\mu \mathrm{M}$ final concentration). Bacteria were pelleted by centrifugation at $4000 \mathrm{rpm}$ for 30 minutes. Bacterial pellets were frozen at $-80^{\circ} \mathrm{C}$. Bacterial pellets were resuspended in lysis buffer (50 mM Tris base, $1 \mathrm{mM}$ EDTA, and 10\% sucrose) supplemented with protease inhibitors (aprotinin $[1 \mu \mathrm{g} / \mathrm{mL}]$, leupeptin $[1 \mu \mathrm{g} / \mathrm{mL}]$, pepstatin $[1 \mu \mathrm{g} / \mathrm{mL}]$, and PMSF $[500 \mu \mathrm{M}])$. Lysozyme $(1 \mathrm{mg} / \mathrm{mL}$ final concentration) was added to the resuspended bacteria and allowed to mix at $4^{\circ} \mathrm{C}$ for 30 minutes. Subsequently, $10 \%$ NP40 $(20 \mu \mathrm{L} / \mathrm{mL})$ was added to the suspension and allowed to mix at $4^{\circ} \mathrm{C}$ for 30 minutes. The suspension was then cleared by centrifugation at $20,000 \mathrm{rpm}$ for 30 minutes at $4^{\circ} \mathrm{C}$. Glutathione beads ( $50 \%$ slurry) were then added to the cleared supernatant and allowed to mix for 2 hours at $4{ }^{\circ} \mathrm{C}$. Glutathione beads were retrieved by centrifugation at 3,000 rpm and washed with $0.2 \%$ Triton-X-100 in PBS 3 times, followed by a wash with PBS plus protease inhibitors. A $20 \mu \mathrm{L}$ sample of the protein bound to the glutathione beads were eluted using Laemmli sample buffer and run on a $4-15 \%$ gel to visualize the quantity and quality of the purified protein (Figure 2.4). Proteins were eluted from the glutathione beads using $10 \mathrm{mM}$ glutathione ( $\mathrm{pH}$ 7.5). Glutathione was subsequently dialyzed away from the proteins using 3 changes of PBS. The concentration of purified proteins was estimated using the Bradford protein estimation assay.

His-S-NS1 proteins were purified using a similar protocol, with a few notable exceptions. Bacterial pellets were resuspended in resuspension buffer ( $25 \mathrm{mM}$ HEPES and $400 \mathrm{mM}$ potassium chloride $(\mathrm{KCl}))$. The $\mathrm{pH}$ of the resuspension buffer was adjusted to 7.4 using potassium hydroxide $(\mathrm{KOH})$. Just before use, $5 \mathrm{mM}$ beta-mercaptoethanol ( $\beta \mathrm{ME}$ ) was added to the resuspension buffer (final concentration of $0.39 \mu \mathrm{L} / \mathrm{mL}$ ). TritonX-100 was added to bacterial pellet (final concentration 2.1\%) instead of NP40. Talon beads ( $50 \%$ slurry) were added to the cleared supernatant and allowed to mix at $4{ }^{\circ} \mathrm{C}$ for 30 minutes. Recovered Talon beads were washed one time in $0.2 \%$ Triton-X-100 in PBS, then 4 times in PBS supplemented with protease inhibitors (aprotinin $[1 \mu \mathrm{g} / \mathrm{mL}]$, leupeptin $[1 \mu \mathrm{g} / \mathrm{mL}]$, pepstatin $[1 \mu \mathrm{g} / \mathrm{mL}]$, and PMSF [500 $\mu \mathrm{M}]$ ). A $20 \mu \mathrm{L}$ sample of the proteins bound to the Talon beads were eluted using $1 \mathrm{M}$ imidazole, blotted onto a nitrocellulose membrane and probed with S-HRP antibody to visualize the quantity of the purified protein (Figure 2.5). Proteins were eluted from the Talon beads using $0.1 \mathrm{M}$ imidazole. The concentrations of purified proteins were estimated using the Bradford protein estimation assay.

Purified GST-SAP-97 PDZ proteins $(2 \mu \mathrm{g})$ were incubated with $200 \mathrm{ng}$ of purified His-S-NS1-WT protein for 1 hour at room temperature. Glutathione-Sepharose beads (Thermo Scientific) were then added and allowed to mix for an additional hour. Glutathione beads were spun down, washed 3 times with lysis buffer, and protein was eluted using Laemmli sample buffer. The resulting protein eluate was separated in 4$15 \%$ SDS-PAGE, transferred to a PVDF membrane, and immunoblotted for NS1 using SHRP (Figure 2.6). 

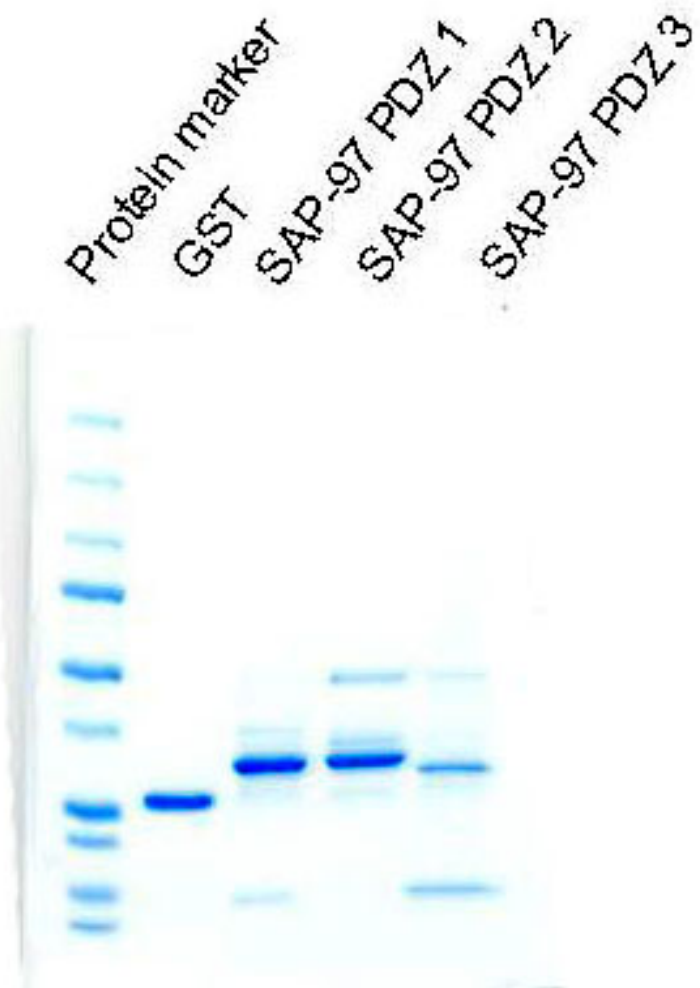

Figure 2.4. Purified GST-SAP-97 PDZ Proteins.

The individual PDZ domains of SAP-97 were cloned into pGEX4T1. Protein was expressed in E. coli and purified. 


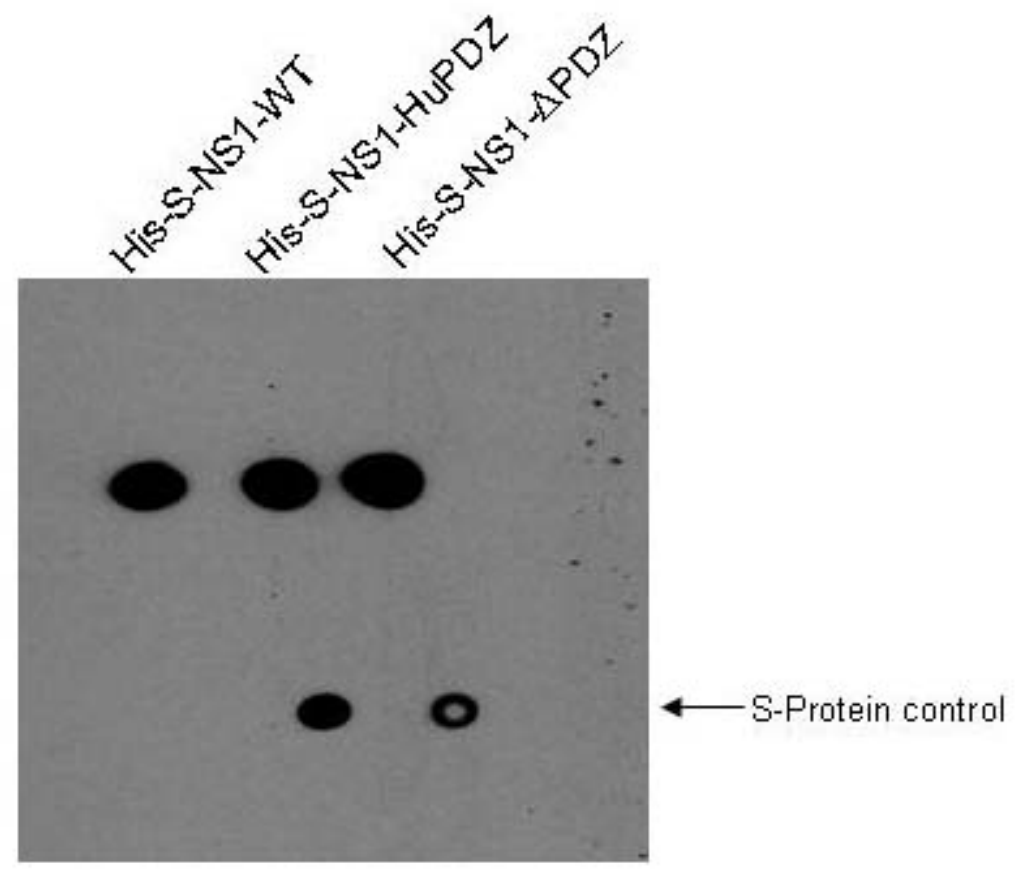

Figure 2.5. Purified His-S-NS1 Proteins.

The NS1 constructs were cloned into pTriEX4. Protein was expressed in Oragami $E$. coli and purified. 


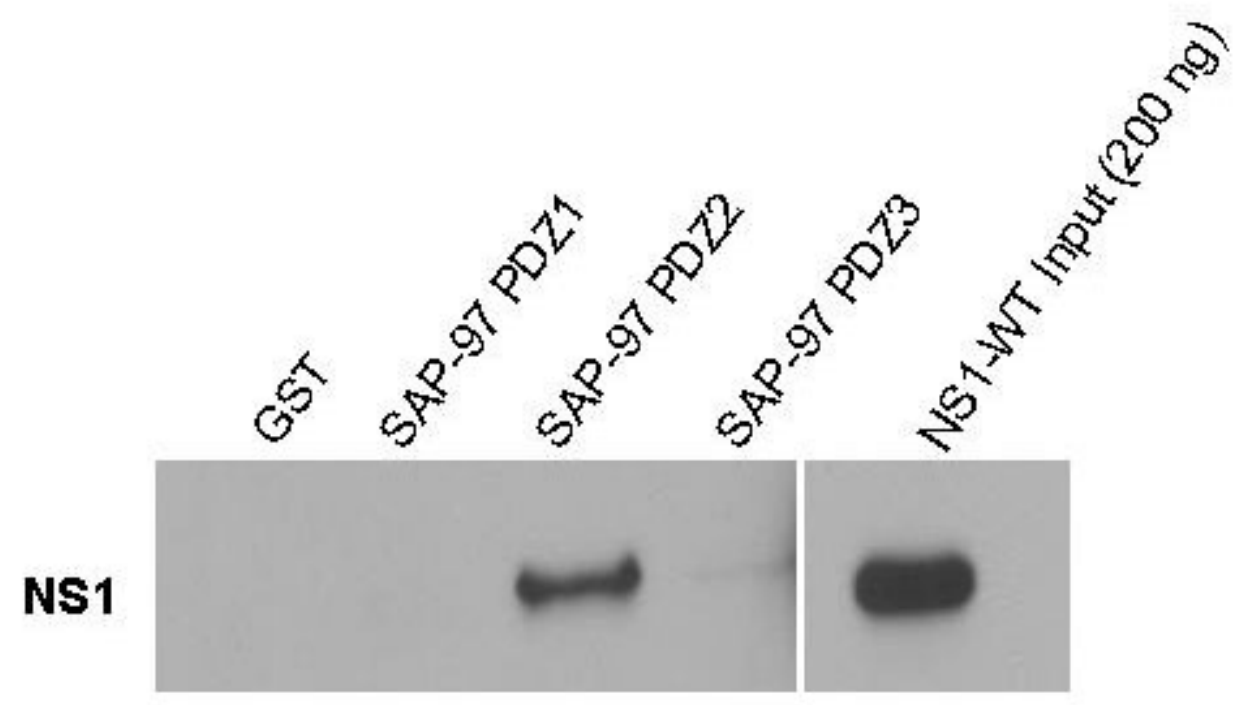

Figure 2.6. Pairwise binding of NS1 and individual PDZ domains of SAP-97. The purified His-S-NS1-WT protein and the purified individual PDZ domain proteins of SAP-97 were incubated together in a pairwise binding assay. 


\subsubsection{Alpha Screen Assay}

AlphaScreen ${ }^{\mathrm{TM}}$ association assay for interaction between biotin-NS1-WT (biotin-KM-A-R-T-I-E-S-E-V) peptide and GST SAP-97 PDZs proteins (PDZ 1, PDZ 2 and PDZ 3) was performed using an AlphaScreen Glutathione-S-Transferase (GST) detection kit (PerkinElmer). Starting from $100 \mu \mathrm{M}$ of final concentration, biotin-NS1-WT peptide was serially diluted (in $1 / 2 \log$ dilution series) in assay buffer $(25 \mathrm{mM}$ HEPES, $100 \mathrm{mM}$ $\mathrm{NaCl}, 0.1 \%$ BSA, $0.05 \%$ Tween $20, \mathrm{pH}$ 7.4) containing GST SAP-97 PDZs (100 nM final concentration). The resulting solutions were incubated at room temperature for 30 minutes. Each sample solution $(15 \mu \mathrm{L})$ was transferred to a white OptiPlate ${ }^{\mathrm{TM}}-384$ microplate (PerkinElmer) in triplicates into which anti-GST acceptor beads $(5 \mu \mathrm{L}, 20$ $\mu \mathrm{g} / \mathrm{mL}$ final concentration) were added and incubated for 30 minutes at room temperature. Streptavidin donor beads $(5 \mu \mathrm{L}, 20 \mu \mathrm{g} / \mathrm{mL}$ final concentration) were then added and incubated for 1 hour at room temperature. The plate was read on an EnVision $^{\mathrm{TM}} 2103{ }^{\mathrm{TM}}$ Plate Reader (PerkinElmer). Results of this assay are shown in Figure 2.7.

The procedure of AlphaScreen competition assay of NS1-WT (K-M-A-R-T-I-E-S-EV), NS1-HuPDZ (K-M-A-R-T-I-R-S-K-V) or NS1-APDZ (Q-K-R-K-M-A-R-T-I-E) peptide against biotin-NS1-WT peptide binding to GST SAP-97 PDZ 2 protein was similar to the above described AlphaScreen association assay except that NS1-WT, NS1HuPDZ or NS1- $\triangle$ PDZ peptides (final concentrations from $1 \mathrm{mM}$ to $3 \mathrm{nM}$ ) were diluted in assay buffer ( $25 \mathrm{mM}$ HEPES, $100 \mathrm{mM} \mathrm{NaCl}, 0.1 \% \mathrm{BSA}, 0.05 \%$ Tween $20, \mathrm{pH} 7.4)$ containing GST SAP-97 PDZ 2 (100 nM final concentration) and biotin-NS1-WT peptide (100 nM final concentration). After the addition of Streptavidin donor beads, the plate was incubated for 4 hours at room temperature prior to reading. The results of this assay are shown in Figure 2.8.

\subsection{Results and Discussion}

We identified that SAP-97, an adherens junction protein with 3 PDZ domains (Figure 1.2), can complex with NS1 in pull-down assays using HEK-293 cell lysate. NS1-WT protein is able to pull down SAP-97, while NS1-HuPDZ and NS1- $\triangle$ PDZ were not able to pull down SAP-97 (Figure 2.3), suggesting that the interaction between NS1 and SAP-97 is PDZ motif-dependent. Next, I sought to determine if this interaction was direct and the minimum domain of SAP-97 required to bind NS1. To accomplish this, each PDZ domain of SAP-97 was individually cloned, protein purified, and incubated with NS1-WT in a pairwise binding assay (Figure 2.6) The results show that NS1 binds the second PDZ domain of SAP-97 (PDZ 2) but does not bind PDZ 1 or PDZ 3 (Figure 2.6). These results are consistent with AlphaScreen analysis, which shows that biotinylated NS1-WT peptide binds PDZ 2 of SAP-97 but does not bind PDZ 1 or PDZ 3 (Figure 2.7). An AlphaScreen competition assay demonstrated that NS1-HuPDZ and NS1- $\triangle$ PDZ peptides do not compete with biotinylated NS1-WT in binding PDZ 2 of SAP-97 (Figure 2.8). Using the Alpha Screen assay results, the $\mathrm{IC}_{50}$ of the NS1-WT and SAP-97 interaction was calculated to be $1.5 \mu \mathrm{M}$. 


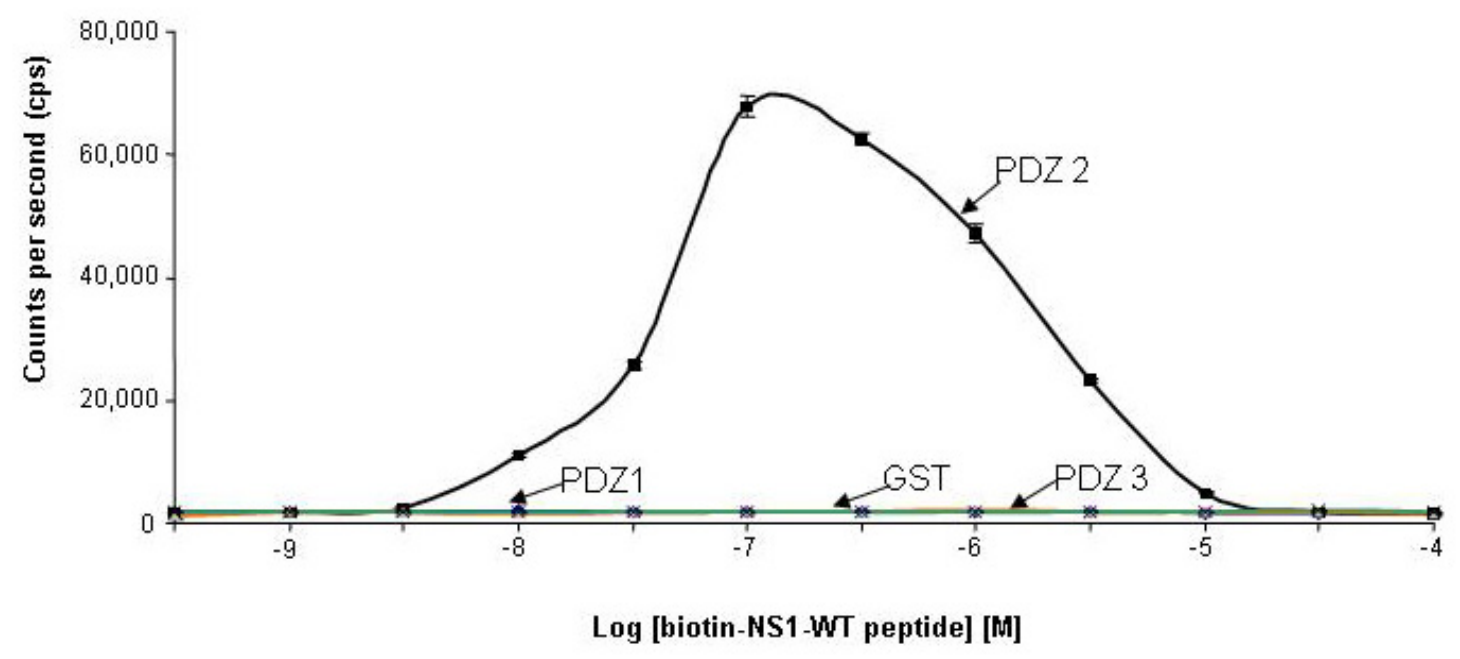

Figure 2.7. Interaction of biotinylated NS1-WT peptide and individual PDZ domains of SAP-97 as detected by AlphaScreen.

The purified His-S-NS1-WT protein and the purified individual PDZ domain proteins of SAP-97 were incubated together in an AlphaScreen assay. The sequence of the NS1-WT peptide used is biotin- K-M-A-R-T-I-E-S-E-V. 


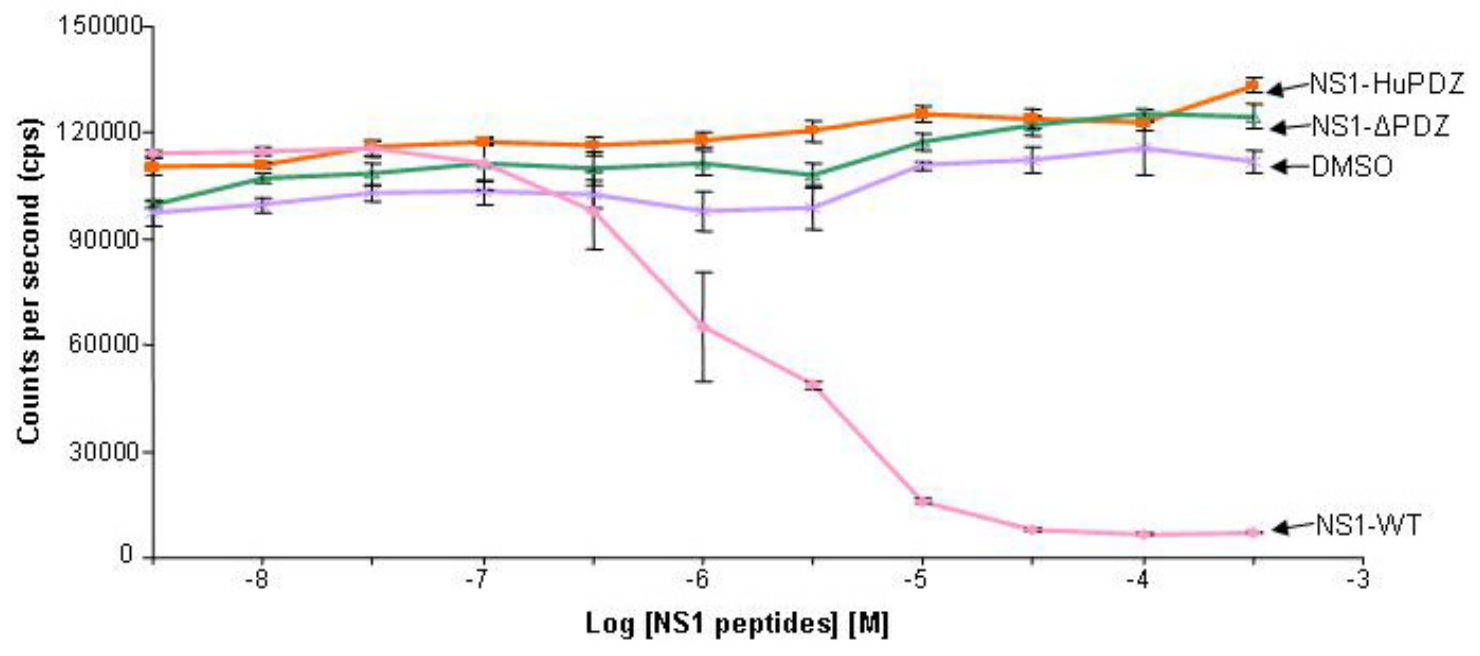

Figure 2.8. AlphaScreen competition assay between NS1 peptide binding to SAP97 PDZ 2.

AlphaScreen competition assay between NS1 peptides against biotinylated NS1-WT peptides binding to PDZ 2 of SAP-97. Sequences for the peptides used were as follows: NS1-WT peptide (K-M-A-R-T-I-E-S-E-V); NS1-HuPDZ peptide (K-M-A-RT-I-R-S-K-V); NS1- $\triangle$ PDZ peptide (Q-K-R-K-M-A-R-T-I-E); DMSO was used as solvent to prepare the peptide solutions. 


\section{CHAPTER 3. SAP-97 LOCALIZATION IS ALTERED IN NS1 TRANSFECTED CELLS AND H5N1 INFECTED TISSUES}

\subsection{Introduction}

To investigate whether localization of SAP-97 is altered during H5N1 infection, mice were infected with two H5N1 recombinant viruses. The virus A/Vietnam/1203/04 was utilized. This virus has a natural truncation in the NS1 protein and therefore contains no PDZ motif and will be referred to as H5N1-NS1- $\triangle$ PDZ in this study. A second virus was also utilized for these studies. The recombinant virus is referred to as H5N1-NS1WT. The H5N1-NS1-WT virus has the background of A/Vietnam/1203/04 with the NS gene of $\mathrm{A} / \mathrm{Chicken} / \mathrm{Vietnam} / \mathrm{C} 58 / 04$. The NS1 protein of this recombinant virus contains the PDZ motif ESEV, a PDZ motif commonly found in highly pathogenic avian influenza viruses. Balb/c mice were infected intranasally with these $\mathrm{H} 5 \mathrm{~N} 1$ viruses, and at 6 days post infection the mice were sacrificed. The lungs and intestines were harvested and fixed in $10 \%$ neutral buffered formalin. Paraffin embedded mouse lungs and intestines were labeled with SAP-97 IgG to study the localization of SAP-97 in these tissues.

\subsection{Materials and Methods}

\subsubsection{Plasmid Construction}

To create the plasmids pcDNA3-CFP-NS1-WT and pcDNA3-CFP-NS1- $\triangle$ PDZ, a pcDNA3-CFP construct already in use in the Naren lab was utilized. This plasmid contains XhoI and KpnI restriction sites 3' to the CFP insert. Primers created for cloning NS1 into pcDNA3-CFP contained 5' XhoI and 3' KpnI restriction sites. The same forward primer was used for the construction of both plasmids because these two constructs only vary in sequence at the 3 ' end. The sequence for the forward primer used was as follows: 5' CCGCTCGAGCAATGGATTCCAACACTGTGTCA 3'. The sequences for the reverse primers used were for NS1-WT ( 5'CGG GGTACC TCA AAC TTC TGA CTC AAT TGT 3') and for NS1- $\triangle$ PDZ (5' CGG GGTACC TCA CTC AAT TGT TCT CGC CAT 3'). The templates used for PCR reactions were pTriEX4-NS1-WT and pTriEX4-NS1- $\triangle \mathrm{PDZ}$. PCR products were generated using the following conditions: 2 minute denaturation at $95^{\circ} \mathrm{C}, 30$ amplification cycles with an annealing temperature of $68^{\circ} \mathrm{C}$ and final extension of $72^{\circ} \mathrm{C}$ for 7 minutes. A $10 \mu \mathrm{L}$ sample of the complete PCR reaction was run on a $1 \%$ agarose gel to verify that the PCR inserts were of the proper size. The PCR products were then purified using a Qiagen PCR purification kit and digested with XhoI and KpnI at $37^{\circ} \mathrm{C}$. The pCDNA3-CFP vector was digested with the same enzymes. The digested vector and inserts were purified on a $1 \%$ agarose gel and extracted using the Qiagen gel extraction kit. The purified vector and insert were ligated using the Takara DNA ligation kit version 1. Plasmids were transformed using DH5 $\alpha$ competent $E$. coli. Miniprep DNA was purified from colonies and was screened for the proper size insert by digesting with XhoI and KpnI (Figure 3.1). The plasmids were 


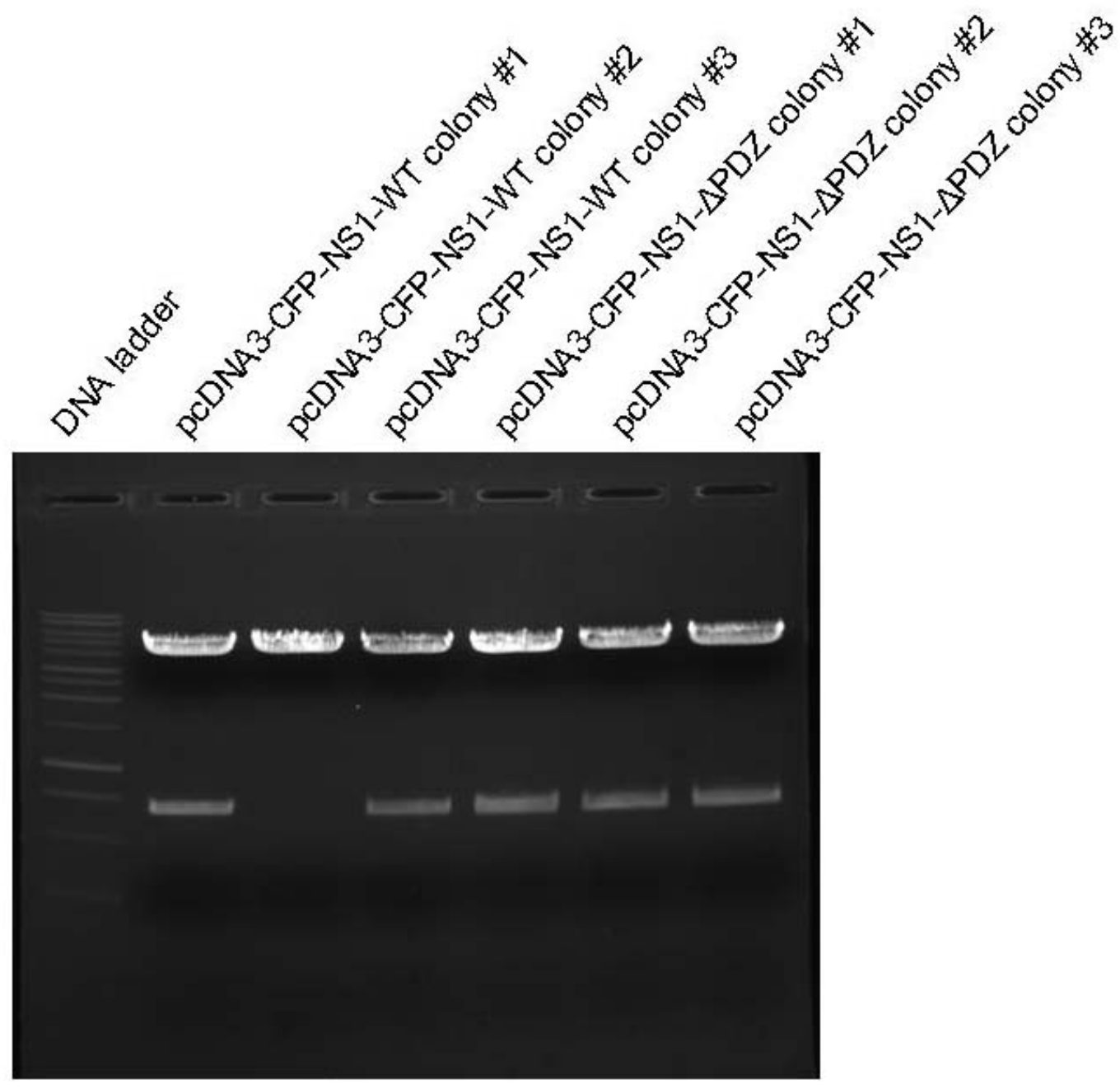

Figure 3.1 Screened colonies of cloning pCDNA3-CFP-NS1-WT and pCDNA3-CFP-NS1-APDZ constructs.

Agarose gel to confirm proper size of inserts in the cloning of pCDNA3-CFPNS1-WT and pCDNA3-CFP-NS1- $\triangle$ PDZ. Miniprep DNA from select colonies was digested with XhoI and KpnI. Colonies with proper insert size were sent for sequencing at the Molecular Resource Center. 
confirmed by sequencing at the Molecular Resource Center at The University of Tennessee Health Science Center, Memphis, TN with the T7 forward and Sp6 reverse primers.

\subsubsection{Cell Culture and Transfection}

Caco-2 cells were grown in DMEM (Gibco) supplemented with 10\% FBS. Cells were cultured in a $5 \% \mathrm{CO}_{2}$ incubator at $37^{\circ} \mathrm{C}$. Caco- 2 cells were transfected using the following protocol: Cells were seeded on glass cover slips placed inside $35 \mathrm{~mm}$ tissue culture dishes at $70-80 \%$ confluency. The next day the cells were washed with culture media containing no antibiotics, then incubated with $1.5 \mathrm{~mL}$ of the antibiotic free media. The transfection mix was set up in two tubes. The first tube contained $200 \mu \mathrm{L}$ of OptiMEM ${ }^{\circledR}$ Reduced Serum Media and $1 \mu \mathrm{g}$ DNA. The second tube contained $200 \mu \mathrm{L}$ of Opti-MEM® Reduced Serum Media and $2.5 \mu \mathrm{L}$ of Lipofectamine ${ }^{\mathrm{TM}} 2000$ Transfection Reagent (Invitrogen). These tubes were mixed gently, then allowed to incubate at room temperature for 20 minutes. Following incubation, the contents of the tube containing the transfection reagent was added to the tube containing the DNA mixture. The tube was mixed gently and allowed to incubate at room temperature for 30 minutes. The transfection mixture was then added to the cell culture dishes in a drop wise fashion and incubated at $37^{\circ} \mathrm{C}$ for 48 hours.

\subsubsection{Animal Infection}

Animal studies were approved by the St. Jude Children's Research Hospital Institutional Animal Use and Care Committee.

Six week old Balb/c mice were infected with $10^{3}$ EID50 units of influenza virus A/Vietnam/1203/04 (H5N1-NS1- $\Delta$ PDZ) or with A/Vietnam/1203/04 containing the NS1 gene of A/Chicken/Vietnam/C58/04 (H5N1-NS1-WT) intranasally. Day 6 post infection, the mice were sedated using avertin and sacrificed. The lungs and intestines were harvested and fixed using 10\% neutral buffered formalin for 2 weeks before being embedded in paraffin.

\subsubsection{Tissue Processing}

After 2 weeks fixation in 10\% neutral buffered formalin, tissues were dehydrated through passage of graded alcohol. During the dehydration process, the tissue was treated with each of the flowing agents for 1 hour: $70 \%$ ethanol, $80 \%$ ethanol, 2 changes of $95 \%$ ethanol, and 4 changes of $100 \%$ ethanol. After dehydration, the tissue was dealcoholized in xylene, and then infiltrated with paraffin. Four micron sections of the tissue were mounted on glass laboratory slides for further evaluation. 


\subsubsection{Fluorescent Immunohistochemistry}

Paraffin embedded tissue sections of normal Balb/c mice and H5N1 infected Balb/c mice ( 6 days post infection) were deparaffinized using 3 changes of xylene and rehydrated through graded ethanol. Heat-induced epitope retrieval was performed using RTU Rodent Decloaker (Biocare Medical). Sections were incubated with rabbit antiSAP-97 antibody (Santa Cruz, CA) followed by AlexaFluor ${ }^{\circledR}$ 488-conjugated anti-rabbit IgG. The fluorescence was visualized using a Zeiss LSM 5 laser scanning confocal microscope, and images were collected using Zeiss LSM 5 Pascal software.

\subsubsection{Immunofluorescent Staining of Caco-2 Cells}

Caco- 2 cells were seeded on coverslips at $80 \%$ confluence were incubated overnight. The following morning, Caco-2 cells were transfected with constructs containing Nterminal CFP tagged NS1-WT or NS1- $\triangle$ PDZ (pcDNA3-CFP-NS1-WT or pcDNA3-CFPNS1- $\triangle$ PDZ. Forty-eight hours post transfection, the cells were washed 3 times with PBS and fixed using ice cold acetone methanol (1:1). The cells were rehydrated with 3 washes of PBS, 10 minutes each, then permeabilized using $0.2 \%$ Trition-X-100 in PBS for 5 minutes. Blocking was performed using 4\% skim milk in TBST at room temperature in a humidifying chamber. To stain for the SAP-97 protein, cells were incubated for 2 hours with mouse anti-SAP-97 antibody (Santa Cruz) at a 1:150 dilution in $4 \%$ milk. After 3 washes in PBS, slides were incubated with the secondary anti-mouse conjugated AlexaFluor 568 antibody. The secondary antibody was used at a 1:200 dilution in $4 \%$ milk. Coverslips were incubated with the secondary antibody for 1 hour at room temperature in a humidifying chamber in the dark. The fluorescence was visualized using an Olympus FluoView ${ }^{\mathrm{TM}}$ FV1000 fluorescence microscope. Images were collected at $40 \mathrm{X}$ magnification using SlideBook ${ }^{\mathrm{TM}} 5.0$ imaging software.

\subsection{Results and Discussion}

In normal mouse lungs, SAP-97 localizes at lateral membranes of alveolar cells (Figure 3.2), whereas in H5N1-NS1-WT-infected lungs, SAP-97 shows an intracellular distribution (Figure 3.2). An increased cellular infiltrate can also been seen in the lungs of H5N1-NS1-WT-infected mice (Figure 3.2), which is a consequence of the disrupted epithelial barrier. In the lungs of mice infected with H5N1-NS1- $\mathrm{PDDZ}$, SAP-97 can still be seen to localize to lateral membranes of alveoli (Figure 3.2), even though other pathology, such as dilated airspaces, is present in these tissues. 
Figure 3.2. SAP-97 staining in normal and H5N1 infected mouse lungs.

(A) SAP-97 staining in normal mouse lung showing staining localized to the lateral membranes of alveolar epithelial cells. (B) Inset of normal mouse lung. (C) SAP-97 staining in H5N1-NS1- $\triangle$ PDZ infected mouse lung, demonstrating that SAP-97 is still localized to the lateral membranes of alveolar cells. (D) Inset of H5N1- NS1- $\triangle$ PDZ infected mouse lung. (E) H5N1-NS1-WT-infected mouse lung, showing diffuse SAP-97 staining that is not restricted to the lateral membranes. (F) Inset of H5N1-NS1-WTinfected mouse lung. All images were collected by confocal microscopy at 40X magnification. 

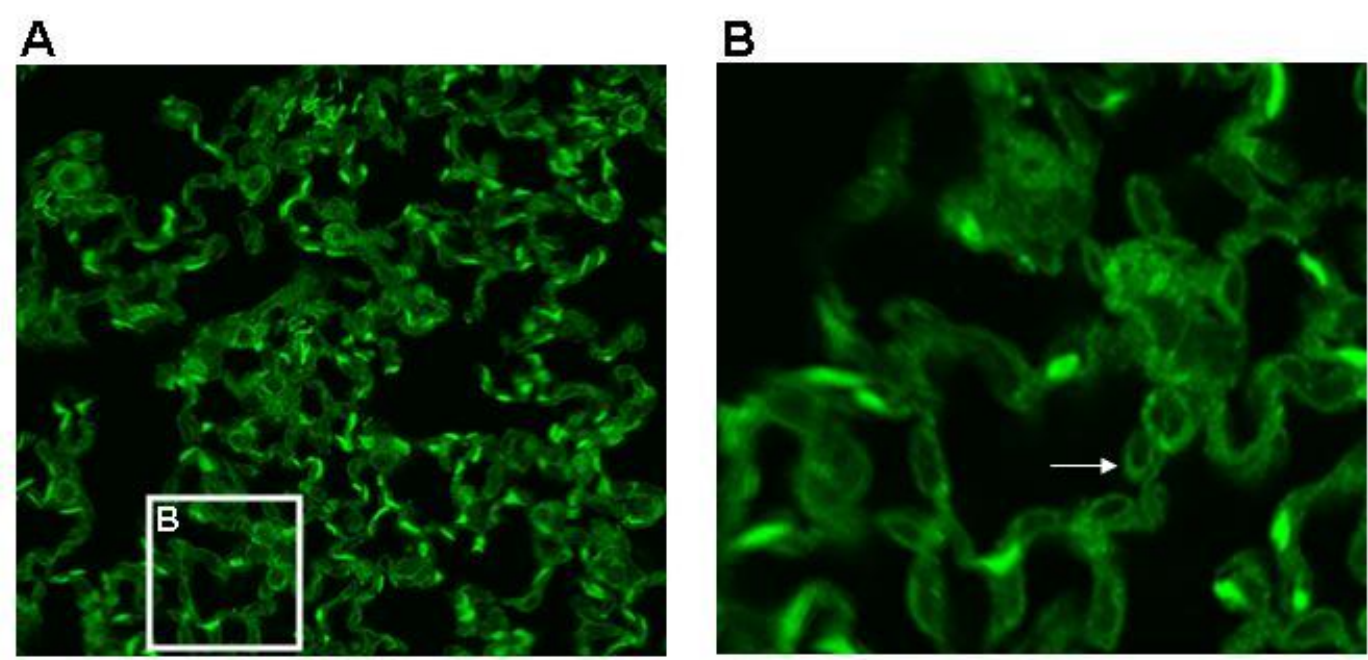

C
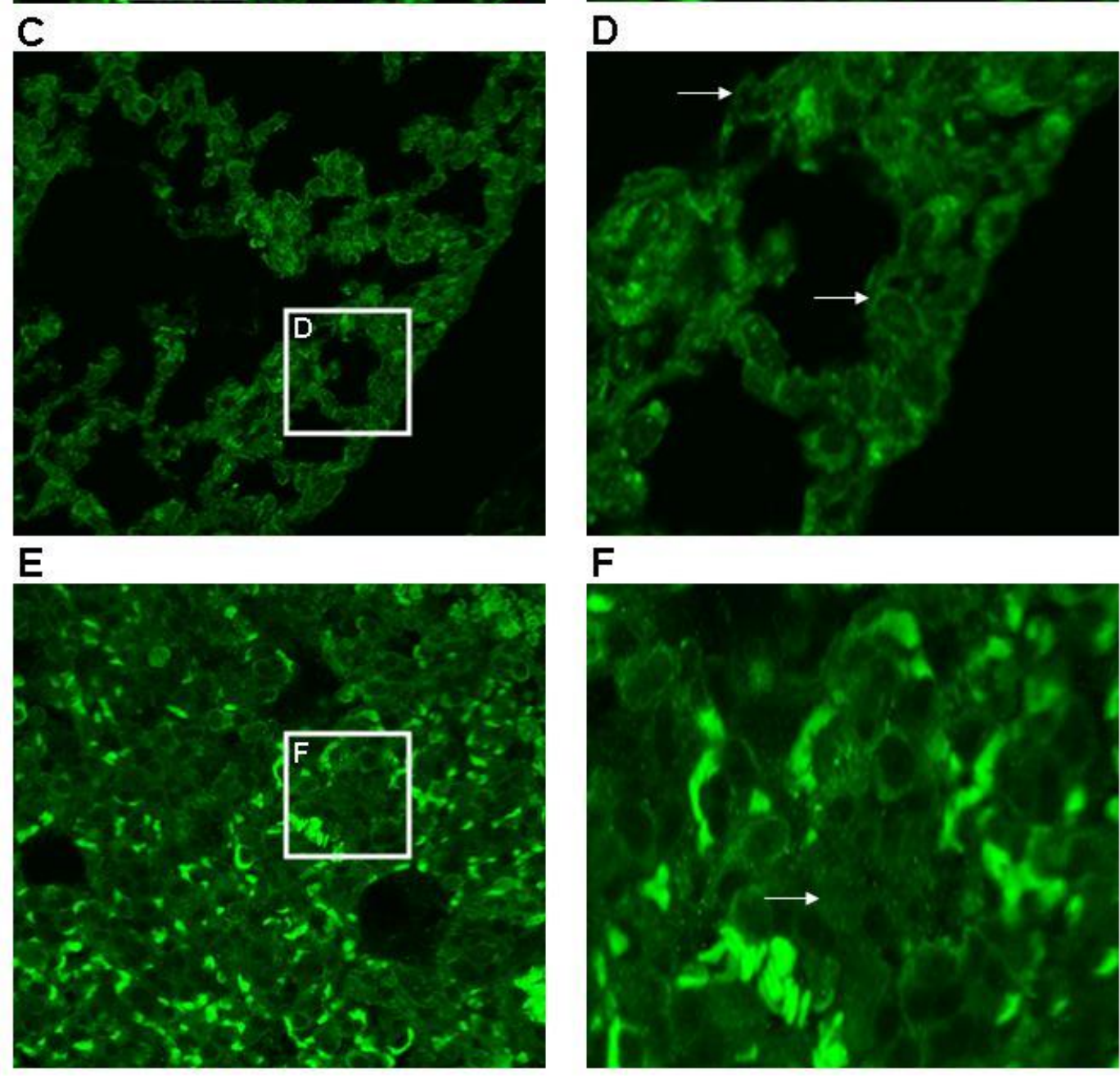
The intestinal epithelia of H5N1-NS1-WT-infected mice show SAP-97 distribution is altered in the tips of the villi compared to uninfected controls (Figure 3.3). The altered SAP-97 distribution can also be seen in the intestines of mice infected with H5N1-NS1$\triangle \mathrm{PDZ}$ but appears rarely when compared to the intestines of mice infected with H5N1NS1-WT (Figure 3.3).

In Caco-2 cells, SAP-97 distribution is largely at the lateral membranes at sites of cell-cell contact, but when Caco-2 cells are transfected with NS1-WT, SAP-97 staining is observed intracellularly and is absent at sites of cell-cell contact (Figure 3.4).

These findings are of significance as they indicate that in H5N1 infected tissues and cells expressing NS1-WT the interaction between NS1 and SAP-97 redistributes SAP-97. This perturbs the junctional integrity of the epithelia and thus causes pulmonary edema in the lung tissue and diarrhea in the intestines. 
Figure 3.3. SAP-97 staining in proximal small intestine of normal and H5N1 infected mice.

(A) SAP-97 staining in normal mouse intestine. (B) SAP-97 staining in intestine of mouse infected with H5N1-NS1- $\triangle$ PDZ, showing a re-localization of SAP-97 in a small area of epithelial disruption. (C) SAP-97 staining in the intestine of H5N1-NS1-WTinfected mouse, showing extensive re-localization of SAP-97 and. widespread disruption of the epithelial barrier. 
A

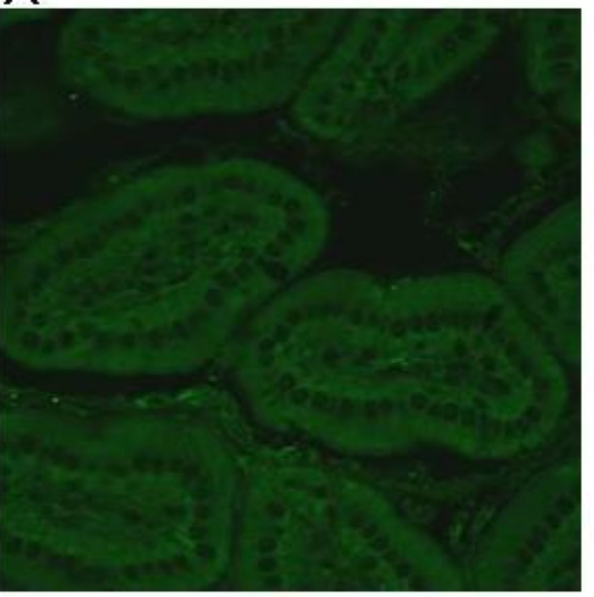

B

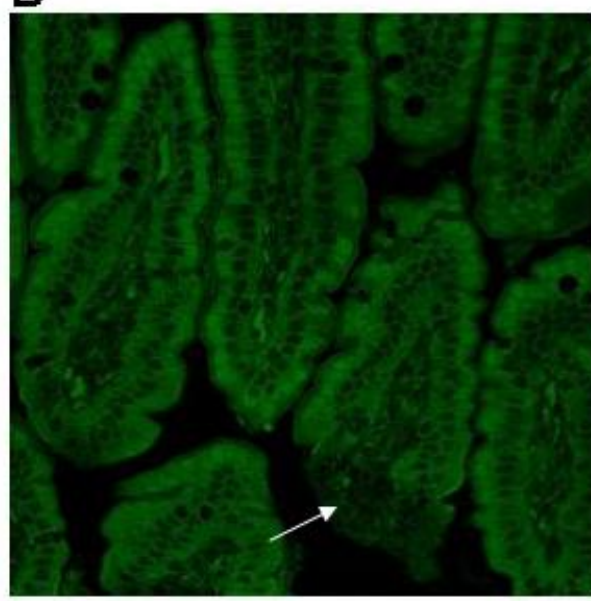

C

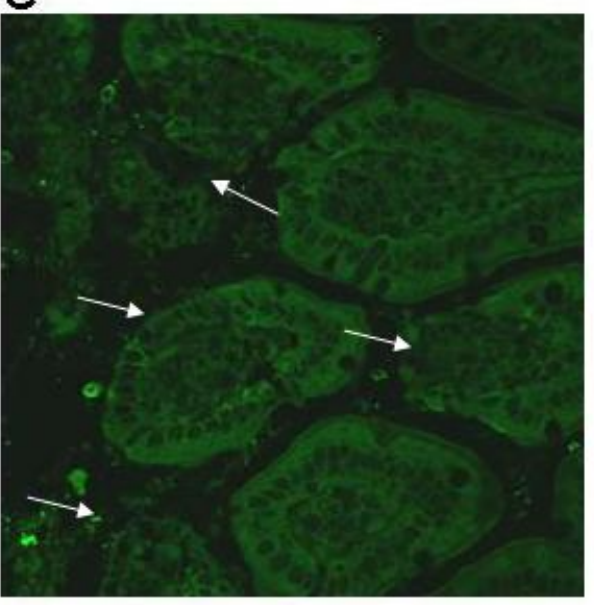


Figure 3.4. SAP-97 staining in NS1 transfected Caco-2 cells.

(A) Caco-2 cells transfected with cyan fluorescent protein (CFP) tagged NS1- $\triangle \mathrm{PDZ}$ and immunofluorescently stained with anti-SAP-97 antibody (red). SAP-97 staining is seen at cell-cell junctions. (B) Caco-2 cells transfected with CFP-NS1-WT and

immunofluorescently stained with anti-SAP-97 antibody (red). SAP-97 staining is not visible at cell-cell junctions in the presence of NS1-WT. All images were collected by fluorescent microscopy at $60 \mathrm{X}$ magnification. 


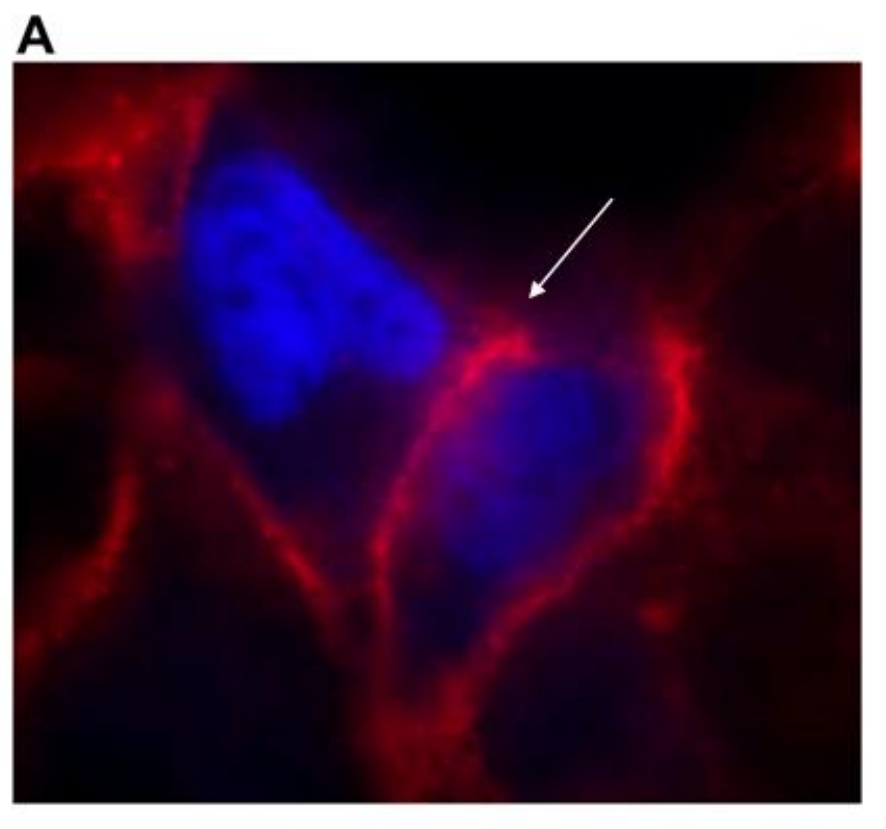

B 


\section{CHAPTER 4. NS1 INTERACTION WITH SAP-97 DISRUPTS EPITHELIAL BARRIER FUNCTION}

\subsection{Introduction}

Given that NS1-WT and SAP-97 are interacting physically, we continued to investigate whether the interaction plays a functional role in the assembly of epithelial junctions. To that end, we utilized assays that are commonly used to assess the assembly and integrity of epithelial junctions. These assays are the calcium switch assay and the inulin flux assay. Caco-2 cells were chosen for these studies because they are a well characterized human colonic epithelial cell line that has a similar morphology to the columnar epithelium of the small intestine [104]. Calu-3 cells were also used in calcium switch experiments. Calu-3 cells are a serosal lung epithelial cell line that form resistant monolayers, and it was of interest to see if NS1-WT would act similarly on this cell type. Thus, we strived to utilize cell lines that would give us relevant information for the two pathological symptoms of $\mathrm{H} 5 \mathrm{~N} 1$ that we were most interested in, diarrhea and pulmonary edema.

\subsection{Materials and Methods}

\subsubsection{Plasmid Construction}

The SAP-97 siRNA (5'-GATATCCAGGAACA-3') and its control scrambled siRNA (5'-CCATAATACCAGGTATAA-3') were cloned into the pSuper plasmid (OligoEngline Corp.) as described previously [105]. These plasmids were a kind gift from the lab of Dr. Suleiman Bahouth. The pTriEX-NS1 constructs were generated, as described in Chapter 2.

We obtained, from the lab of Dr. Richard Webby, the pSH1203-NS construct, which encodes NS1 of influenza A/Vietnam/1203/04. This plasmid was used as a template to create the pTriEx-4-NS1-VTN and pTriEX-4-NS1-VTN-ESEV constructs by ligationindependent cloning (LIC). The 5' primer used is the same as the one used for pTriEXNS1-WT cloning since these two genes are identical at the 5' end. The reverse primer used to create NS1-VTN was 5' GAG GAG AAG CCC GGT TCA CCG TTT CTG ATT TGG AGG G 3'. The reverse primer used to create NS1-VTN-ESEV was 5' GAG GAG AAG CCC GGT TCA CAC CTC TCA TTC CCG TTT CTG ATT TGG AGG 3'. NS1-VTN and NS1-VTN-ESEV were amplified using the polymerase chain reaction (PCR). The PCR conditions used were as follows: 2 minute denaturation at $95^{\circ} \mathrm{C}, 30$ amplification cycles with an annealing temperature of $62^{\circ} \mathrm{C}$, and final extension of $72^{\circ} \mathrm{C}$ for 7 minutes. PCR products were run on a $1 \%$ agarose gel (Figure 4.1). PCR products of the correct size were excised from the gel and extracted using QIAquick Gel Extraction Kit (Qiagen) 


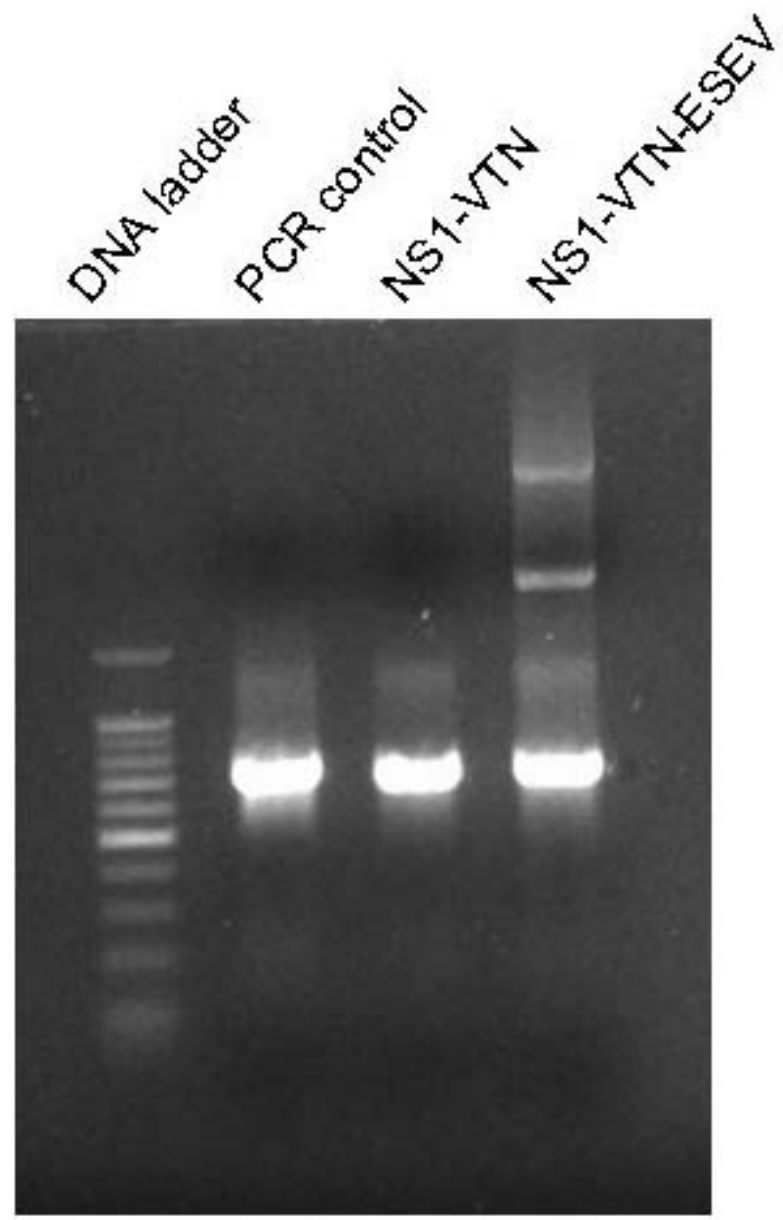

Figure 4.1 PCR products for cloning pTriEX-NS1-VTN constructs. Agarose gel to confirm proper size of PCR products for the cloning of pTriEX-NS1-VTN and pTriEX-NS1-VTN-ESEV. 
gel extraction kit. Purified PCR products were treated with T4 DNA polymerase at room temperature for 30 minutes to create overhangs that are compatible with the vector. T4 DNA polymerase was then heat inactivated by incubation for 20 minutes at $75^{\circ} \mathrm{C}$. Each insert was then incubated with pTriEX-4 Ek/LIC vector for annealing. Resulting plasmids were transformed using NovaBlue competent E.coli. for DNA expression. DNA was extracted from select colonies using a Qiagen miniprep kit. Clones were screened for proper sequence at The University of Tennessee Health Science Center's Molecular Resource Center using the T7 promoter primer and the TriEx-DOWN primer. The pTriEx vector has N-terminal his6 and S tags.

\subsubsection{Cell Culture and Transfection}

Caco-2 cells were grown in DMEM (Gibco) supplemented with 10\% FBS. Cells were cultured in a $5 \% \mathrm{CO}_{2}$ incubator at $37^{\circ} \mathrm{C}$. Calu-3 cells were grown in MEM (Gibco) supplemented with $10 \% \mathrm{FBS}$ and $1 \%$ each of sodium pyruvate and non-essential amino acids.

Caco-2 cells were transfected using the following protocol: Cells were seeded in 60 $\mathrm{mm}$ tissue culture dishes at $70-80 \%$ confluency. The next day the cells were washed with culture media containing no antibiotics, then incubated with $1.5 \mathrm{~mL}$ of the antibiotic free media. The transfection mix was set up in two tubes. The first tube contained $200 \mu \mathrm{L}$ of OptiMEM media and $1 \mu \mathrm{g}$ DNA. The second tube contained $200 \mu \mathrm{L}$ of OptiMEM media and $2.5 \mu \mathrm{L}$ of Lipofectamine ${ }^{\mathrm{TM}} 2000$ transfection reagent (Invitrogen). These tubes were mixed gently then allowed to incubate at room temperature for 20 minutes. Following incubation the contents of the tube containing the transfection reagent is added to the tube containing the DNA mixture. The tube was mixed gently and allowed to incubate at room temperature for 30 minutes. The transfection mixture was then added to the cell culture dishes in a drop wise fashion and incubated at $37^{\circ} \mathrm{C}$ for 24 hours.

Calu-3 cells were transfected using FuGENE® 6 transfection reagent (Roche). Cells were seeded on $60 \mathrm{~mm}$ tissue culture dishes at $50-60 \%$ confluence. The next day, cells were rinsed two times with serum free media, then incubated with serum free media with no antibiotics for 30 minutes. To set up transfection, $6 \mu \mathrm{L}$ of FuGENE 6 was added to 94 $\mu \mathrm{L}$ of serum free media, mixed and allowed to incubate for five minutes. After the five minute incubation, $1 \mu \mathrm{g}$ of DNA was added to the transfection mix and incubated for 20 minutes. The transfection mix was then added to the cells in a drop wise fashion and allowed to incubate at $37^{\circ} \mathrm{C}$ for 24 hours.

\subsubsection{Measurements of TER, Calcium Switch Assays and Inulin Flux Assay}

Caco-2 cells were transiently transfected with NS1 constructs, SAP-97 siRNA, or scrambled siRNA using Lipofectamine 2000 (Invitrogen). Twenty-four hours post transfection, Caco-2 cells were trypsinized, counted and seeded on $12 \mathrm{~mm}$ polycarbonate

membranes in transwells (Costar) at $2 \times 10^{5}$ cells/membrane. Calcium switch assays 
performed on Caco-2 cells were done as described previously on the fourth or fifth day post transfection[106]. On the day of the calcium switch, cells were serum starved for one hour using glutamine free DMEM. After serum starvation, baseline transepithelial electrical resistance (TER) measurements were recorded. Caco-2 cells were treated with $4 \mathrm{mM}$ ethyleneglyol-bis(2-aminoethylether) $\mathrm{N}, \mathrm{N}, \mathrm{N}^{\prime}, \mathrm{N}^{\prime}$, tetraactetic acid (EGTA) in DMEM ( $\mathrm{pH} 7.35)$ in both the apical and basolateral wells to reduce the transepithelial electrical resistance. Cells were then washed 3 times with DMEM to remove EGTA. TER was measured at regular intervals after EGTA was removed to monitor reestablishment of cell junctions. TER was measured using a electric voltometer purchased from World Precision Instruments.

Calcium switch assays performed in Calu-3 cells were performed using a different strategy than was used with Caco-2 cells. Calu-3 cells were transfected with NS1 constructs using FuGENE 6 (Roche). Twenty-four hours post transfection, cells were seeded on $6.5 \mathrm{~mm}$ transwells (Costar) at $7.2 \times 10^{4}$ cells $/$ membrane in low calcium media $\left(0.5 \mathrm{mM} \mathrm{CaCl}_{2}, 5 \%\right.$ dialyzed $\mathrm{FBS}, 200 \mathrm{mM} \mathrm{L}$-glutamine, $1 \%$ sodium pyruvate, and $1 \%$ penicillin in calcium free DMEM). Twenty-four hours post seed the cells were washed four times with glutamine free MEM and baseline TER was recorded. After cells were switched to normal growth media, TER was recorded at 30 min intervals.

Inulin flux assays in Caco-2 cells were performed as described previously on the fourth or fifth day post transfection [106]. After the calcium switch, cells were incubated with $0.5 \mathrm{mg} / \mathrm{mL}$ fluorescein isothiocyanate-inulin (FITC-inulin) in the basal well. At various time points $100 \mathrm{ul}$ of media was withdrawn from both the basal and apical wells and fluorescence was measured using a fluorescence plate reader (BioTEK Instruments). The excitation of FITC inulin is $488 \mathrm{~nm}$ and emission was read at $505 \mathrm{~nm}$. Flux into the apical well was calculated as percentage of the total fluorescence of the basal well $/ \mathrm{hr} / \mathrm{cm}^{2}$ of the surface area.

Statistical analyses were done using Student's t-test (homoscedastic, 2-tailed). A $p$ value of $<0.05$ was considered significant. All the results are represented as mean \pm standard error mean.

\subsection{Results and Discussion}

First, we transfected Caco-2 cells with SAP-97 siRNA or scrambled siRNA to validate the role of SAP-97 in maintaining adherens junction integrity. Briefly, transfected cells were plated on transwell inserts, and after they had formed resistant monolayers, they were treated with EGTA to disrupt cell-cell contacts and monitored for reestablishment of cell junctions using trans-epithelial resistance (TER) measurements. As shown in Figure 4.2, in cells transfected with SAP-97 siRNA, junctional formation was impaired compared to scrambled siRNA transfected cells, as indicated by low TER values for SAP-97 siRNA transfected cells. This result is consistent with a previous report that SAP-97 plays a critical role in cell junction formation as measured by TER [107]. Next, we transfected Caco-2 cells with NS1-WT and monitored reestablishment of 


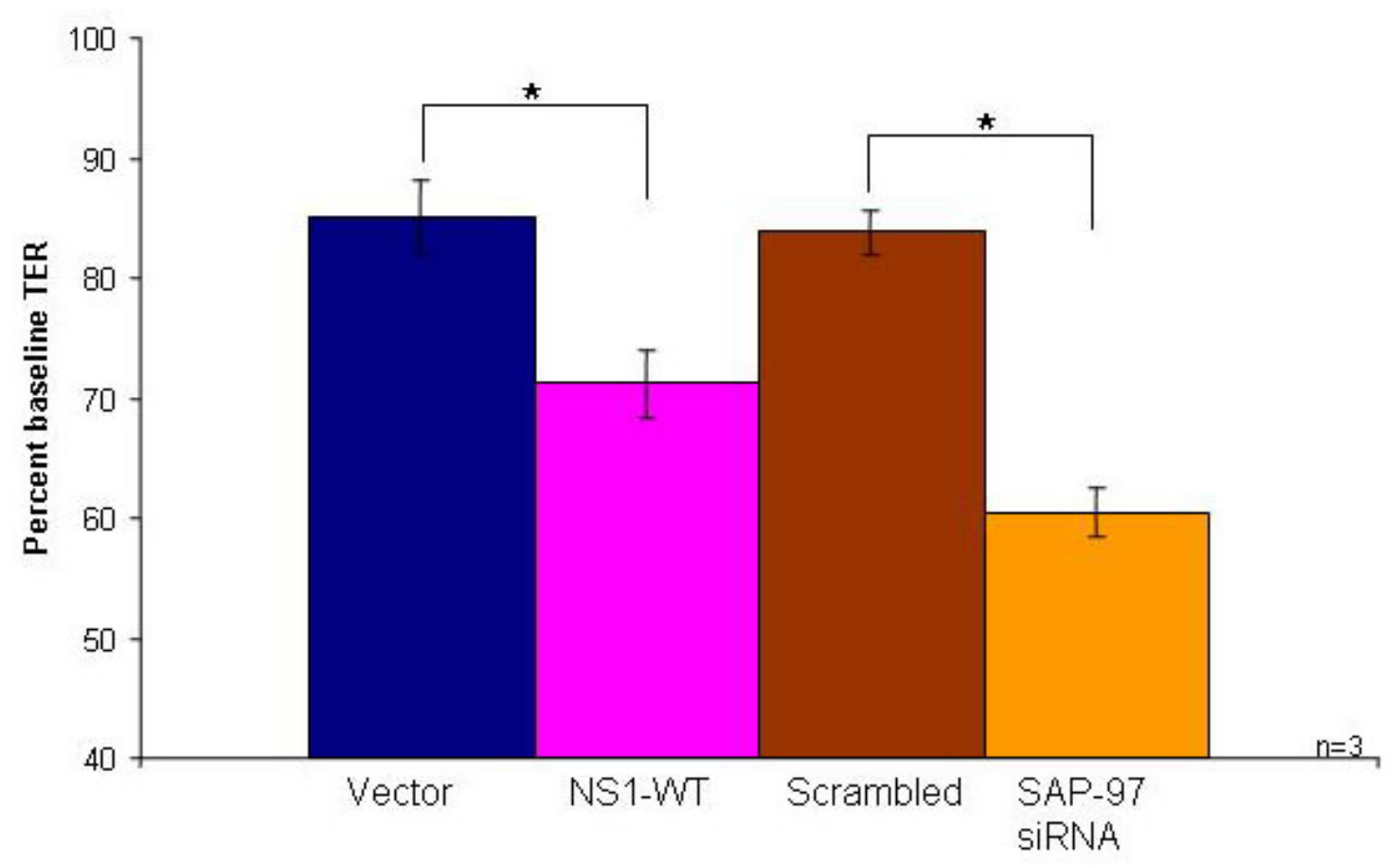

Figure 4.2 NS1 and SAP-97 siRNA disrupt junctional integrity in transfected Caco-2 cells.

Transepithelial electrical resistance (TER) measurements in transfected Caco-2 cells at 90 minutes post calcium switch. Cells were transfected with empty vector (Vector), pTriEX-NS1-WT (NS1-WT), pSuper-scrambled siRNA (Scrambled) or pSuper-SAP-97 siRNA (SAP-97 siRNA). Figure is representative of three separate experiments. $\mathrm{n}=3$ for each experiment. ${ }^{*} p<0.05$ 
TER after calcium switch. The result clearly shows that junctional assembly of NS1-WT transfected cells are impaired compared to vector transfected cells; however, cells transfected with NS1-HuPDZ or NS1- $\triangle \mathrm{PDZ}$ are not impaired in reestablishing cell-celljunctions (Figure 4.2 and Figure 4.3).

A similar trend was observed in polarized Calu-3 cells transfected with NS1-WT (Figure 4.4). Notably, the TER of Calu-3 cells transfected with NS1- $\triangle \mathrm{PDZ}$ is similar to vector transfected cells (Figure 4.4). This result indicates that the PDZ motif-dependent interaction between NS1-WT and SAP-97 disrupts the assembly of epithelial junctions.

This hypothesis was further supported by results of inulin flux assays in which Caco2 cells were transfected with NS1-WT. The inulin flux assay measures the ability of a large molecule (inulin $M_{\mathrm{r}} \approx 5000$ ) to move from the basolateral to apical side of the cell monolayer. Due to its large size, inulin will only be able to move across the epithelial cell monolayer if the barrier is compromised. As can be seen in Figure 4.5, NS1-WT transfected cells demonstrate higher rates of inulin flux compared to cells transfected with vector, indicating that juctional integrity is impaired in these cells (Figure 4.5). However, Caco-2 cells transfected with NS1- $\triangle$ PDZ showed similar inulin flux rates to cells transfected with vector. Taken together, the data indicate that the PDZ motifdependent interaction of NS1-WT and SAP-97 disrupts the functional assembly of epithelial junctions, a process integral to the integrity of epithelial barriers.

To further examine the importance of the PDZ motif in the disruption of functional cell-cell junctions, other NS1 constructs were created from the NS1 gene of the virus A/Vietnam/1203/04. This construct was named NS1-VTN. The NS1 protein of the Vietnam virus has a truncation of the last 10 amino acids and therefore does not contain a PDZ motif. In addition to this early stop codon, the NS1 of the Vietnam virus has 5 additional amino acid changes when compared to the NS1 protein of A/Chicken/Vietnam/C58/04 (NS1-WT). An additional construct was created in which the PDZ motif ESEV was added to the end of the VTN protein. This construct was named NS1-VTN-ESEV. Both of these constructs were tested in calcium switch assays in Caco-2 cells and compared to NS1-WT and NS1- $\triangle$ PDZ. As can be seen in Figure 4.6, NS1-VTN, which has no PDZ motif, behaves similarly to NS1- $\triangle$ PDZ. Reestablishment of cell junctions is not impaired in the presence of these two proteins (NS1- $\triangle \mathrm{PDZ}$ and NS1-VTN). However, when the PDZ motif is introduced to the NS1-VTN protein, epithelial junction formation is impaired similarly to NS1-WT (Figure 4.6). This result is evidence that the PDZ motif of NS1 plays a critical role in the disruption of the epithelial barrier. Taken together, the data indicate that the PDZ motif-dependent interaction of NS1-WT and SAP-97 disrupts the functional assembly of epithelial junctions, a process integral to the integrity of epithelial barriers. 


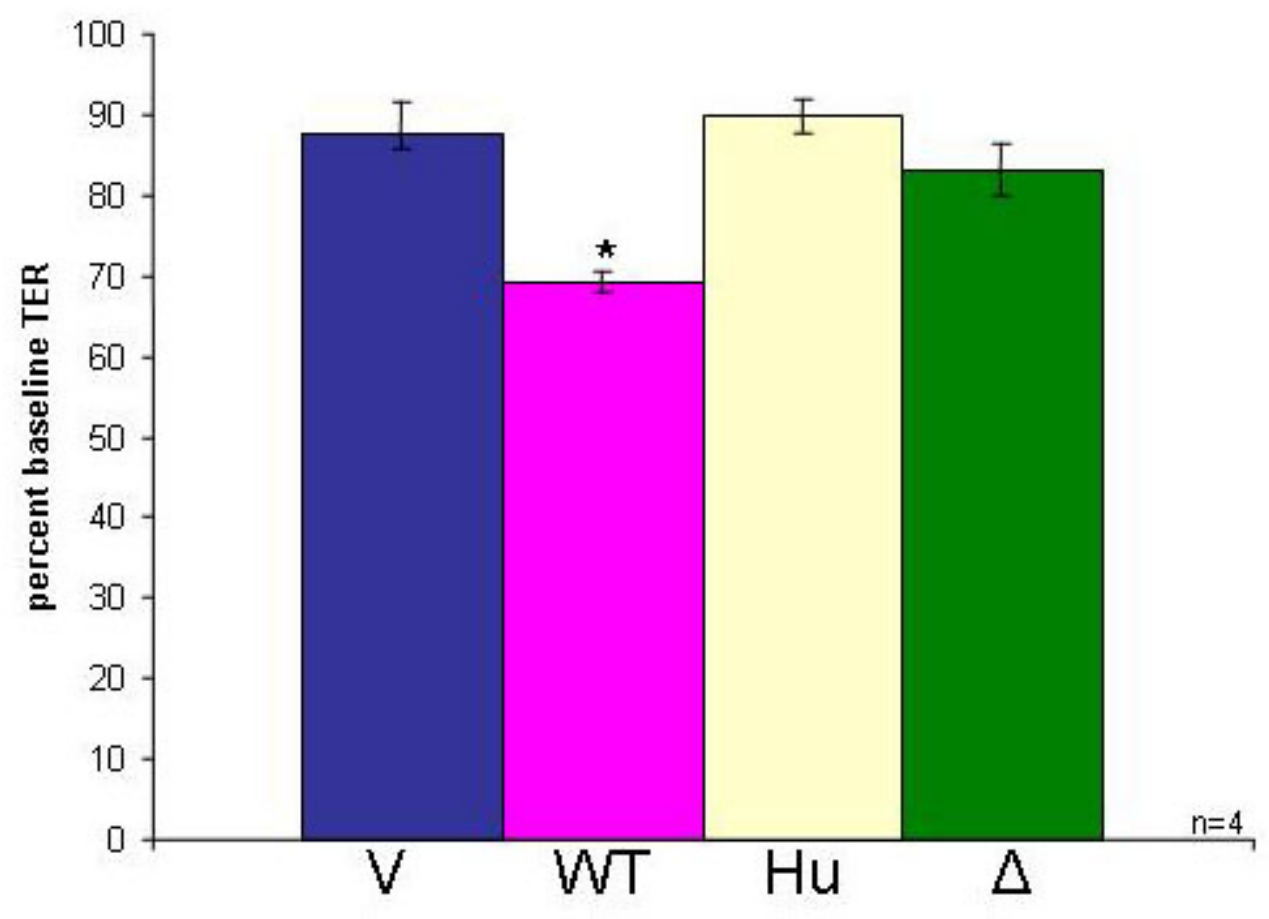

Figure 4.3 NS1 disrupts junctional integrity in transfected Caco-2 cells.

Transepithelial electrical resistance (TER) measurements in transfected Caco-2 cells after 90 minutes after EGTA disruption of the cell junctions. NS1-WT (WT) transfected cells display much lower TER values than vector transfected controls $(\mathrm{V})$. NS1-HuPDZ $(\mathrm{Hu})$ and NS1- $\triangle \mathrm{PDZ}(\Delta)$ transfected cells are not statistically different from vector controls $(\mathrm{V})$. Figure is representative of two separate experiments. $\mathrm{n}=4$ for each experiment. ${ }^{*} p<0.05$ 


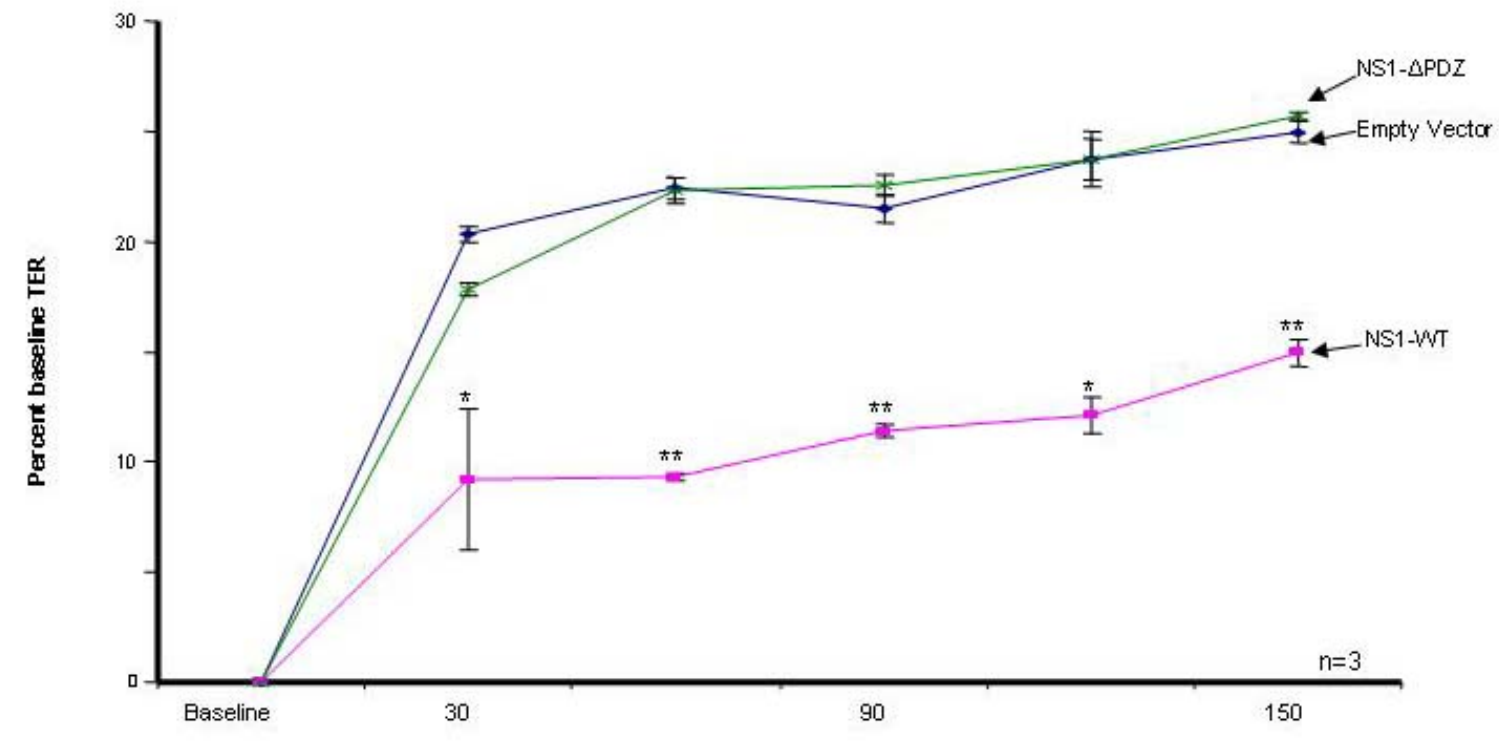

Figure 4.4 NS1 disrupts junctional integrity in transfected Calu-3 cells. TER in transfected Calu-3 cells after switch from low calcium media to normal growth media. Figure is representative of three separate experiments. $n=3$ for each experiment. ${ }^{*} p<0.05 * * p<0.005$ 


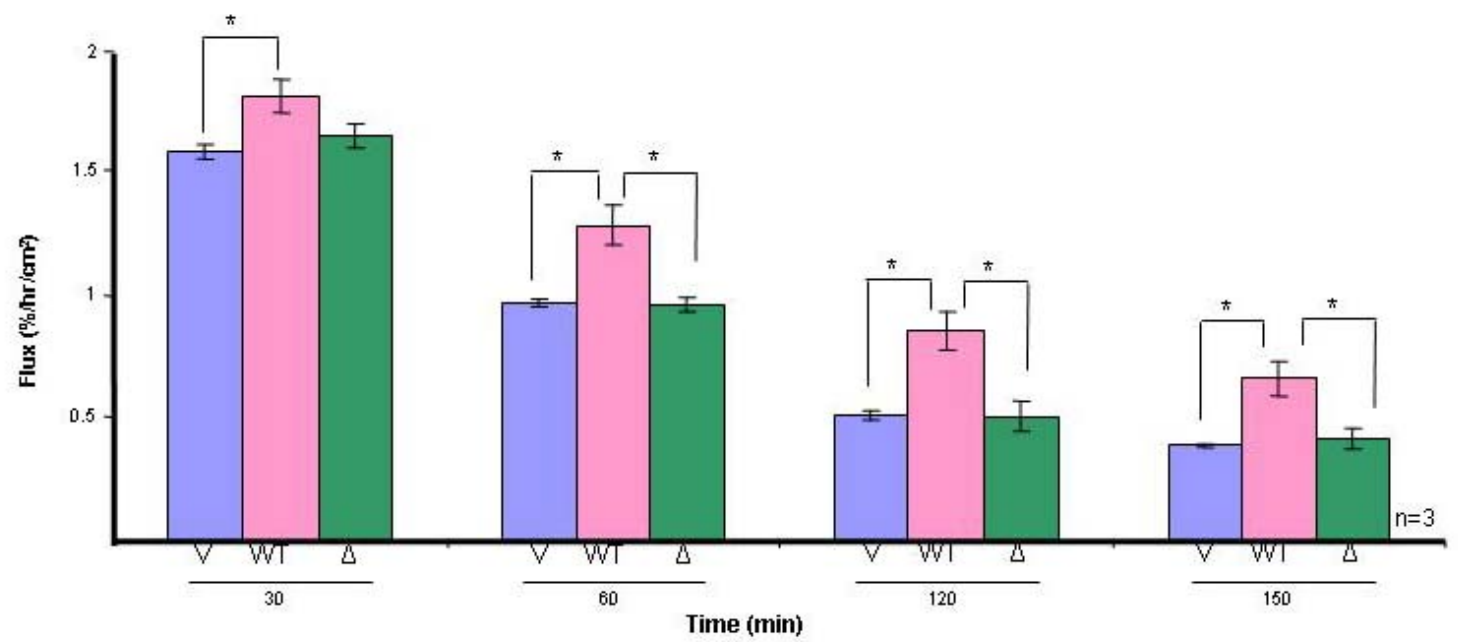

Figure 4.5 Inulin Flux in NS1 transfected Caco-2 cells.

Inulin flux measurements in Caco-2 cells transfected with vector (V), NS1-WT (WT), or NS1- $\Delta \mathrm{PDZ}(\Delta)$ post calcium switch. Flux values between vector and NS1- $\Delta \mathrm{PDZ}$ transfected cells are not significant. ${ }^{*} p<0.05$ 


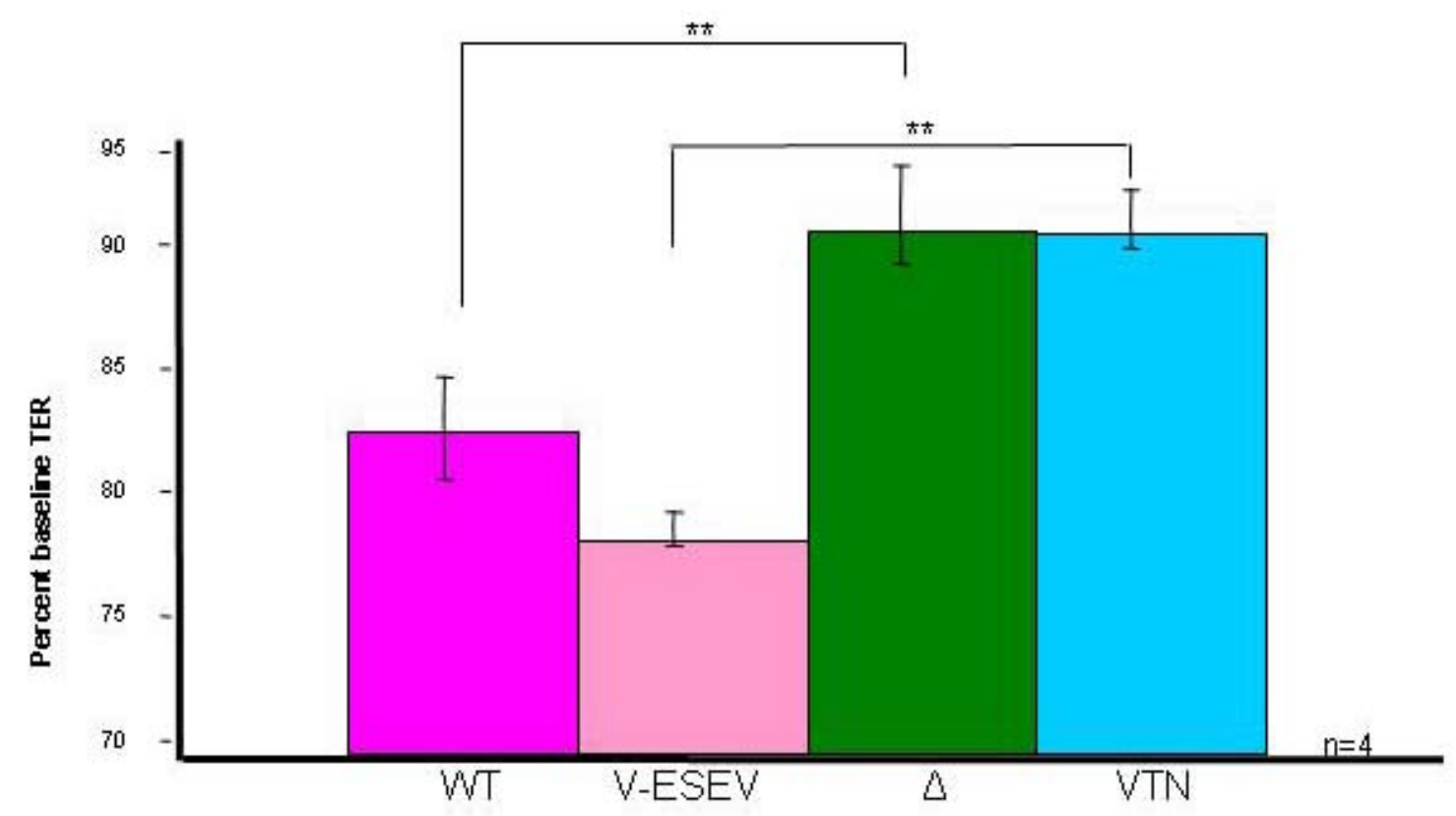

Figure 4.6 Calcium switch assay in NS1-VTN and NS1-VTN-ESEV transfected Caco- 2 cells.

TER measurements in transfected Caco-2 cells after 90 minutes after recovery from EGTA disruption of the cell junctions. NS1- $\triangle$ PDZ $(\Delta)$ and NS1-VTN (VTN) transfected cells show little inhibition of recovering cell-cell junctions after treatment, while NS1WT (WT) and NS1-VTN-ESEV (V-ESEV) transfected cells are markedly inhibited in their ability to establish cell-cell junctions. Figure is representative of two separate experiments. $\mathrm{n}=4$ for each experiment. ${ }^{*} p<0.005$ 


\section{CHAPTER 5. THE PDZ MOTIF OF NS1 ACTS AS A VIRULENCE FACTOR IN H5N1 INFECTED TISSUES}

\subsection{Introduction}

The PDZ motif of NS1 has previously been postulated to modulate virulence in influenza viruses of avian origin $[69,71]$. To characterize the pathogenicity of H5N1 virus containing the PDZ motif in the NS1 protein, the virus A/Vietnam/1203/04 was utilized. This virus has a truncated NS1 protein and thus has no PDZ motif and will be referred to as H5N1-NS1- $\triangle \mathrm{PDZ}$ in this study. Using the same background (A/Vietnam/1203/04), a recombinant virus containing the NS gene of A/Chicken/Vietnam/C58/04 was engineered. The NS1 protein of this recombinant virus contains the PDZ motif ESEV commonly found in highly pathogenic avian influenza viruses. The recombinant virus was referred to as H5N1-NS1-WT in these studies.

\subsection{Materials and Methods}

\subsubsection{Animal Studies}

Six week old Balb/c mice were infected with $10^{3}$ units of influenza virus A/Vietnam/1203/04 (H5N1-NS1- PDZ) or with A/Vietnam/1203/04 containing the NS1 gene of A/Chicken/Vietnam/C58/04 (H5N1-NS1-WT) intranasally. Day 6 post infection, the mice were sedated using avertin and sacrificed. The lungs and intestines were harvested and fixed using 10\% neutral buffered formalin then embedded in paraffin. Paraffin sections were stained with hematoxylin and eosin (H\&E) for evaluation.

\subsubsection{Tissue Processing}

After two weeks fixation in 10\% neutral buffered formalin, tissues were dehydrated through passage of graded alcohol. During the dehydration process, the tissue was treated with each of the flowing agents for 1 hour: $70 \%$ ethanol, $80 \%$ ethanol, two changes of $95 \%$ ethanol, and four changes of $100 \%$ ethanol. After dehydration, the tissue was cleared in xylene, and then infiltrated with paraffin. Four micron sections of the paraffin embedded tissue were mounted on glass laboratory slides for further evaluation.

A routine hematoxylin and eosin staining procedure was used to stain paraffin embedded tissue sections. First the sections were deparaffinized using three changes of xylene at 5 minutes each. Sections were then rehydrated by passage through graded alcohols for 2 minutes each. These included two changes of $100 \%$ ethanol, $95 \%$ ethanol, and $80 \%$ ethanol. The slides were then rinsed in water. To stain cell nuclei, slides were incubated for 2 minutes in Harris's hematoxylin solution. Excess hematoxylin was removed by rinsing slides in tap water and decolorized by incubating slides in $0.5 \%$ acid 
alcohol for a few seconds. Color of hematoxylin was adjusted by incubating slides for 1 minute in Scott's Bluing Reagent. The cytoplasm of cells was counterstained by incubating slides with $0.5 \%$ alcoholic eosin for 1 minute. Tissue sections were then dehydrated by passage through graded ethanol for 1 minute each (two changes of $95 \%$ ethanol, and three changes of $100 \%$ ethanol). Tissue sections were then cleared by passage through three changes of xylene before being mounted with permanent mounting media.

\subsubsection{Pathology Scoring}

Paraffin sections were stained with hematoxylin and eosin for evaluation. For lung pathology scores, each lobe of infected lungs was examined and given severity scores for interstitial infiltrate and alveolar infiltrate. A score of 0 was given to normal tissues. Tissues that were mildly affected, moderately affected, or severely affected were given scores of 1,2 , and 3 , respectively.

Each affected area of intestinal villi in infected mice was viewed at high power magnification (40X). Only affected areas of villi were examined. The percentages of affected villi were counted for each field. Areas that had $30-45 \%$ edematous tissue were given a score of 1 , while areas with $46-60 \%$ edematous tissue, areas with $61-75 \%$ edematous tissue, and areas with 76-100\% edematous tissue were given scores of 2, 3, and 4, respectively. The number of fields counted for mice infected with H5N1-NS1$\triangle \mathrm{PDZ}(\mathrm{n}=6)$ was less than those for H5N1-NS1-WT $(\mathrm{n}=17)$ due to less of the tissue displaying pathology. Each tissue section was counted only once.

Pathology scores were assigned by a medical pathologist who had no previous knowledge of the aims of our study.

\subsubsection{Immunohistochemical Staining of H5N1 Antigen}

Staining for influenza A virus was performed in the same tissues that were stained with hematoxylin and eosin for pathologic evaluation. Paraffin embedded tissue sections of normal Balb/c mice, H5N1-NS1-WT, and H5N1-NS1- $\Delta$ PDZ infected Balb/c mice (six days post infection) were deparaffinized, using three changes of xylene, and rehydrated through graded ethanol (two changes of 100\% ethanol, 95\% ethanol, $70 \%$ ethanol, then water). Sections were treated with peroxidized I (Biocare Medical) for 5 minutes to reduce background staining by endogenous peroxidases in the tissue. Heat induced epitope retrieval was performed by pressure cooking slides in Borg Decloaker (Biocare Medical). Rodent block M (Biocare Medical) was utilized for the blocking buffer and was carried out at room temperature in a dark humidifying chamber. Sections were incubated with antibody against influenza A (US Biological) diluted 1:1000 in DaVinci green antibody diluent (Biocare Medical) for 2 hours at room temperature in a dark humidifying chamber. Primary antibody was washed from the slides in 2 changes of TBS (tris buffered saline). The secondary antibody incubation utilized biotin conjugated 
donkey anti-goat secondary antibody (Santa Cruz) diluted 1:200 in DaVinci green antibody diluent. Vectastain Elite ABC kit (Vector Laboratories) and DAB Chromagen Kit (Biocare Medical) were used to visualize the protein. Slides were counterstained with Gill's Hematoxylin. Color of hematoxylin was adjusted by incubating slides for 1 minute in Scott's Bluing reagent. Tissue sections were then dehydrated by passage through graded ethanol for 1 minute each (two changes of 95\% ethanol, and three changes of $100 \%$ ethanol). Tissue sections were then cleared by passage through three changes of xylene before being mounted with permanent mounting media.

\subsection{Results and Discussion}

To characterize the pathogenicity of $\mathrm{H} 5 \mathrm{~N} 1$ virus containing the PDZ motif in the NS1 protein, the virus A/Vietnam/1203/04 was utilized. This virus, referred to as H5N1NS1- $\triangle \mathrm{PDZ}$, has a truncated NS1 protein and thus has no PDZ motif. Using the same background (A/Vietnam/1203/04), a recombinant virus containing the NS gene of $\mathrm{A} /$ Chicken/Vietnam/C58/04 was engineered. The NS1 protein of this recombinant virus contains the PDZ motif ESEV, a PDZ motif commonly found in highly pathogenic avian influenza viruses. The recombinant virus is referred to as H5N1-NS1-WT in these studies. Balb/c mice were infected intranasally. At 6 days post infection, the mice were sacrificed and the lung and intestines were harvested for histological analysis.

Hematoxylin and eosin staining of the tissues revealed multi-focal lesions and pulmonary edema in H5N1-NS1-WT-infected lungs (Figure 5.1). Severe alveolitis, primary viral pneumonia, and dilated airspaces were observed in the H5N1-NS1- nfected lung tissues (Figure 5.1). Cellular infiltrate of lung tissues and hemorrhage into airspaces were also commonly observed (Figure 5.1). These disease states are evidence that the epithelial barrier function in the lung has been compromised. To evaluate disease pathology, each lobe of the infected lungs was examined and given a score to reflect the severity of the interstitial and alveolar infiltrate. Lungs of mice infected with H5N1NS1-WT tended to have higher scores in both the severity of interstitial and alveolar infiltrates than lungs of mice infected with H5N1-NS1- $\mathrm{PDZ}$ (Figure 5.2). Immunohistological staining for the influenza A revealed that virus was present in both H5N1-NS1-WT and H5N1-NS1- $\triangle$ PDZ lungs (Figure 5.3); therefore, the difference in pathology is not due to differences in infectivity of the two viruses.

Pathology in the small intestines of H5N1-NS1-WT-infected mice included edema in the tips of the lamina propia. Both intercellular and intracellular edema could be seen at the tips of the villi (Figure 5.4). The small intestines of mice infected with H5N1-NS1$\triangle \mathrm{PDZ}$ were only mildly focally affected (Figure 5.4). An evaluation of the percentage of affected villi in each high powered field revealed that H5N1-NS1-WT-infected intestines tended to have greater percentages of affected villi per field (Figure 5.5).

The differences seen in the pathology of tissues of mice infected with the virus H5N1-NS1-WT versus tissues of mice infected with H5N1-NS1- $\Delta$ PDZ gives clear 
A

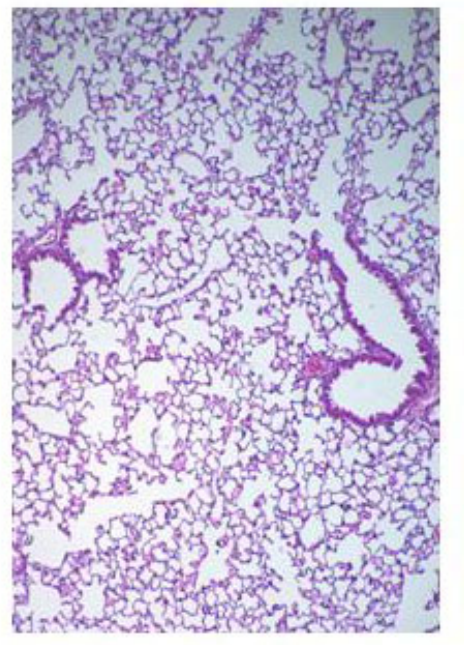

B

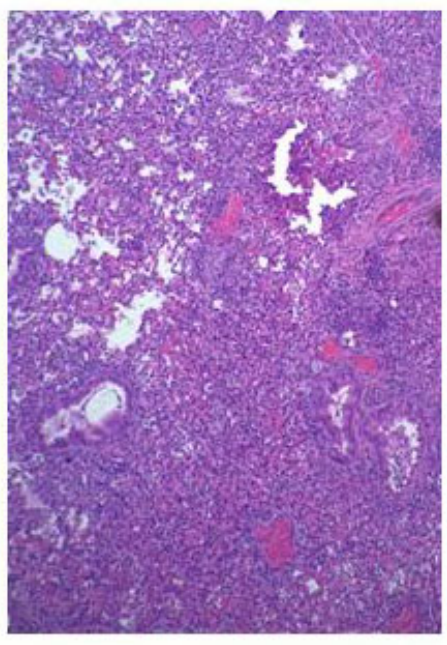

C

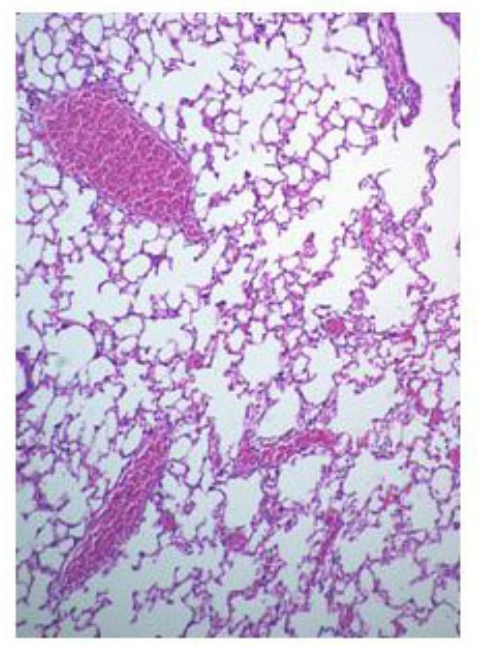

Figure 5.1 Pathology of H5N1 infection in mouse lungs.

(A) Uninfected mouse lung. (B) Lung of H5N1-NS1-WT-infected mouse at 6 days post infection showing viral pneumonia and pulmonary edema. (C) Lung of H5N1NS1- $\triangle$ PDZ-infected mouse at 6 days post infection displaying little inflammation. 
A

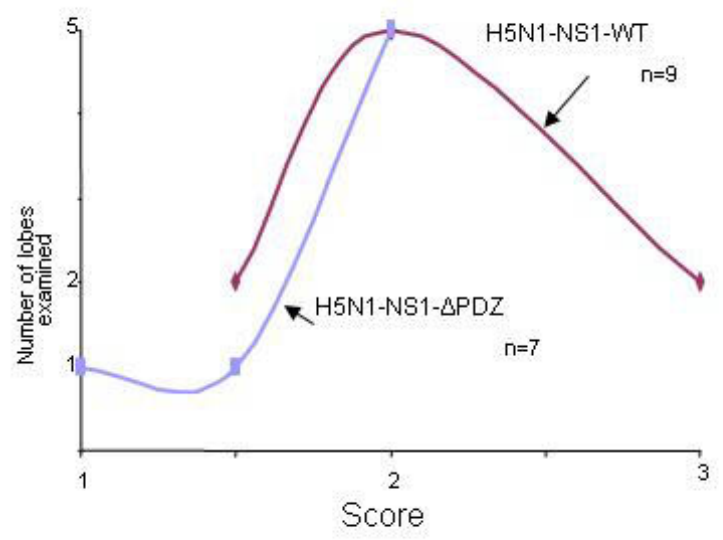

B

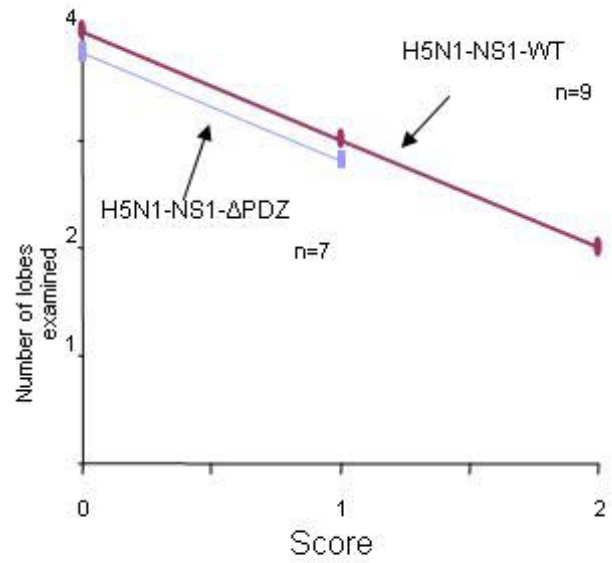

Figure 5.2 Lung pathology scoring of H5N1 infection in mouse lungs.

(A) Interstitial infiltrate severity scores of H5N1-NS1-WT ( $\mathrm{n}=9)$ and H5N1-NS1$\triangle$ PDZ-infected lung lobes $(\mathrm{n}=7)$ examined. (B) Alveolar infiltrate severity scores of H5N1-NS1-WT ( $\mathrm{n}=9)$ and H5N1- NS1- $\triangle$ PDZ $(\mathrm{n}=7)$ lung lobes examined. The first two points overlap but have been adjusted in order for both groups to be seen. 

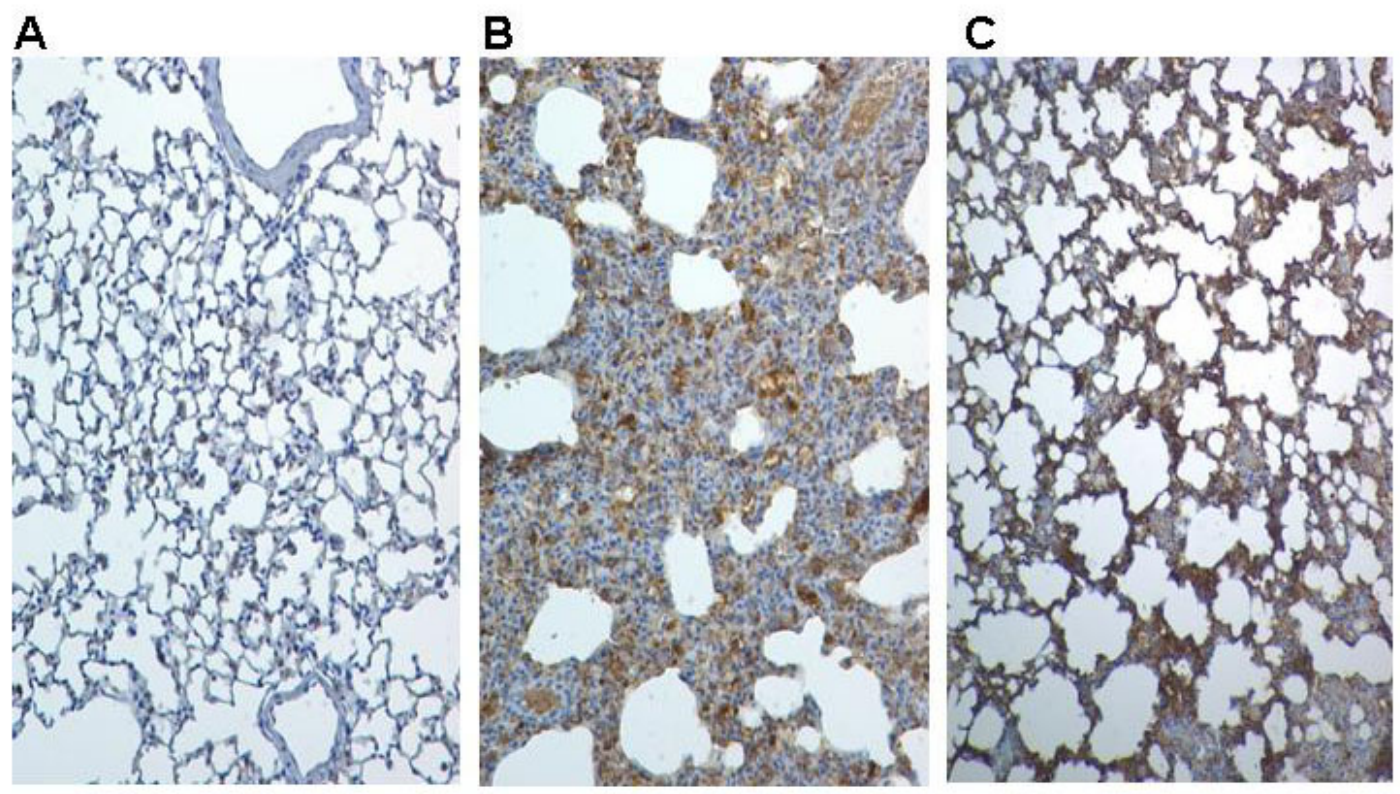

Figure 5.3 Influenza A antigen staining in H5N1 infected mouse lungs.

(A) Influenza A antigen (DAB chromagen, brown color) staining in uninfected mouse lung. (B) Influenza A antigen staining in H5N1-NS1-WT and (C) H5N1-NS1$\triangle \mathrm{PDZ}$ infected mouse lungs. Sections were counterstained with hematoxylin. 

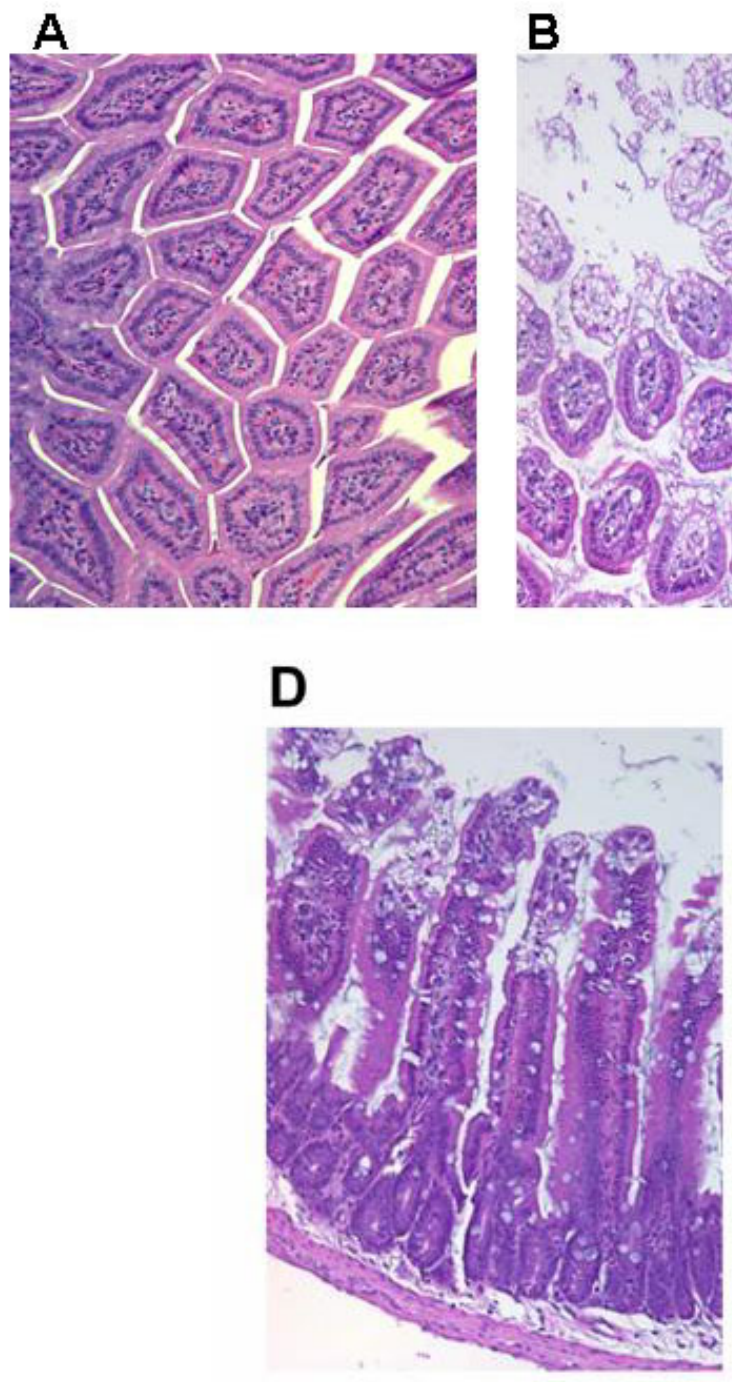

B

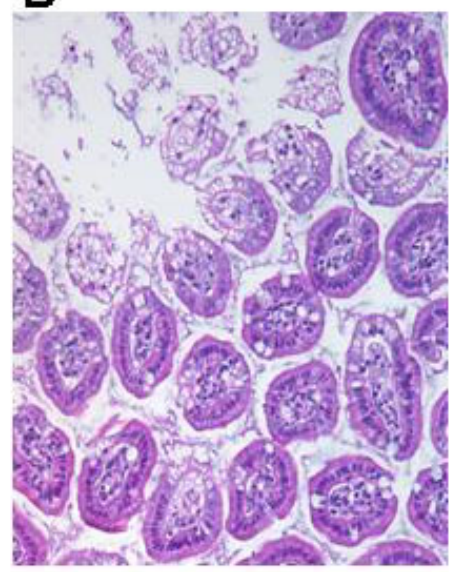

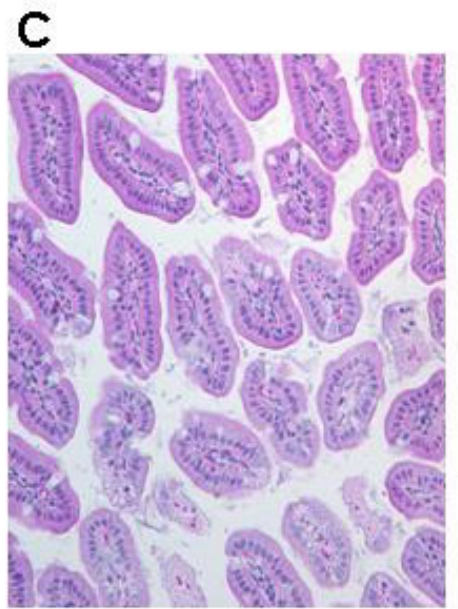

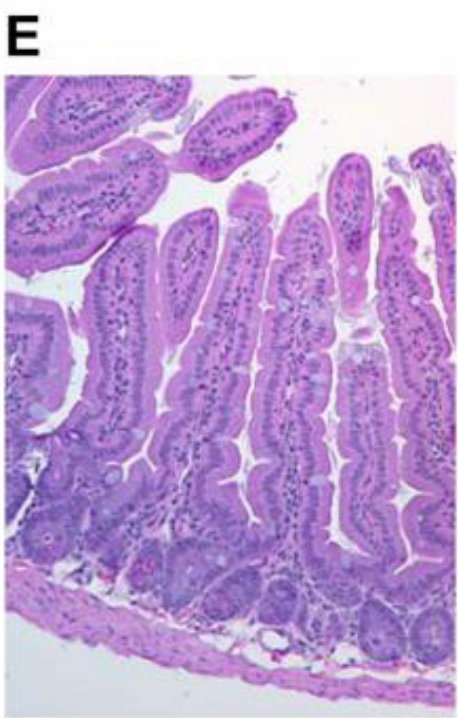

Figure 5.4 Pathology of H5N1 infection in mouse intestines.

(A) Normal mouse small intestine. (B) Small intestine of H5N1-NS1-WT-infected mouse showing intracellular and intercellular edema in the epithelial layer and the lamina propia. (C) Small intestine of mouse infected with H5N1-NS1- $\triangle$ PDZ showing only mild focal edema. (D) Proximal small intestine of H5N1-NS1-WTinfected mouse in which both crypts and villi can be seen. (E) Proximal small intestine of H5N1-NS1- $\triangle$ PDZ-infected mouse in which both crypts and villi can be seen. 


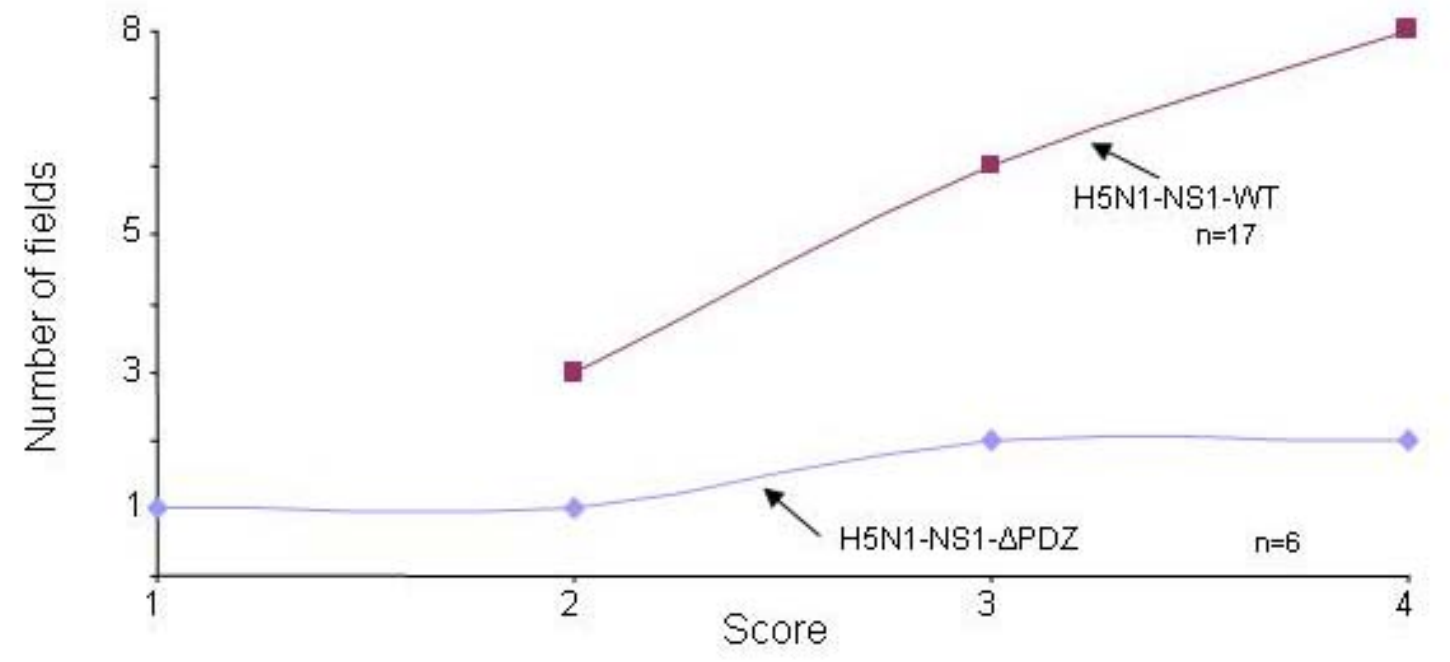

Figure 5.5 Pathology scoring of edematous tissue in intestines of mice infected with H5N1.

Edematous intestinal tissue scores of mice infected with H5N1-NS1-WT or H5N1NS1- $\triangle$ PDZ. 
evidence that the PDZ motif of NS1 acts as a virulence factor in avian H5N1 influenza viruses. 


\section{CHAPTER 6. DISCUSSION}

Clinical features of the H5N1 virus in human infection include respiratory symptoms and diarrhea, two disease states in which epithelial barrier function is disrupted [21]. Autopsies of H5N1 victims have revealed diffuse alveolar damage, edema, fibrous exudates, hyaline membranes, and hyperplasia of type II pneumocytes in the lungs $[22,24,25]$. Pathology has also been noted in other organs such as the spleen, bone marrow, and lymph nodes $[22,24]$. Our study focuses on the clinical features of pulmonary edema and diarrhea and therefore the lung and intestines.

The aim of this study was to define how PDZ motif-mediated interactions of NS1 contribute to the pathogenicity of the virus, particularly in the lung and intestine. We sought to examine whether the disease phenotype was altered in the presence or absence of the PDZ motif of NS1. Balb/c mice infected with H5N1 showed more severe disease pathology when infected with H5N1-NS1-WT, a virus that contains the PDZ motif ESEV in NS1, as compared to mice infected with H5N1-NS1- $\mathrm{PDZ}$ (a virus that has no PDZ motif in the NS1 protein). Pathology findings include primary viral pneumonia, pulmonary edema, and alveolitis. The difference in disease phenotype between H5N1NS1-WT- and H5N1-NS1- $\triangle$ PDZ-infected mice is best reflected by the disease severity scores assigned by a pathologist. H5N1-NS1-WT-infected lungs tended to receive higher scores for interstitial and alveolar infiltrate than did the lungs of mice infected with H5N1-NS1- $\triangle \mathrm{PDZ}$. The difference in disease phenotype is not due to a difference in infectivity of the two viruses, as evidenced by our observation that antigen staining for influenza A virus was robust in both the H5N1-NS1-WT and H5N1- NS1- $\triangle \mathrm{PDZ}$ mouse lungs. The intestines of H5N1-infected mice also showed differential disease pathology. The intestines of mice infected with H5N1-NS1-WT tended to have more edematous villi than intestines of mice infected with H5N1-NS1- $\triangle$ PDZ. It is of importance to note that the pathologist who analyzed the mouse tissue and assigned pathology scores did so without previous knowledge of the aim of our study.

There are five amino acid differences in the NS1 proteins of these two viruses (H5N1-NS1-WT and H5N1-NS1- $\triangle$ PDZ), in addition to the truncation mutation found in NS1 of H5N1-NS1- $\triangle$ PDZ. Further, mutations at the C-terminus of NS1 cause mutations in the NS2/NEP protein due to an overlapping reading frame. The contributions of these individual mutations to the overall phenotype seen in the pathology studies cannot be ruled out. However, the differences seen in pathology, taken together with the functional studies (Figure 4.6), lead us to conclude that the PDZ-binding ligand of NS1 plays the major role in disrupting the epithelial barrier, thus leading to the differences in pathology of the two different viruses in the mouse lung and intestine.

Viral antigens and viral RNA have been detected in patient lung, brain, spleen, and intestine $[24,25,27]$. A large number of $\mathrm{H} 5 \mathrm{~N} 1$ patients present with diarrhea; therefore, it was of interest to further investigate mechanisms behind this disease symptom. One retrospective report documenting the clinical features of $\mathrm{H} 5 \mathrm{~N} 1$ in Vietnam found that diarrhea was more common in fatal than nonfatal $\mathrm{H} 5 \mathrm{~N} 1$ cases [23]. Viral RNA has also 
been detected in rectal swabs of patients [28,29]. Our efforts to stain for viral antigen in mouse intestines were only successful when harsh antigen retrieval methods were used. This left the tissue damaged, and therefore images are not included here. We are confident that these results are not false-positive staining artifacts, because negative controls did not stain for the viral antigen. Instead, we think these results represent a technical limitation in the sensitivity of the immunohistochemistry procedure. The technical difficulty in IHC staining in intestinal tissue is consistent with reports of human $\mathrm{H} 5 \mathrm{~N} 1$ infection in which IHC staining was negative, yet viral RNA was detected in the same tissues $[24,25]$.

Since the onset of the H5N1 outbreak, global efforts have been aimed at understanding this highly pathogenic virus. Attempts to elucidate the molecular mechanisms for viral pathogenesis have been pursued. Among the findings are the single amino acid change in the RNA polymerase PB2 at position 627 and an amino acid change at position 66 of the PB1-F2 protein - both of which modulate virulence [30-32]. The hemagglutinin protein also has been shown to be an important mediator of virulence in $\mathrm{H} 5 \mathrm{~N} 1$ viruses. Increased cleavability of the receptor by ubiquitous proteases has been shown to correlate with increased virulence [30,32]. In addition, NS1 has been reported to play a role in the virulence of H5N1. Single amino acid changes in NS1 at residues 42, 92, and 149 have been found to increase the virulence of H5N1 [33,34,108].

The PDZ motif of NS1 was previously found to modulate virulence of H5N1 in mice, yet the cellular pathway responsible for this affect was undetermined [71]. Our work helps bridge this understanding by defining one of the mechanisms by which the PDZ motif of NS1 is contributing to the pathogenicity of the virus. We are the first to show that NS1 can interact with SAP-97 and that this interaction has functional consequence in disrupting epithelial barrier integrity.

In this study, our aim was to understand how the host and viral protein-protein interactions of NS1, through its PDZ-binding motif, may contribute to the disease phenotype of pulmonary edema and diarrhea. Here, we characterize the interaction between NS1 and the adherens junction protein SAP-97. SAP-97 function is crucial for adherens junction integrity, and therefore inhibiting this pathway can lead to loss of epithelial barrier function $[85,88,89,92-95]$.

Based on our data, we conclude that NS1 of H5N1 binds PDZ 2 of SAP-97. The interaction between NS1 and SAP-97 is PDZ motif-dependent; NS1 with an altered PDZ motif (NS1-HuPDZ) and NS1 lacking the PDZ binding motif (NS1- $\triangle \mathrm{PDZ}$ ) are not able to bind SAP-97. In virus-infected tissues, where there is evidence of disruption in the epithelial barriers, the normal distribution of SAP-97 is altered. In NS1-WT-transfected cells, we demonstrated that the epithelia are delayed in forming cell-cell junctions, as evidenced by their inability to form resistant monolayers and high rates of paracellular flux. SAP-97-depleted cells also display delays in junctional formation and have high paracellular flux rates. This functional data clearly suggests that NS1 is able to inhibit the establishment of cell junctions through interacting with SAP-97. Therefore, the interaction between NS1 and SAP-97 has a functional consequence in disrupting the 
adherens junction, thus contributing to the disease severity of the virus. The physical and functional interaction between NS1 and SAP-97 may help us understand one of mechanisms by which H5N1-infected tissues accumulate edema that leads to pulmonary edema in the lung and diarrhea in the intestines.

I propose the following model to explain the mechanism by which NS1 acts on SAP97 to disrupt epithelial barrier integrity. At the epithelial cell membrane, NS1 interacts with SAP-97 in a PDZ-dependent manner. The binding of NS1 to PDZ 2 of SAP-97 sequesters SAP-97, thus preventing it from participating in the maintenance of the adherens junction. A loss of SAP-97 at the adherens junction soon leads to disruption in the integrity of the junctional complex and consequently a loss in the integrity of the epithelial barrier. The subsequent compromise in the epithelial barrier function contributes to disease phenotypes seen in H5N1 infection: pulmonary edema in the lung and diarrhea in the intestines.

The interaction of NS1 of H5N1 and SAP-97 is the only interaction of NS1 with a host protein that has been investigated. The individual interactions of NS1 with other host proteins have not been fully defined and the functionally of these interations merits future investigation. These studies do not rule out the possibility that PDZ motifdependent interactions of NS1 with other proteins of the junctional complex or polarity proteins may contribute to the disease phenotype observed in these studies. As these protein-protein interactions are studied the pathogenic mechanisms of the highly virulent $\mathrm{H} 5 \mathrm{~N} 1$ virus will be better understood. 


\section{LIST OF REFERENCES}

1. (2007) Fields Virology; Knipe DM, Howley PM, editors. Philadelphia: Lippincott Williams \& Wilkins.

2. Webster RG, Bean WJ, Gorman OT, Chambers TM, Kawaoka Y (1992)

Evolution and ecology of influenza A viruses. Microbiol Rev 56: 152-179.

3. McAuley JL, Zhang K, McCullers JA (2010) The effects of influenza A virus PB1-F2 protein on polymerase activity are strain specific and do not impact pathogenesis. J Virol 84: 558-564.

4. Conenello GM, Palese P (2007) Influenza A virus PB1-F2: a small protein with a big punch. Cell Host Microbe 2: 207-209.

5. Brown EG (2000) Influenza virus genetics. Biomed Pharmacother 54: 196-209.

6. O'Neill RE, Talon J, Palese P (1998) The influenza virus NEP (NS2 protein) mediates the nuclear export of viral ribonucleoproteins. Embo J 17: 288-296.

7. Fouchier RA, Munster V, Wallensten A, Bestebroer TM, Herfst S, et al. (2005) Characterization of a novel influenza A virus hemagglutinin subtype (H16) obtained from black-headed gulls. J Virol 79: 2814-2822.

8. Taubenberger JK, Morens DM (2008) The pathology of influenza virus infections. Annu Rev Pathol 3: 499-522.

9. Hay AJ, Gregory V, Douglas AR, Lin YP (2001) The evolution of human influenza viruses. Philos Trans R Soc Lond B Biol Sci 356: 1861-1870.

10. Zambon MC (1999) Epidemiology and pathogenesis of influenza. J Antimicrob Chemother 44 Suppl B: 3-9.

11. Osterhaus AD, Rimmelzwaan GF, Martina BE, Bestebroer TM, Fouchier RA (2000) Influenza B virus in seals. Science 288: 1051-1053.

12. Guo YJ, Jin FG, Wang P, Wang M, Zhu JM (1983) Isolation of influenza C virus from pigs and experimental infection of pigs with influenza $\mathrm{C}$ virus. J Gen Virol 64 (Pt 1): 177-182.

13. Chen R, Holmes EC (2006) Avian influenza virus exhibits rapid evolutionary dynamics. Mol Biol Evol 23: 2336-2341.

14. Carrat F, Flahault A (2007) Influenza vaccine: the challenge of antigenic drift. Vaccine 25: 6852-6862. 
15. Nelson MI, Holmes EC (2007) The evolution of epidemic influenza. Nat Rev Genet 8: 196-205.

16. Tam JS (2002) Influenza A (H5N1) in Hong Kong: an overview. Vaccine 20 Suppl 2: S77-81.

17. Webby RJ, Webster RG (2001) Emergence of influenza A viruses. Philos Trans R Soc Lond B Biol Sci 356: 1817-1828.

18. Osterhaus AD, de Jong JC, Rimmelzwaan GF, Claas EC (2002) H5N1 influenza in Hong Kong: virus characterizations. Vaccine 20 Suppl 2: S82-83.

19. Hui DS (2008) Review of clinical symptoms and spectrum in humans with influenza A/H5N1 infection. Respirology 13 Suppl 1: S10-13.

20. WHO (2009) Confirmed Human Cases of Avian Influenza A (H5N1) reported to WHO. Available: http://www.who.int/csr/disease/avian influenza/en/ February $12,2010$.

21. Tran TH, Nguyen TL, Nguyen TD, Luong TS, Pham PM, et al. (2004) Avian influenza A (H5N1) in 10 patients in Vietnam. N Engl J Med 350: 1179-1188.

22. Peiris JS, Yu WC, Leung CW, Cheung CY, Ng WF, et al. (2004) Re-emergence of fatal human influenza A subtype H5N1 disease. Lancet 363: 617-619.

23. Liem NT, Tung CV, Hien ND, Hien TT, Chau NQ, et al. (2009) Clinical features of human influenza A (H5N1) infection in Vietnam: 2004-2006. Clin Infect Dis 48: 1639-1646.

24. Gu J, Xie Z, Gao Z, Liu J, Korteweg C, et al. (2007) H5N1 infection of the respiratory tract and beyond: a molecular pathology study. Lancet 370: 11371145.

25. Uiprasertkul M, Puthavathana P, Sangsiriwut K, Pooruk P, Srisook K, et al. (2005) Influenza A H5N1 replication sites in humans. Emerg Infect Dis 11: 10361041.

26. Korteweg C, Gu J (2008) Pathology, molecular biology, and pathogenesis of avian influenza A (H5N1) infection in humans. Am J Pathol 172: 1155-1170.

27. Zhang Z, Zhang J, Huang K, Li KS, Yuen KY, et al. (2009) Systemic infection of avian influenza A virus H5N1 subtype in humans. Hum Pathol 40: 735-739.

28. de Jong MD, Bach VC, Phan TQ, Vo MH, Tran TT, et al. (2005) Fatal avian influenza A (H5N1) in a child presenting with diarrhea followed by coma. N Engl J Med 352: 686-691. 
29. de Jong MD, Simmons CP, Thanh TT, Hien VM, Smith GJ, et al. (2006) Fatal outcome of human influenza A (H5N1) is associated with high viral load and hypercytokinemia. Nat Med 12: 1203-1207.

30. Chen H, Bright RA, Subbarao K, Smith C, Cox NJ, et al. (2007) Polygenic virulence factors involved in pathogenesis of 1997 Hong Kong H5N1 influenza viruses in mice. Virus Res 128: 159-163.

31. Conenello GM, Zamarin D, Perrone LA, Tumpey T, Palese P (2007) A single mutation in the PB1-F2 of H5N1 (HK/97) and 1918 influenza A viruses contributes to increased virulence. PLoS Pathog 3: 1414-1421.

32. Hatta M, Gao P, Halfmann P, Kawaoka Y (2001) Molecular basis for high virulence of Hong Kong H5N1 influenza A viruses. Science 293: 1840-1842.

33. Li Z, Jiang Y, Jiao P, Wang A, Zhao F, et al. (2006) The NS1 gene contributes to the virulence of H5N1 avian influenza viruses. J Virol 80: 11115-11123.

34. Jiao P, Tian G, Li Y, Deng G, Jiang Y, et al. (2008) A single-amino-acid substitution in the NS1 protein changes the pathogenicity of $\mathrm{H} 5 \mathrm{~N} 1$ avian influenza viruses in mice. J Virol 82: 1146-1154.

35. Seo SH, Hoffmann E, Webster RG (2004) The NS1 gene of H5N1 influenza viruses circumvents the host anti-viral cytokine responses. Virus Res 103: 107113.

36. Shapiro GI, Gurney T, Jr., Krug RM (1987) Influenza virus gene expression: control mechanisms at early and late times of infection and nuclear-cytoplasmic transport of virus-specific RNAs. J Virol 61: 764-773.

37. Krug RM, Yuan W, Noah DL, Latham AG (2003) Intracellular warfare between human influenza viruses and human cells: the roles of the viral NS1 protein. Virology 309: 181-189.

38. Wang W, Riedel K, Lynch P, Chien CY, Montelione GT, et al. (1999) RNA binding by the novel helical domain of the influenza virus NS1 protein requires its dimer structure and a small number of specific basic amino acids. Rna 5: 195-205.

39. Lin D, Lan J, Zhang Z (2007) Structure and function of the NS1 protein of influenza A virus. Acta Biochim Biophys Sin (Shanghai) 39: 155-162.

40. Chien CY, Xu Y, Xiao R, Aramini JM, Sahasrabudhe PV, et al. (2004) Biophysical characterization of the complex between double-stranded RNA and the N-terminal domain of the NS1 protein from influenza A virus: evidence for a novel RNA-binding mode. Biochemistry 43: 1950-1962.

41. Bornholdt ZA, Prasad BV (2006) X-ray structure of influenza virus NS1 effector domain. Nat Struct Mol Biol 13: 559-560. 
42. Hale BG, Barclay WS, Randall RE, Russell RJ (2008) Structure of an avian influenza A virus NS1 protein effector domain. Virology 378: 1-5.

43. Hale BG, Randall RE, Ortin J, Jackson D (2008) The multifunctional NS1 protein of influenza A viruses. J Gen Virol 89: 2359-2376.

44. Chen Z, Krug RM (2000) Selective nuclear export of viral mRNAs in influenzavirus-infected cells. Trends Microbiol 8: 376-383.

45. Fortes P, Beloso A, Ortin J (1994) Influenza virus NS1 protein inhibits premRNA splicing and blocks mRNA nucleocytoplasmic transport. Embo J 13: 704712.

46. Garaigorta U, Ortin J (2007) Mutation analysis of a recombinant NS replicon shows that influenza virus NS1 protein blocks the splicing and nucleocytoplasmic transport of its own viral mRNA. Nucleic Acids Res 35: 4573-4582.

47. Qian XY, Alonso-Caplen F, Krug RM (1994) Two functional domains of the influenza virus NS1 protein are required for regulation of nuclear export of mRNA. J Virol 68: 2433-2441.

48. Nemeroff ME, Barabino SM, Li Y, Keller W, Krug RM (1998) Influenza virus NS1 protein interacts with the cellular $30 \mathrm{kDa}$ subunit of CPSF and inhibits 3 'end formation of cellular pre-mRNAs. Mol Cell 1: 991-1000.

49. Chen Z, Li Y, Krug RM (1999) Influenza A virus NS1 protein targets poly(A)binding protein II of the cellular 3'-end processing machinery. Embo J 18: 22732283.

50. Li Y, Chen ZY, Wang W, Baker CC, Krug RM (2001) The 3'-end-processing factor CPSF is required for the splicing of single-intron pre-mRNAs in vivo. Rna 7: 920-931.

51. Satterly N, Tsai PL, van Deursen J, Nussenzveig DR, Wang Y, et al. (2007) Influenza virus targets the mRNA export machinery and the nuclear pore complex. Proc Natl Acad Sci U S A 104: 1853-1858.

52. de la Luna S, Fortes P, Beloso A, Ortin J (1995) Influenza virus NS1 protein enhances the rate of translation initiation of viral mRNAs. J Virol 69: 2427-2433.

53. Salvatore M, Basler CF, Parisien JP, Horvath CM, Bourmakina S, et al. (2002) Effects of influenza A virus NS1 protein on protein expression: the NS1 protein enhances translation and is not required for shutoff of host protein synthesis. $\mathrm{J}$ Virol 76: 1206-1212.

54. Malmgaard L (2004) Induction and regulation of IFNs during viral infections. J Interferon Cytokine Res 24: 439-454. 
55. Kim MJ, Latham AG, Krug RM (2002) Human influenza viruses activate an interferon-independent transcription of cellular antiviral genes: outcome with influenza A virus is unique. Proc Natl Acad Sci U S A 99: 10096-10101.

56. Mibayashi M, Martinez-Sobrido L, Loo YM, Cardenas WB, Gale M, Jr., et al. (2007) Inhibition of retinoic acid-inducible gene I-mediated induction of beta interferon by the NS1 protein of influenza A virus. J Virol 81: 514-524.

57. Silverman RH (2007) Viral encounters with 2',5'-oligoadenylate synthetase and RNase L during the interferon antiviral response. J Virol 81: 12720-12729.

58. Min JY, Krug RM (2006) The primary function of RNA binding by the influenza A virus NS1 protein in infected cells: Inhibiting the 2'-5' oligo (A) synthetase/RNase L pathway. Proc Natl Acad Sci U S A 103: 7100-7105.

59. Schultz-Cherry S, Dybdahl-Sissoko N, Neumann G, Kawaoka Y, Hinshaw VS (2001) Influenza virus ns1 protein induces apoptosis in cultured cells. J Virol 75: 7875-7881.

60. Lam WY, Tang JW, Yeung AC, Chiu LC, Sung JJ, et al. (2008) Avian influenza virus $\mathrm{A} / \mathrm{HK} / 483 / 97(\mathrm{H} 5 \mathrm{~N} 1) \mathrm{NS} 1$ protein induces apoptosis in human airway epithelial cells. J Virol 82: 2741-2751.

61. Zhirnov OP, Konakova TE, Wolff T, Klenk HD (2002) NS1 protein of influenza A virus down-regulates apoptosis. J Virol 76: 1617-1625.

62. Stasakova J, Ferko B, Kittel C, Sereinig S, Romanova J, et al. (2005) Influenza A mutant viruses with altered NS1 protein function provoke caspase-1 activation in primary human macrophages, resulting in fast apoptosis and release of high levels of interleukins 1beta and 18. J Gen Virol 86: 185-195.

63. Shin YK, Li Y, Liu Q, Anderson DH, Babiuk LA, et al. (2007) SH3 binding motif 1 in influenza A virus NS1 protein is essential for PI3K/Akt signaling pathway activation. J Virol 81: 12730-12739.

64. Ehrhardt C, Wolff T, Pleschka S, Planz O, Beermann W, et al. (2007) Influenza A virus NS1 protein activates the PI3K/Akt pathway to mediate antiapoptotic signaling responses. J Virol 81: 3058-3067.

65. Hale BG, Jackson D, Chen YH, Lamb RA, Randall RE (2006) Influenza A virus NS1 protein binds p85beta and activates phosphatidylinositol-3-kinase signaling. Proc Natl Acad Sci U S A 103: 14194-14199.

66. Hale BG, Batty IH, Downes CP, Randall RE (2008) Binding of influenza A virus NS1 protein to the inter-SH2 domain of p85 suggests a novel mechanism for phosphoinositide 3-kinase activation. J Biol Chem 283: 1372-1380. 
67. Shin YK, Liu Q, Tikoo SK, Babiuk LA, Zhou Y (2007) Influenza A virus NS1 protein activates the phosphatidylinositol 3-kinase (PI3K)/Akt pathway by direct interaction with the p85 subunit of PI3K. J Gen Virol 88: 13-18.

68. Lipatov AS, Andreansky S, Webby RJ, Hulse DJ, Rehg JE, et al. (2005) Pathogenesis of Hong Kong H5N1 influenza virus NS gene reassortants in mice: the role of cytokines and B- and T-cell responses. J Gen Virol 86: 1121-1130.

69. Obenauer JC, Denson J, Mehta PK, Su X, Mukatira S, et al. (2006) Large-scale sequence analysis of avian influenza isolates. Science 311: 1576-1580.

70. Bernard O (2007) Lim kinases, regulators of actin dynamics. Int J Biochem Cell Biol 39: 1071-1076.

71. Jackson D, Hossain MJ, Hickman D, Perez DR, Lamb RA (2008) A new influenza virus virulence determinant: the NS1 protein four C-terminal residues modulate pathogenicity. Proc Natl Acad Sci U S A 105: 4381-4386.

72. Harris BZ, Lim WA (2001) Mechanism and role of PDZ domains in signaling complex assembly. J Cell Sci 114: 3219-3231.

73. Sheng M, Sala C (2001) PDZ domains and the organization of supramolecular complexes. Annu Rev Neurosci 24: 1-29.

74. Tonikian R, Zhang Y, Sazinsky SL, Currell B, Yeh JH, et al. (2008) A specificity map for the PDZ domain family. PLoS Biol 6: e239.

75. Funke L, Dakoji S, Bredt DS (2005) Membrane-associated guanylate kinases regulate adhesion and plasticity at cell junctions. Annu Rev Biochem 74: 219245.

76. Hillier BJ, Christopherson KS, Prehoda KE, Bredt DS, Lim WA (1999) Unexpected modes of PDZ domain scaffolding revealed by structure of nNOSsyntrophin complex. Science 284: 812-815.

77. Wu H, Feng W, Chen J, Chan LN, Huang S, et al. (2007) PDZ domains of Par-3 as potential phosphoinositide signaling integrators. Mol Cell 28: 886-898.

78. Hartsock A, Nelson WJ (2008) Adherens and tight junctions: structure, function and connections to the actin cytoskeleton. Biochim Biophys Acta 1778: 660-669.

79. Niessen CM, Gottardi CJ (2008) Molecular components of the adherens junction. Biochim Biophys Acta 1778: 562-571.

80. Fujita A, Kurachi Y (2000) SAP family proteins. Biochem Biophys Res Commun 269: 1-6. 
81. Lue RA, Marfatia SM, Branton D, Chishti AH (1994) Cloning and characterization of hdlg: the human homologue of the Drosophila discs large tumor suppressor binds to protein 4.1. Proc Natl Acad Sci U S A 91: 9818-9822.

82. Kuhlendahl S, Spangenberg O, Konrad M, Kim E, Garner CC (1998) Functional analysis of the guanylate kinase-like domain in the synapse-associated protein SAP97. Eur J Biochem 252: 305-313.

83. Mantovani F, Massimi P, Banks L (2001) Proteasome-mediated regulation of the hDlg tumour suppressor protein. J Cell Sci 114: 4285-4292.

84. Muller BM, Kistner U, Veh RW, Cases-Langhoff C, Becker B, et al. (1995) Molecular characterization and spatial distribution of SAP97, a novel presynaptic protein homologous to SAP90 and the Drosophila discs-large tumor suppressor protein. J Neurosci 15: 2354-2366.

85. Laprise P, Viel A, Rivard N (2004) Human homolog of disc-large is required for adherens junction assembly and differentiation of human intestinal epithelial cells. J Biol Chem 279: 10157-10166.

86. Caruana G, Bernstein A (2001) Craniofacial dysmorphogenesis including cleft palate in mice with an insertional mutation in the discs large gene. Mol Cell Biol 21: $1475-1483$.

87. Reuver SM, Garner CC (1998) E-cadherin mediated cell adhesion recruits SAP97 into the cortical cytoskeleton. J Cell Sci 111 ( Pt 8): 1071-1080.

88. Woods DF, Bryant PJ (1991) The discs-large tumor suppressor gene of Drosophila encodes a guanylate kinase homolog localized at septate junctions. Cell 66: 451-464.

89. Woods DF, Hough C, Peel D, Callaini G, Bryant PJ (1996) Dlg protein is required for junction structure, cell polarity, and proliferation control in Drosophila epithelia. J Cell Biol 134: 1469-1482.

90. Firestein BL, Rongo C (2001) DLG-1 is a MAGUK similar to SAP97 and is required for adherens junction formation. Mol Biol Cell 12: 3465-3475.

91. Bossinger O, Klebes A, Segbert C, Theres C, Knust E (2001) Zonula adherens formation in Caenorhabditis elegans requires dlg-1, the homologue of the Drosophila gene discs large. Dev Biol 230: 29-42.

92. Ide N, Hata Y, Nishioka H, Hirao K, Yao I, et al. (1999) Localization of membrane-associated guanylate kinase (MAGI)-1/BAI-associated protein (BAP) 1 at tight junctions of epithelial cells. Oncogene 18: 7810-7815. 
93. Nguyen MM, Nguyen ML, Caruana G, Bernstein A, Lambert PF, et al. (2003)

Requirement of PDZ-containing proteins for cell cycle regulation and differentiation in the mouse lens epithelium. Mol Cell Biol 23: 8970-8981.

94. Watson RA, Rollason TP, Reynolds GM, Murray PG, Banks L, et al. (2002) Changes in expression of the human homologue of the Drosophila discs large tumour suppressor protein in high-grade premalignant cervical neoplasias. Carcinogenesis 23: 1791-1796.

95. Bilder D, Li M, Perrimon N (2000) Cooperative regulation of cell polarity and growth by Drosophila tumor suppressors. Science 289: 113-116.

96. Wu H, Reuver SM, Kuhlendahl S, Chung WJ, Garner CC (1998) Subcellular targeting and cytoskeletal attachment of SAP97 to the epithelial lateral membrane. J Cell Sci 111 ( Pt 16): 2365-2376.

97. Laprise P, Chailler P, Houde M, Beaulieu JF, Boucher MJ, et al. (2002) Phosphatidylinositol 3-kinase controls human intestinal epithelial cell differentiation by promoting adherens junction assembly and p38 MAPK activation. J Biol Chem 277: 8226-8234.

98. Lee SS, Weiss RS, Javier RT (1997) Binding of human virus oncoproteins to $\mathrm{hDlg} / \mathrm{SAP} 97$, a mammalian homolog of the Drosophila discs large tumor suppressor protein. Proc Natl Acad Sci U S A 94: 6670-6675.

99. Suzuki T, Ohsugi Y, Uchida-Toita M, Akiyama T, Yoshida M (1999) Tax oncoprotein of HTLV-1 binds to the human homologue of Drosophila discs large tumor suppressor protein, hDLG, and perturbs its function in cell growth control. Oncogene 18: 5967-5972.

100. Gardiol D, Kuhne C, Glaunsinger B, Lee SS, Javier R, et al. (1999) Oncogenic human papillomavirus E6 proteins target the discs large tumour suppressor for proteasome-mediated degradation. Oncogene 18: 5487-5496.

101. Kiyono T, Hiraiwa A, Fujita M, Hayashi Y, Akiyama T, et al. (1997) Binding of high-risk human papillomavirus E6 oncoproteins to the human homologue of the Drosophila discs large tumor suppressor protein. Proc Natl Acad Sci U S A 94: 11612-11616.

102. Pim D, Thomas M, Javier R, Gardiol D, Banks L (2000) HPV E6 targeted degradation of the discs large protein: evidence for the involvement of a novel ubiquitin ligase. Oncogene 19: 719-725.

103. Watson RA, Thomas M, Banks L, Roberts S (2003) Activity of the human papillomavirus E6 PDZ-binding motif correlates with an enhanced morphological transformation of immortalized human keratinocytes. J Cell Sci 116: 4925-4934. 
104. Hidalgo IJ, Raub TJ, Borchardt RT (1989) Characterization of the human colon carcinoma cell line (Caco-2) as a model system for intestinal epithelial permeability. Gastroenterology 96: 736-749.

105. Gardner LA, Naren AP, Bahouth SW (2007) Assembly of an SAP97-AKAP79cAMP-dependent protein kinase scaffold at the type 1 PSD-95/DLG/ZO1 motif of the human beta(1)-adrenergic receptor generates a receptosome involved in receptor recycling and networking. J Biol Chem 282: 5085-5099.

106. Seth A, Sheth P, Elias BC, Rao R (2007) Protein phosphatases 2A and 1 interact with occludin and negatively regulate the assembly of tight junctions in the CACO-2 cell monolayer. J Biol Chem 282: 11487-11498.

107. Stucke VM, Timmerman E, Vandekerckhove J, Gevaert K, Hall A (2007) The MAGUK protein MPP7 binds to the polarity protein hDlg1 and facilitates epithelial tight junction formation. Mol Biol Cell 18: 1744-1755.

108. Long JX, Peng DX, Liu YL, Wu YT, Liu XF (2008) Virulence of H5N1 avian influenza virus enhanced by a 15 -nucleotide deletion in the viral nonstructural gene. Virus Genes 36: 471-478. 


\section{VITA}

Veronica Garcia Conoley was born in September 1980 in McAllen, Texas. She attended Loyola University Chicago where she obtained a bachelors of science in biology in May 2002. While attending Loyola University Chicago, she was a multi-year recipient of the National Hispanic Scholarship. She began her graduate studies at the University of Tennessee Health Science Center in 2005. During her tenure at the University Of Tennessee, she was the recipient of a Ruth L. Kirschstein National Research Service Award. Veronica will receive her Ph.D. from the University of Tennessee Health Science Center in May 2010. 